\title{
DESENVOLVIMENTO E IMPLEMENTAÇÃO DE UM MODELO PARA DISCIPLINAS INTRODUTÓRIAS EM ENGENHARIA ELÉTRICA
}

Jorge Sebastião Canova

Dissertação de Mestrado apresentada ao Departamento de Engenharia Elétrica da Escola de Engenharia de São Carlos da Universidade de São Paulo, como parte dos requisitos para obtenção do título de Mestre em Engenharia Elétrica

ORIENTADOR: Prof. Tit. Ruy A. C. Altafim 
A minha esposa, por muito amor e incentivo, com grande paciência ao meu lado.

Aos meus pais, pelos esforços e toda a dedicação desde os primeiros dias de minha vida. 
Ao Professor Ruy Alberto Corrêa Altafim, pela amizade e grande orientação durante a elaboração deste trabalho.

Aos Professores Azauri Albano de Oliveira Jr., Edson Gesualdo, Evandro Luís Linhari Rodrigues, José Carlos Sartori e Paulo Roberto Veronesi do Departamento de Engenharia Elétrica da EESC/USP, por grande participação, apoio e amizade.

À Pedagoga Nídia Pavan Kuri do CETEPE/EESC/USP, pelo apoio pedagógico e por grande participação e amizade.

A todos os colegas, funcionários, professores e demais pessoas do Departamento de Engenharia Elétrica da EESC/USP, que de alguma forma contribuíram com a realização deste trabalho.

À FAPESP - Fundação de Amparo à Pesquisa do Estado de São Paulo, pelo apoio financeiro, com a bolsa de estudos e a reserva técnica. 


\section{Sumário}

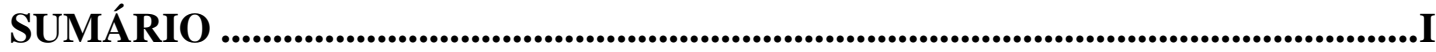

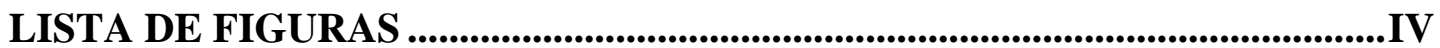

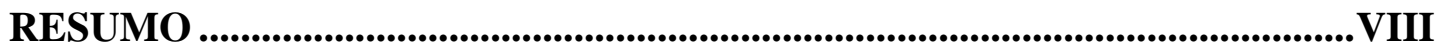

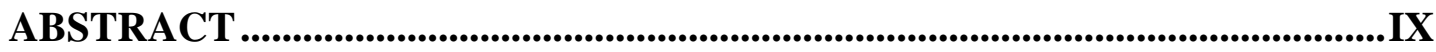

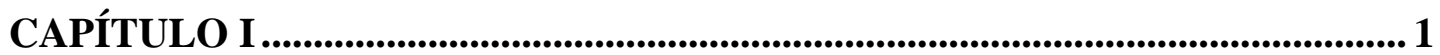

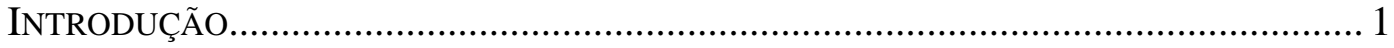

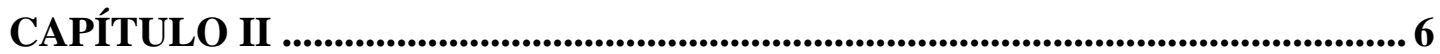

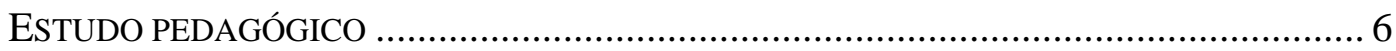

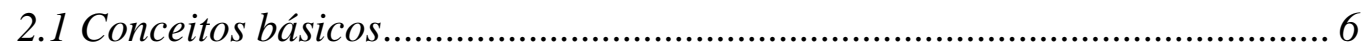

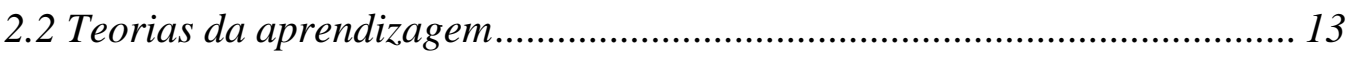

2.3 Planejamento e entrega da instrução ........................................................ 15

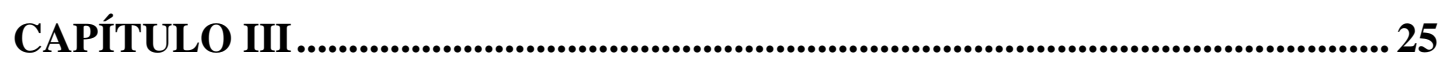

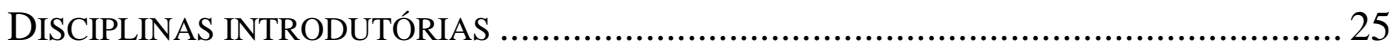

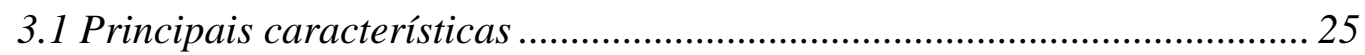

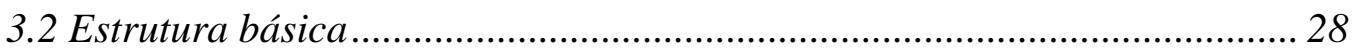

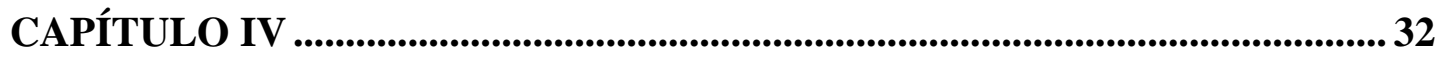

UM MODELO DE DISCIPLINA INTRODUTÓRIA EM ENGENHARIA ELÉTRICA ................. 32 


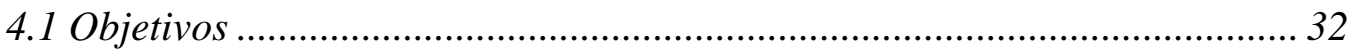

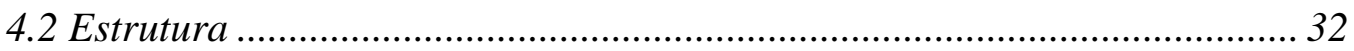

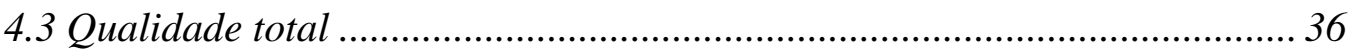

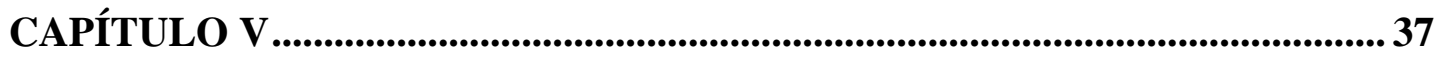

IMPLEMENTAÇÃO DO MODELO PROPOSTO NA DISCIPLINA SEL-300 ........................ 37

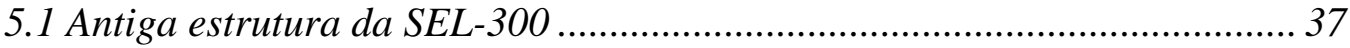

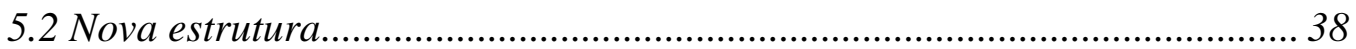

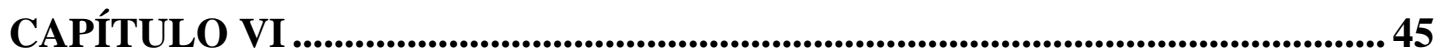

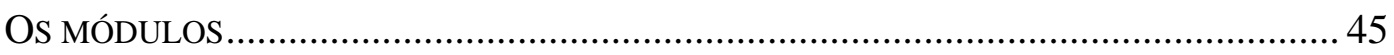

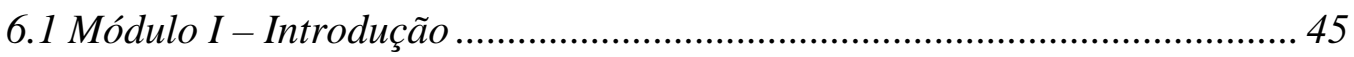

6.2 Módulo II - Circuitos eletrônicos ............................................................ 47

6.3 Módulo III - Instrumentação e Medidas......................................................... 50

6.4 Módulo IV - Controle e Eletrônica de Potência............................................ 53

6.5 Módulo V-Sistemas de Potência ................................................................ 56

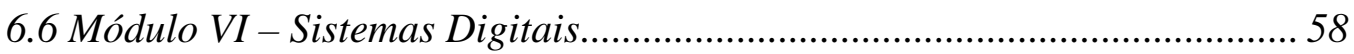

6.7 Módulo VII - Telecomunicações.................................................................. 60

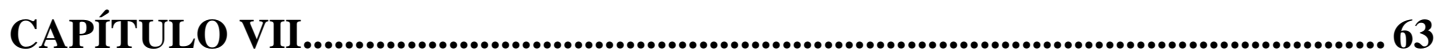

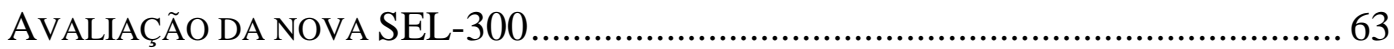

7.1 Avaliação pelo corpo docente ..................................................................... 63

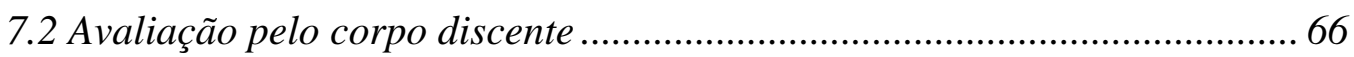

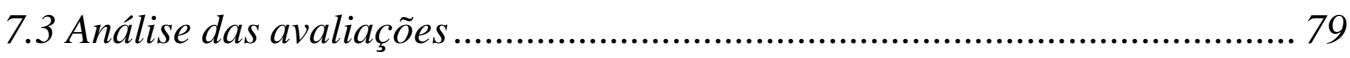

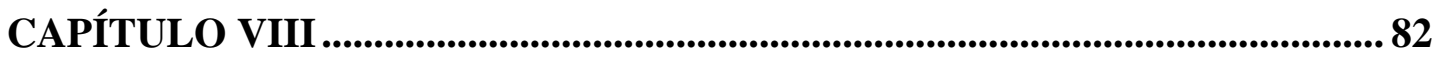

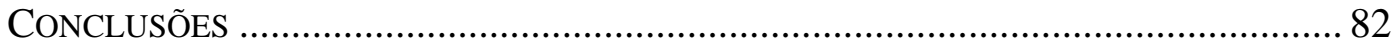




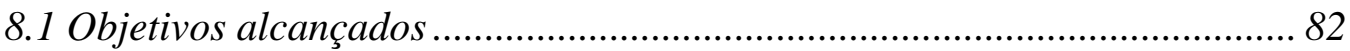

8.2 Importância de um elo de ligação.................................................................. 85

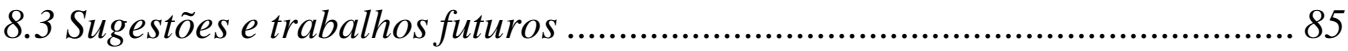

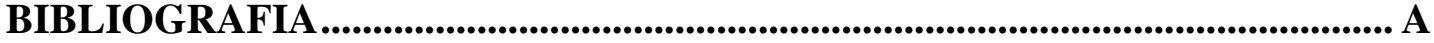




\section{Lista de Figuras}

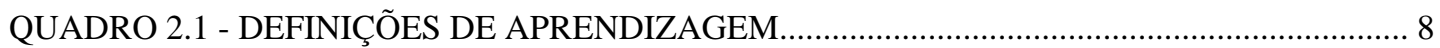

QUADRO 2.2 - RECOMENDAÇÕES AOS EDUCADORES …………........................................... 11

QUADRO 2.3 - SÍNTESE PARA A PRÁTICA EDUCATIVA............................................................... 14

QUADRO 2.4 - ELEMENTOS BÁSICOS DA APRENDIZAGEM COOPERATIVA …………….... 17

QUADRO 2.5 - CLASSIFICAÇÃO DOS ESTILOS DE APRENDIZAGEM E DE ENSINO

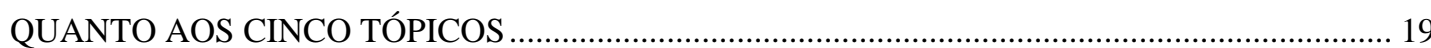

QUADRO 2.6 - TÉCNICAS DE ENSINO PARA ATINGIR TODOS OS ESTILOS DE

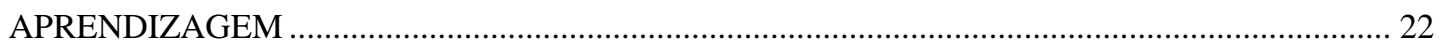

QUADRO 2.7 - SUGESTÕES PARA UM BOM DESENVOLVIMENTO DA DISCIPLINA .......... 23

FIGURA 3.1 - EXEMPLO DE ASSOCIAÇÃO DA TEORIA COM O COTIDIANO ……………...... 28

FIGURA 5.1 - CAMINHO TRAÇADO PARA A ESTRUTURA MODULAR .................................... 40

FIGURA 5.2 - SEQÜÊNCIA DE ELABORAÇÃO E CORREÇÃO DE CADA MÓDULO ............... 42

FIGURA 5.3 - ILUSTRAÇÃO DE UMA DAS AULAS DA SEL-300 NO ANFITEATRO................ 43

FIGURA 6.1.1 - SEQUÊNCIA DO CONTEÚDO DO MÓDULO I ...................................................... 45

FIGURA 6.1.2 -QUADROS EXTRAÍDOS SEQUENCIALMENTE DO VÍDEO DO ROVER ......... 46

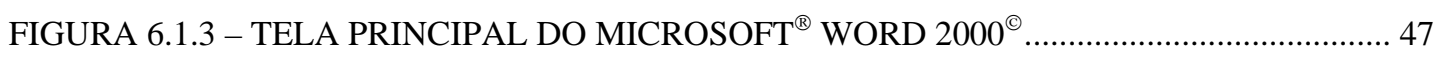

FIGURA 6.2.1 - SEQUÊNCIA DO CONTEÚDO DO MÓDULO II..................................................... 47

FIGURA 6.2.2 - ILUSTRAÇÕES APRESENTADAS AOS CALOUROS POR MEIO DE “SLIDES” ANIMADOS 48 
FIGURA 6.2.3 - ILUSTRAÇÕES APRESENTADAS AOS CALOUROS POR MEIO DE “SLIDES” ANIMADOS

FIGURA 6.2.4 - TELA PRINCIPAL DO ELETRONIC WORKBENCH 5.C ${ }^{\circledR}$ 50

FIGURA 6.3.1 - SEQÜÊNCIA DO CONTEÚDO DO MÓDULO III 50 FIGURA 6.3.2 - ILUSTRAÇÕES APRESENTADAS AOS CALOUROS POR MEIO DE “SLIDES” ANIMADOS 51

FIGURA 6.3.3 - ILUSTRAÇÕES APRESENTADAS AOS CALOUROS POR MEIO DE “SLIDES”ANIMADOS 51

FIGURA 6.3.4 - TELA PRINCIPAL DO MICROCAL ${ }^{\mathrm{TM}}$ ORIGIN $^{\mathrm{TM}}$ 5.0 COM UMA CURCA TRAÇADA

FIGURA 6.3.5 - ILUSTRAÇÕES APRESENTADAS AOS CALOUROS POR MEIO DE “SLIDES”ANIMADOS 52

FIGURA 6.4.1 - SEQÜÊNCIA DO CONTEÚDO DO MÓDULO IV 53

FIGURA 6.4.2 - ILUSTRAÇÕES APRESENTADAS AOS CALOUROS POR MEIO DE “SLIDES”ANIMADOS

FIGURA 6.4.3 - ILUSTRAÇÕES APRESENTADAS AOS CALOUROS POR MEIO DE “SLIDES”ANIMADOS 54

FIGURA 6.4.4 - ILUSTRAÇÕES APRESENTADAS AOS CALOUROS POR MEIO DE “SLIDES”ANIMADOS 55

FIGURA 6.5.1 - SEQÜÊNCIA DO CONTEÚDO DO MÓDULO V... 57

FIGURA 6.5.2 - ILUSTRAÇÕES APRESENTADAS AOS CALOUROS POR MEIO DE “SLIDES”ANIMADOS

FIGURA 6.5.3 - TELA PRINCIPAL DO MICRSOFT ${ }^{\circledR}$ POWERPOINT $^{\odot} 2000$ 58 FIGURA 6.6.1 - SEQUÊNCIA DO CONTEÚDO DO MÓDULO VI 59 
FIGURA 6.6.2 - ILUSTRAÇÕES APRESENTADAS AOS CALOUROS POR MEIO DE "SLIDES”ANIMADOS

FIGURA 6.6.3 - ILUSTRAÇÕES APRESENTADAS AOS CALOUROS POR MEIO DE “SLIDES”ANIMADOS

FIGURA 6.7.1 - SEQUÊNCIA DO CONTEÚDO DO MÓDULO VII. 61

FIGURA 6.7.2 - ILUSTRAÇÕES APRESENTADAS AOS CALOUROS POR MEIO DE "SLIDES”ANIMADOS 61

FIGURA 6.7.3 - ILUSTRAÇÕES APRESENTADAS AOS CALOUROS POR MEIO DE "SLIDES”ANIMADOS

FIGURA 7.1.1 -PONTUAÇÃO PARA PARTICIPAÇÃO DOS CALOUROS EM CADA MÓDULO 64

FIGURA 7.1.2 - PONTUAÇÃO MÉDIA PARA A PARTICIPAÇÃO DOS CALOUROS EM CADA MÓDULO 64

FIGURA 7.1.3 - DISTRIBUIÇÃO DAS NOTAS DE AVALIAÇÃO DOS RELATÓRIOS EM 1999, 2000 E 2001 65

FIGURA 7.2.1 - LEVANTAMENTO DAS RESPOSTAS PARA A QUESTÃO 1. 67 FIGURA 7.2.2 - LEVANTAMENTO DAS RESPOSTAS PARA A QUESTÃO 2 67 FIGURA 7.2.3 - LEVANTAMENTO DAS RESPOSTAS PARA A QUESTÃO 3 68 FIGURA 7.2.4 - LEVANTAMENTO DAS RESPOSTAS PARA A QUESTÃO 4. 68 FIGURA 7.2.5 - LEVANTAMENTO DAS RESPOSTAS PARA A QUESTÃO 5 69 FIGURA 7.2.6 - LEVANTAMENTO DAS RESPOSTAS PARA A QUESTÃO 6. 69 FIGURA 7.2.7 - LEVANTAMENTO DAS RESPOSTAS PARA A QUESTÃO 7 70 FIGURA 7.2.8 - LEVANTAMENTO DAS RESPOSTAS PARA A QUESTÃO 8 70 FIGURA 7.2.9 - LEVANTAMENTO DAS RESPOSTAS PARA A QUESTÃO 9 71 FIGURA 7.2.10 - LEVANTAMENTO DAS RESPOSTAS PARA A QUESTÃO 10 71 
FIGURA 7.2.11 - LEVANTAMENTO DAS RESPOSTAS PARA A QUESTÃO 11 .......................... 72

FIGURA 7.2.12 - LEVANTAMENTO DAS RESPOSTAS PARA A QUESTÃO 12 ......................... 72

FIGURA 7.2.13 - LEVANTAMENTO DAS RESPOSTAS PARA A QUESTÃO 13 ......................... 73

FIGURA 7.2.14 - LEVANTAMENTO DAS RESPOSTAS PARA A QUESTÃO 14 ......................... 73

FIGURA 7.2.15 - LEVANTAMENTO DAS RESPOSTAS PARA A QUESTÃO 15 .......................... 74

FIGURA 7.2.16 - LEVANTAMENTO DAS RESPOSTAS PARA A QUESTÃO 16 ......................... 74

FIGURA 7.2.17.A - PONTOS FAVORÁVEIS APRESENTADOS NA QUESTÃO 1 ....................... 75

FIGURA 7.2.17.B - PONTOS DESFAVORÁVEIS APRESENTADOS NA QUESTÃO 1 ................ 75

FIGURA 7.2.18.A - MÓDULOS QUE MAIS DESPERTARAM O INTERESSE DOS CALOUROS

EM 1999 E 2000

FIGURA 7.2.18.B - MÓDULOS QUE MAIS DESPERTARAM O INTERESSE DOS CALOUROS

EM 2001 76

FIGURA 7.2.19.A - ÁREAS MAIS APONTADAS PELOS CALOUROS EM 1999/2000 77

FIGURA 7.2.19.B - ÁREAS MAIS APONTADAS PELOS CALOUROS EM 2001. 78

FIGURA 7.2.20 - SUGESTÕES APRESENTADAS PELOS CALOUROS 78

FIGURA 7.2.21 - ESCLARECIMENTOS NECESSÁRIOS 79

FIGURA 7.2.23 - COMENTÁRIOS E SUGESTÕES FINAIS 79

FIGURA 7.3 - PERFIL DOS ESTILOS DE APRENDIZAGEM DOS CALOUROS EM 2001 83 


\section{Resumo}

CANOVA, J. S. (2000). Desenvolvimento e implementação de um modelo para disciplinas introdutórias em engenharia elétrica. São Carlos, 2000, 80p. Dissertação (Mestrado) - Escola de Engenharia de São Carlos, Universidade de São Paulo.

Neste trabalho são apresentados o desenvolvimento e a implementação de um modelo para disciplinas introdutórias em engenharia elétrica fundamentados em duas partes básicas. A primeira parte refere-se a um estudo pedagógico, no qual foram estudados alguns conceitos básicos de pedagogia, teorias de aprendizagem, vantagens da aprendizagem cooperativa, estilos de aprendizagem e ensino e cuidados a serem considerados ao elaborar-se uma disciplina. A segunda parte refere-se a um estudo sobre a experiência de outros educadores em disciplinas introdutórias, verificando-se as principais características, o conteúdo, os recursos utilizados, as pessoas envolvidas e os resultados alcançados com estas disciplinas. A partir destes estudos foi proposto um modelo para uma disciplina introdutória em engenharia elétrica, com o objetivo de motivar e preparar o calouro para o curso de engenharia, o mercado de trabalho e a sociedade, dentro do atual mundo globalizado. Um exemplo de implementação do modelo proposto foi a reestruturação da disciplina introdutória SEL-300 - Informação profissional em engenharia elétrica, do curso de engenharia elétrica da EESC - Escola de Engenharia de São Carlos, da USP - Universidade de São Paulo. Os resultados obtidos com esta experiência indicaram ser um modelo adequado para uma disciplina introdutória. Detalhes como conteúdo, recursos utilizados, pessoas envolvidas e resultados deste exemplo também são apresentados.

Palavras-chave: educação em engenharia, disciplina introdutória, reestruturação de disciplina. 


\begin{abstract}
A bstract
CANOVA, J. S. (2000). A model for introductory Electrical Engineering Disciplines: Design and Implementation. São Carlos, 2000, 80p. Dissertação (Mestrado) - Escola de Engenharia de São Carlos, Universidade de São Paulo.
\end{abstract}

In this work we present the design and implementation of a model for electrical engineering introductory disciplines based on two basic parts. First one refers to a pedagogical study, in which some pedagogy basic concepts were studied, learning theories, cooperative learning advantages, learning and teaching styles and care in discipline preparation. Second refers to a study over other educators experience in introductory disciplines, checking for its main characteristics, the contents, used resources, people involved and obtained results. From these studies a model for introductory disciplines in electrical engineering was proposed, with the objective of motivating and preparing the new student for the engineering course, professional work and society considering the modern globalization. One example of proposed model was the implementation of SEL-300 introductory discipline structure - professional information in electrical engineering, from electrical engineering course of Escola de Engenharia de São Carlos, University of São Paulo. Obtained results from this experience indicated the model to be adequate for introductory disciplines. Details as contents, used resources, involved people and this example results are presented.

Keywords: education in engineering, introductory discipline, discipline restructuring. 


\section{Capítulo I}

\section{Introdução}

A aprendizagem tem sido objeto de reflexões, ponderações e observações desde a Antiguidade Clássica, antes da era cristã, até a atualidade. Desde os grandes filósofos como Sócrates, Platão e Aristóteles, o homem sempre esteve procurando adequar melhor seus modos de adquirir, saber, agir, viver e conviver. Este processo de aprendizagem tão freqüente e constante em nossas vidas está intimamente ligado ao ensino e ambos correspondem às atividades fundamentais presentes no ambiente escolar (PFROMM NETO, 1987).

Dentro deste ambiente, está o ensino superior que atravessou o tempo passando por algumas mudanças. Na época colonial, os estudantes eram preparados para se tornarem líderes cívicos ou religiosos. No século XIX, os estudantes passaram a ser preparados para serviços orientados como administrar eficientemente as fábricas, apresentar melhores produtividades agrícolas e servir o governo. Ao final do século XIX, os estudantes eram considerados como recipientes vazios esperando por uma transferência de ensino, por parte de quem muitas vezes acreditava que simplesmente saber sobre um determinado campo do conhecimento, isto é, sendo um doutor no mesmo, seria o suficiente para ensinar este campo aos estudantes (JOHNSON; JOHNSON; SMITH, 1998). 
Hoje os estudantes são considerados construtores ativos que descobrem ou recebem a informação e transformam-na em conhecimento. Perante esta nova concepção, os educadores procuram tornar-los profissionais capacitados a comunicação efetiva, liderança, trabalho em equipe, iniciativa e criatividade, estando assim preparados para as exigências do mutante mercado de trabalho neste mundo globalizado, onde o avanço tecnológico é mais rápido que o as reformas do ensino (BELHOT;GUERRA;KURI, 1998).

Para que este objetivo seja alcançado, nos últimos anos estão ocorrendo cada vez mais reformas no sistema de ensino, no qual está incluso o ensino de engenharia (KULACKI \& KRUEGER, 1998), que é vasto, abrangendo temas como ensino à distância, reestruturação de disciplinas, reformulações curriculares, disciplinas introdutórias, ferramentas didáticas e metodologias de ensino.

Muito tem sido publicado a respeito nos vários veículos de comunicação e desenvolver um trabalho que envolva todos esses temas, pode ser um tanto extenso e complexo. Dentre os vários temas, disciplinas introdutórias foi o escolhido devido à possibilidade de desenvolvimento e implementação imediata de um trabalho de pesquisa numa disciplina de introdução à engenharia elétrica.

Esta disciplina é a SEL-300 - Informação profissional em engenharia elétrica $^{1}$, que, segundo OLIVEIRA JR. (2000)², possuía uma estrutura indefinida e sem padrões quanto ao material ministrado, às vezes com incompatibilidade entre estilos de aprendizagem e de ensino, e alto nível técnico para um estudante novato,

\footnotetext{
${ }^{1}$ Disciplina introdutória do curso de engenharia elétrica da Escola de Engenharia de São Carlos (EESC) da Universidade de São Paulo (USP), a partir de 1997.

2 OLIVEIRA JR, A. A. (2000). Coordenador da SEL-300. Descreve a antiga estrutura da $S E L-300$ e as necessidades de mudanças. Personal e-mail (10 Apr).
} 
comprometendo possivelmente a aprendizagem e a correta escolha de carreira do calouro.

A estrutura da SEL-300 foi estuda, ficando constatado a incoerência com os moldes atuais de uma disciplina introdutória, que tem como objetivo contribuir na formação de um profissional com conceitos éticos, sociais e culturais, capacitado a atender as exigências da sociedade e do mercado de trabalho (WULF, 1998). Características importantes como motivação, apresentação do curso e integração entre estudantes, professores e departamento garantindo um necessário nivelamento dos calouros (CRADDOCK, 1997), a apresentação de ferramentas computacionais utilizadas na engenharia (HELMER, 1997) e conceitos de organização e elaboração de trabalhos (NARASIMHAN; TEMARES; LEE, 1997) não foram identificadas na SEL-300. A presença de todas essas características numa disciplina introdutória proporcionaria aos alunos condições de começarem a escolher uma carreira a seguir dentro da engenharia (ENTERLINE \& KALONJI \& ERIDLEY, 1997).

Este trabalho propõe o desenvolvimento de um modelo para disciplinas introdutórias em engenharia elétrica, procurando manter a compatibilidade entre os estilos de aprendizagem e de ensino (FELDER \& SILVERMAN, 1988) e as características importantes de uma disciplina introdutória, utilizando técnicas de multimídia e recursos áudios visuais, que facilitam o planejamento e a entrega da instrução (STRAKOS \& KEBO, 1998).

O modelo proposto foi implementado na reestruturação da SEL-300, sendo avaliado por dois anos consecutivos pelos corpos docente e discente envolvidos neste período. Resultados importantes como grande participação dos calouros na disciplina, comparada à antiga estrutura, e críticas construtivas para um 
aperfeiçoamento contínuo indicaram ser um modelo adequado e compatível com os moldes atuais para uma disciplina introdutória em engenharia elétrica.

Desenvolver um modelo de estrutura para uma disciplina envolve atividades fundamentais como aprendizagem e ensino, desde o planejamento até a entrega da instrução, sendo necessário um estudo pedagógico para aprender conceitos, processos e teorias importantes presentes na área de pedagogia (RIBAS; SILVA FILHO; COMIOTTO, 1998). Este estudo é apresentado no capítulo 2.

Foram verificadas também as experiências de outros educadores com disciplinas introdutórias, servindo de referência para o modelo aqui proposto. Esta verificação é apresentada no capítulo 3.

No capítulo 4, é proposto o modelo para uma disciplina introdutória em engenharia elétrica, onde um grande projeto de engenharia amplamente divulgado na mídia foi utilizado, fragmentado-o em pequenas partes, chamadas de módulos, contendo conceitos básicos como a lei de Ohm e a lei de Faraday, noções básicas sobre eletrônica, controle, sistemas de potência, instrumentação, sistemas digitais, telecomunicações e ferramentas computacionais de grande aplicação na engenharia elétrica (ALTAFIM; CANOVA; et al., 1998).

A implementação do modelo proposto na SEL-300 é apresentada no capítulo 5, onde estão presentes detalhes como a escolha do grande projeto de engenharia e sua fragmentação, pessoas e recursos envolvidos. Informações sobre a SEL-300 antes e depois da reestruturação, também estão neste capítulo.

Os detalhes de cada módulo gerado como conteúdo, ferramentas computacionais, exercícios, aulas práticas, fotos e "slides” estão apresentados no capítulo 6. 
No capítulo 7, é apresentada uma avaliação final sobre a experiência com a nova estrutura da SEL-300 através de um questionário e de observações de comportamento dos estudantes no decorrer da disciplina, durante os dois anos consecutivos. Esta avaliação possibilitou a análise do modelo proposto, onde foi verificada a necessidade de algumas correções na estrutura e na implementação do mesmo.

No capítulo 8, estão apresentados conclusões finais, temas e correções pendentes e propostas para trabalhos futuros. 


\section{Capítulo II}

\section{Estudo pedagógico}

\subsection{Conceitos básicos}

A reestruturação de qualquer disciplina, como qualquer outro tema ligado ao ensino e à educação, requer além do conhecimento sobre o conteúdo desta disciplina, um estudo pedagógico das atividades fundamentais que aqui serão desenvolvidas. Este estudo abrange conceitos básicos, como aprendizagem, capacidade, motivação, educação, ensino, planejamento e entrega da instrução e aprendizagem cooperativa.

\subsubsection{Aprendizagem}

A aprendizagem é um processo interno, freqüente e pessoal, que acompanha o educando durante toda a sua vida. Bebês, crianças, adolescentes, adultos e idosos estão continuamente aprendendo.

Durante o processo de aprendizagem pode-se observar duas fases, a interna e a externa. Na fase interna o educando recorre a vários processos mentais como associar, interpretar, comparar, compreender, imaginar, julgar e recordar. Já na fase externa, ele pode recorrer a vários processos como escutar, falar, olhar, ler, escrever, executar operações e manipular objetos.

No entanto, a aprendizagem efetiva só pode ser verificada por um observador externo através do comportamento do aprendiz, não sendo possível verificar ou 
identificar realmente o que ocorre com o indivíduo. Por exemplo, o comportamento ou desempenho de um aprendiz muito tenso, ansioso ou com pouca motivação durante um exame, nem sempre indica os verdadeiros conhecimentos e capacidades que ele possui. Algumas pessoas reagem positivamente, sentem-se estimuladas perante estados de tensão e ansiedade, enquanto outras reagem negativamente com comportamentos desastrosos, como tropeçar e gaguejar.

O conceito de aprendizagem está presente tanto na psicologia como na pedagogia, que a definem como um processo complexo que envolve muitas variáveis, combináveis de diversos modos, estando sujeita à influência de vários fatores internos e externos, individuais e sociais (PFROMM NETO, 1987). Por exemplo, um aprendiz sonolento ou mesmo preocupado com algum assunto estranho à disciplina que assiste, provavelmente não conseguirá dispor da atenção necessária a aprendizagem desta disciplina.

Na literatura podem ser encontradas várias definições de aprendizagem deste século, estando algumas destas apresentadas no quadro 2.1 a seguir.

"Embora existam muitas definições de aprendizagem, todas incluem a idéia de que aprendizagem é uma mudança no comportamento de um organismo decorrente de experiências anteriores” (NOVAK, 1981, p.47), independente dos tipos de aprendizagem, condicionamento clássico, condicionamento instrumental, aquisição de habilidades, aprendizagem de discriminação, formação de conceitos, aprendizagem verbal, aprendizagem de princípios, aprendizagem por imitação de modelos, solução de problemas e outros, assim a aprendizagem pode então ser definida como a mudança do estado de não-aprendido para aprendido em relação ao conhecimento ou a capacidade a ser aprendida. 
- A aprendizagem ocorre sempre que o comportamento exibe uma mudança ou tendência progressiva, com a repetição da mesma situação estimulante, e quando a mudança no receptor ou efetor...As tendências no comportamento denominadas aprendizagem são presumivelmente devidas a mudanças no sistema nervoso e possíveis virtudes da plasticidade e retentividade desse sistema. W. S. Hunter (1929).

- Processo de modificação do comportamento, pela experiência, como um sentido de adaptação progressiva, ou de valor positivo na integração de todo organismo. M. B. Lourenço Filho (1940).

- Podemos definir a aprendizagem como o processo que se manifesta por meio de mudanças adaptadoras no comportamento individual, como resultado de experiência. W. H. Thorpe (1956).

- Concebemos a aprendizagem como aquisição de conexões que denominamos prontidões meio-fim, ou crenças. As prontidões meio-fim devem ser entendidas como disposições cognitivas aprendidas, que resultam diretamente das práticas precedentes ou de outro treino prévio, relacionado com elas. Concebemos essas disposições adquiridas como um dos principais determinantes do desempenho final. E. C. Tolman (1959).

- A aprendizagem é um subproduto dos empenhos de um organismo para satisfazer suas necessidades. Cada resposta a uma necessidade envolve atividade nervosa integrada, que é registrada como um padrão, modificando, assim, de certo modo, o sistema nervoso. Essas mudanças no sistema nervoso central alteram as respostas subseqüentes do indivíduo. J. A. R. Wilson, M. C. Robeck e W. B. Michael (1974).

- Aprendizagem é a mudança relativamente permanente no conhecimento ou no comportamento de uma pessoa, por causa da experiência. R. E. Mayer (1982).

- A aprendizagem pode ser definida como um processo de construção e de assimilação de uma nova resposta, no sentido de uma progressão de ajustamento do comportamento quer ao ambiente, quer ao projeto que o interessado tem em vista. J. Berbaum (1984).

Conteúdo extraído de PFROMM NETO (1987), p. 10-11.

QUADRO 2.1 - DEFINIÇÕES DE APRENDIZAGEM

\subsubsection{Capacidade}

A capacidade é o estado de aprendido de uma pessoa poder fazer ou compreender alguma coisa. O que uma pessoa aprende é a capacidade. Em outras palavras, o resultado da aprendizagem, são as capacidades adquiridas (estados de aprendido) pela pessoa que tornam possíveis uma variedade de desempenhos (GAGNÉ, 1975). Por exemplo, quando uma criança aprende a nadar, ela aprende a capacidade "nadar”.

Muitas vezes a capacidade é tomada como sinônimo de competência, que é o conhecimento e ou capacidade que uma pessoa possui e que a torna capaz de resolver determinados assuntos, ou executar certas tarefas (DICIONÁRIO DIDÁTICO DE PORTUGUÊS, 1998). Assim se a criança aprendeu a capacidade “nadar”, dizemos 
que ela possui competência para nadar. O que uma pessoa pode aprender com seus dons inatos, está relacionado com o termo aptidão (GAGNÉ, 1975), ou seja, uma pessoa pode ter aptidão em aprender determinadas capacidades.

\subsubsection{Motivação}

Segundo DICIONÁRIO AURÉLIO ELETRÔNICO (1996), a motivação é “um conjunto de fatores psicológicos (conscientes ou inconscientes) de ordem fisiológica, intelectual ou afetiva de um indivíduo, os quais agem entre si e determinam a conduta deste indivíduo”.

A motivação é necessária para que a aprendizagem ocorra. Por exemplo, no ambiente escolar, o aprendiz precisa reconhecer a necessidade de aprender algumas capacidades, mas para isto tem que ser motivado (WANKAT \& OREOVICZ, 1993). Embora esta motivação às vezes possa estar fora do controle do professor, este pode fazer um grande trabalho para motivar os estudantes.

A relação entre aprendizagem e motivação é recíproca, ou seja, um aprendiz pode começar a aprender com pouca motivação, no entanto ao experimentar êxito e competência crescentes, sua motivação pode elevar-se sensivelmente. Para os psicólogos, a motivação ativa e desperta o aprendiz, dirigindo-o para um objetivo específico e mantendo-o em ação. A psicologia da motivação geralmente apresenta dois tipos de motivação, extrínseca e intrínseca. A motivação extrínseca corresponde a fatores externos ao aprendiz, como recompensas, sanções, aprovação social, elogios, etc (PFROMM NETO, 1987). Não há dúvidas que estes fatores externos influem na aprendizagem, porém diferentes aprendizes podem reagir de diferentes formas a um mesmo fator externo. Por exemplo, nem sempre uma criança apresenta bom desempenho escolar quando seu pai lhe promete um presente se for aprovada na 
escola. A motivação intrínseca corresponde a fatores internos ao aprendiz, como a satisfação pessoal de descobrir que tem competência para realizar uma determinada tarefa ou de identificar-se com alguém admirado pelo aprendiz. A motivação intrínseca também pode ser definida como a experiência de sentimento de competência e realização da própria tarefa (COLL; PALACIOS; MARCHESI, 1996). Os fatores internos podem ser motivos suficientes para uma aprendizagem, independentes de qualquer fator externo.

Segundo WANKAT \& OREVICZ (1993), no contexto escolar, os estudantes têm uma grande variedade de problemas motivacionais, que atrapalham a aprendizagem. Por exemplo, muitos estudantes estão na engenharia devido a uma pressão familiar, porém só seus fracassos futuros acabam mostrando o erro desta pressão. Em geral os estudantes que não acreditam na importância dos estudos, apresentam baixo desempenho escolar, entretanto se a motivação for focalizada neste ponto, este quadro pode ser revertido gerando-se excelentes engenheiros. Às vezes o estudante está preocupado apenas em concluir uma disciplina ou um curso, no entanto esta preocupação acaba se tornando motivação para a sua aprendizagem. Alguns problemas motivacionais são externos ao ambiente escolar, como uma morte na família, problemas de saúde, dificuldades financeiras, problemas de relacionamento, e outros mais.

Um outro problema motivacional é o excesso de ansiedade do estudante perante um teste. Esta ansiedade pode ser um fator positivo para alguns estudantes, estimulando-os a um bom desempenho no teste, como também pode ser um fator negativo para outros estudantes, gerando uma grande sensação de desconforto reduzindo a motivação e conseqüentemente o desempenho destes estudantes 
(GOLEMAN, 1995). Ainda segundo GOLEMAN (1995), o otimismo é um grande fator motivador, que “...como a esperança, significa uma forte expectativa de que, em geral, tudo vai dar certo na vida, apesar dos reveses e frustrações. ...o otimismo é uma atitude que protege as pessoas da apatia, desesperança ou depressão diante das dificuldades. E como acontece com sua prima-irmã, a esperança, o otimismo proporciona dividendos à vida (contanto, claro, que seja um otimismo realista; o otimismo demasiado ingênuo pode ser desastroso)”.

O quadro 2.2 a seguir apresenta algumas recomendações feitas aos educadores, com o intuito de promover a motivação nos estudantes e evitar possíveis problemas motivacionais que possam ocorrer, no entanto nem todos estes problemas podem ser evitados, como por exemplo, um luto familiar do estudante.

- Procure traduzir a motivação em termos de recompensas capazes de levar o estudante a trabalhar para obtê-las.

- Use os motivos existentes para desenvolver novos motivos nos estudantes...

- Satisfaça a motivação do estudante quando o comportamento deste for apropriado...

- Nem sempre o que significa recompensa para um estudante funciona como recompensa para outro estudante. Procure determinar o que cada estudante encara como recompensa.

- Não use o termo "motivação" como desculpa para comportamentos inadequados. Não abandone o estudante que parece não ter motivação para aprender; ajude-o.

- Aplique o princípio do reforço positivo. Se um comportamento é consistentemente seguido de reforço, esse comportamento é fortalecido.

- O reforço pode igualmente ser manipulado para diminuir a freqüência de comportamentos indesejáveis...

- A punição é uma faca de dois gumes...

- A maneira de ser do professor frente aos estudantes é fator motivacional significativo na aprendizagem escolar. O mestre entusiasta, simpático, que gosta e acredita nos estudantes geralmente obtém melhores resultados do que o mestre crítico, irritadiço e que subestima a capacidade dos aprendizes.

- Professores que nunca mudam o formato de suas aulas e fazem da monotonia uma constante no seu modo de ensinar gera desatenção e prejudicam a aprendizagem dos estudantes...

- Um alvo das escolas deve ser a busca de excelência. 


\subsubsection{Educação, ensino e instrução}

Os termos educação, ensino e instrução são muitas vezes empregados como sinônimos, apesar de serem termos distintos (PFROMM NETO, 1987).

Educação é o processo de desenvolvimento da capacidade física, intelectual e moral do ser humano durante toda a sua vida, visando uma melhor integração deste na sociedade (DICIONÁRIO AURÉLIO ELETRÔNICO, 1996). Através da interação com a cultura em que vive, o indivíduo desenvolve sua compreensão da realidade, assimilando conhecimentos, técnicas, atitudes, crenças e valores. A educação sofre influências de costumes, tradições e condições gerais da sociedade num dado momento histórico.

Ensino é a transmissão de conhecimentos, informações ou esclarecimentos a um fim qualquer, inclusive a educação (DICIONÁRIO AURÉLIO ELETRÔNICO, 1996). Ensino é a influência de uma pessoa com mais experiências e conhecimentos sobre outras pessoas. "Ensinar é promover a aprendizagem nos estudantes. Para tanto, o professor, além de assenhorear-se plenamente do conteúdo correspondente à área em que trabalha e dominar os recursos metodológicos adequados, deve saber o que é a aprendizagem, como esta ocorre dentro de cada aprendiz, quais são os fatores e condições que facilitam a aprendizagem e os que podem dificultá-la ou impedi-la, e como verificar se os estudantes efetivamente aprenderam o que lhes foi ensinado" (PFROMM NETO, 1987, p. 9).

Instrução é um termo mais limitado, que designa a parte da educação que ocorre de modo intencional, sistemático e planejado. Pode ser definida como um conjunto de eventos planejados para iniciar, ativar e manter a aprendizagem, 
envolvendo tanto o processo de aprendizagem do estudante como o ensino pelo professor, ou por quem fizer a vez de mestre (PFROMM NETO, 1987).

Após a compreensão dos conceitos de aprendizagem, capacidade, motivação, educação, ensino e instrução, foram estudadas as teorias de aprendizagem verificando-se alguns princípios para a prática educacional.

\subsection{Teorias da aprendizagem}

Desde a Antiguidade Clássica, antes da era cristã, o homem sempre esteve procurando adequar melhor seus modos de adquirir, saber, agir, viver e conviver. Observações, proposições e reflexões a respeito do processo de aprendizagem são feitas até hoje e durante todo este tempo surgiram várias teorias para tentar explicar como ocorre este processo. Estas teorias fazem parte de uma grande quantidade de propostas, modelos ou paradigmas, com os quais educadores têm procurado compreender o processo de aprendizagem, para torna-lo mais eficiente na escola, no lar, no trabalho e em outras aplicações afins PFROMM NETO (1987).

A compreensão de uma teoria de aprendizagem não fornece as melhores soluções para todas as situações de ensino, e esperar que uma teoria de aprendizagem proporcione um excelente ensino, pode ser uma experiência frustrante para o professor (WANKAT \& OREVICZ, 1993). Conforme $\operatorname{KIMBLE}^{3}$ (1980, p. 755) apud (PFROMM NETO, 1987), “... nenhuma teoria da aprendizagem cobre mais do que uma pequena fração dos fenômenos da aprendizagem”. Devemos considerar “... as lições que podem ser tiradas de cada teoria da aprendizagem, ao invés de

\footnotetext{
${ }^{3}$ KIMBLE, G.A. (1961). “Learning theories”. Encyclopaedia Britannica, v. 10, p. 754-759, apud PFROMM NETO, S. P. (1987). Psicologia da aprendizagem e do ensino. São Paulo, EPU/EDUSP.
} 
realçarmos oposições, controvérsias e conflitos” (GALLOWAY, 1981) ${ }^{4}$ apud (PFROMM NETO, 1987).

\subsubsection{Princípios para a prática educacional}

Apresentar uma análise detalhada das principais teorias da aprendizagem fugiria do escopo deste projeto, sendo assim apresentado uma síntese obtida a partir das teorias de aprendizagem. Esta síntese, considerada suficiente para a prática educacional em geral, está apresentada no quadro 2.3 a seguir.

- O aprendiz deve ser ativo e suas respostas são fundamentais para que ocorra aprendizagem, sendo que as respostas corretas ou desejáveis devem ser reforçadas, dando-se preferência ao reforço positivo, em oposição ao reforço negativo.

- A freqüência da repetição ou dos exercícios é importante para a aquisição de qualquer habilidade, garantindo a retenção da mesma. A aprendizagem com compreensão é mais permanente e transferível do que a mera decoração sem compreensão ou a aprendizagem de fórmulas.

- $\quad$ As condições motivacionais são importantes. Os aspectos perceptivos das situações e materiais de aprendizagem são condições importantes e indicam a importância da sua estruturação e apresentação, de modo que os aspectos essenciais possam ser captados pelo aprendiz. Deve ser favorecido tanto o pensamento divergente, que conduz a soluções imaginosas de problemas ou á criação de produtos novos e valiosos, como o pensamento convergente, que conduz a respostas logicamente corretas.

- A organização do conhecimento influi na forma e a direção "do simples para o complexo" deve ser, na verdade, de totalidades simplificadas para totalidades complexas. A fixação de alvos ou propósitos, pelo aprendiz, motiva a aprendizagem, e os êxitos e malogros deste influem na especificação de alvos futuros.

- A forma como ocorre a aprendizagem varia de aprendiz para aprendiz, uns aprendem mais rápido, outros mais lentamente. O nível de ansiedade pode ser benéfico para uns e maléfico para outros. Às vezes uma certa situação produz motivação para alguns estudantes, enquanto para outros não.

Conteúdo extraído de PFROMM NETO (1987), pp.75-77.

QUADRO 2.3 - SÍNTESE PARA A PRÁTICA EDUCATIVA

A síntese apresentada no quadro 2.3 deve ser considerada pelo professor no processo de planejamento e entrega da instrução, ao buscar a aprendizagem no estudante.

${ }^{4}$ GALLOWAY, C. 1981. Psicologia da aprendizagem e don ensino. São Paulo, Cultrix, apud PFROMM NETO, S. P. (1987). Psicologia da aprendizagem e do ensino. São Paulo, EPU/EDUSP. HILGARD, E.R.; BOWER, G.H. (1966). Theories OF learning. Prentice-Hall, apud PFROMM NETO, S. P. (1987). Psicologia da aprendizagem e do ensino. São Paulo, EPU/EDUSP. 


\subsection{Planejamento e entrega da instrução}

Uma das mais importantes atividades de um professor é assegurar que a aprendizagem no estudante esteja apoiada de todas as formas possíveis, oferecendo condições favoráveis à ocorrência da aprendizagem (GAGNÉ, 1975). Planejar e entregar a instrução adequadamente é querer garantir que ocorra a aprendizagem no estudante.

Através das teorias de aprendizagem e da própria experiência, o professor poderá efetuar o processo de planejamento e entrega da instrução, desde que, conheça bem o conteúdo a ser ensinado e saiba o que realmente o estudante deve aprender. O professor deve também procurar conhecer quais condições são favoráveis à aprendizagem em cada estudante e as diferenças existentes entre os mesmos. Estas diferenças vão desde conhecimentos adquiridos anteriormente em outros cursos ou disciplinas, até características psicológicas pessoais como preferências, culturas, temperamentos e incompatibilidades entre os estilos de aprendizagem dos estudantes e os estilos de ensino dos professores.

Além de assegurar que ocorra a aprendizagem nos estudantes, o professor tem outra tarefa importante, verificar a ocorrência da aprendizagem, ou seja, verificar se seus estudantes realmente adquiriram as capacidades necessárias para prosseguir o curso de engenharia e para a vida profissional. Estas duas tarefas devem ser levadas em equilíbrio pelo professor, pois o excesso de uma e a falta da outra é muito prejudicial ao estudante (BRENT \& FELDER, 1999).

Ao trabalhar o processo de planejamento e entrega da instrução, o professor deve ter em mente que, hoje seus estudantes são construtores ativos que descobrem ou recebem a informação e transformam-na em conhecimento, devendo ser 
preparados para o mutante mercado de trabalho que os espera. Esta preparação pode ser alcançada com a aprendizagem cooperativa.

\subsubsection{Utilizando aprendizagem cooperativa}

Muito tem sido estudo sobre os tipos de aprendizagem individualista ${ }^{5}$, competitiva $^{6}$ e cooperativa, verificando-se que para o atual perfil dos estudantes (construtores ativos que recebem ou descobrem a informação e transformam-na conhecimento), o melhor tipo é a cooperativa. Através deste tipo de aprendizagem, os estudantes adquirem capacidades necessárias para o atual mercado de trabalho (JOHNSON; JOHNSON; SMITH 1998).

Ainda segundo JOHNSON; JOHNSON; SMITH (1998), implementar uma aprendizagem cooperativa, não significa implementar uma aprendizagem simplesmente baseada no trabalho em equipe. Para que fique caracterizada a aprendizagem cooperativa, é necessário que o trabalho em equipe contemple os cinco elementos básicos descritos no quadro 2.4 a seguir.

A aprendizagem cooperativa pode ocorrer dentro e fora da sala de aula. Dentro, através de resoluções de exercícios, perguntas, discussões de tópicos, etc, e fora da sala de aula, através de pesquisas, elaboração de relatórios e apresentações de trabalhos, etc.

- Interdependência positiva: os integrantes do grupo devem realmente confiar uns nos outros para alcançar uma determinada meta e que se um deles fracassar os demais também fracassarão;

\footnotetext{
5 Na aprendizagem individualista, o estudante trabalha só, buscando a própria aprendizagem (motivação intrínseca) e ou querendo agradar alguém (como professores e pais) ou até evitar um castigo pelo seu mau desempenho (motivação extrínseca) (COLL, PALACIOS, MARCHESI, 1996). Neste tipo de aprendizagem pode ocorrer apoio entre colegas.

${ }^{6} \mathrm{Na}$ aprendizagem competitiva, o estudante é movido pelo incentivo em estar sempre à frente dos demais colegas, independente do modo de avaliação considerado (provas, trabalhos, etc). Neste tipo de aprendizagem, ser melhor que os colegas é mais importante do que simplesmente a própria aprendizagem, verificando-se ainda a falta de apoio entre colegas (COLL, PALACIOS, MARCHESI, 1996)
} 
- Responsabilidade individual: cada integrante do grupo é responsável por pelo menos uma parte do trabalho a ser desenvolvido, porém deve também conhecer todo o trabalho;

- Interação incentivadora: os integrantes do grupo devem ajudar-se uns aos outros, através de avaliações, incentivos e criticas construtivas que proporcionem o desenvolvimento individual e grupal - para facilitar e garantir uma melhor integração, o grupo deve ter 3 ou 4 integrantes no máximo;

- Habilidades de trabalho em equipe: os integrantes do grupo devem ser encorajados e ajudados a praticarem habilidades de liderança, desenvolvimento, comunicação e administração; encorajar e ajudar é tarefa principalmente do professor;

- Processamento do trabalho em equipe: os integrantes do grupo devem analisar periodicamente os desempenhos individual e grupal, para que possam corrigir ou melhorar futuramente estes desempenhos.

Conteúdo extraído de JONHSON; JONHSON; SMITH (1998).

QUADRO 2.4 - ELEMENTOS BÁSICOS DA APRENDIZAGEM COOPERATIVA

Conforme FELDER \& BRENT (1994), a aprendizagem cooperativa, quando comparada com a competitiva e a individualista, proporciona ótimos resultados a estudantes e professores. Os estudantes submetidos a este tipo de aprendizagem, geralmente apresentam maior desempenho acadêmico, maior interesse na conclusão da graduação, alto nível de raciocínio, melhores habilidades, maior motivação intrínseca e melhor controle da ansiedade. Professores que aplicam este tipo de aprendizagem obtém uma redução de documentos gerados pelos estudantes, facilitando e melhorando a análise de desempenho dos mesmos.

Os resultados proporcionados por uma aprendizagem cooperativa, caracterizada pelo quadro 2.4, não são afetados por diferenças de classe étnica, cultural, lingüística e social (JOHNSON; JOHNSON; SMITH, 1998).

Apesar dos ótimos resultados obtidos, a implementação da aprendizagem cooperativa, pode apresentar alguns problemas (FELDER \& BRENT, 1994). Alguns estudantes podem apresentar resistência a este tipo de aprendizagem, não querendo desenvolver trabalhos em grupo. Entre os integrantes de um grupo, podem surgir também alguns conflitos gerados a partir de diferenças de habilidades e senso de responsabilidade, criando uma desarmonia dentro do grupo. Estes problemas podem 
ser contornados pelo professor, com um pouco de paciência e prática na aprendizagem cooperativa, no entanto alguns professores não persistentes acabam desistindo e voltando ao tradicional método de ensino centrado no instrutor, baseado na aprendizagem competitiva e individualista (FELDER \& BRENT, 1999).

Uma maneira de solucionar esta resistência à aprendizagem cooperativa é o professor verificar se há compatibilidade entre os estilos de aprendizagem dos seus estudantes e o seu estilo de ensinar.

\subsubsection{Estilos de aprendizagem e de ensino}

Os estudantes possuem diferentes estilos de aprendizagem, características e preferências de como conduzir o processamento da informação. Alguns estudantes atentam mais para fatos, dados e algoritmos, outros preferem teorias e modelos matemáticos. Alguns estudantes preferem receber a informação visualmente (quadros, diagramas e esquemas), enquanto outros preferem explicações verbais ou escritas. Alguns estudantes preferem aprender de forma ativa e interativa, outros preferem aprender de forma reflexiva e individual (FELDER, 1996a).

Estudantes e professores possuem diferentes estilos de aprendizagem e de ensino, porém nem sempre o estilo de ensino de um professor é compatível com o estilo de aprendizagem de seus estudantes. Esta incompatibilidade de estilos pode ser verificada tanto nos estudantes, como nos professores. Os estudantes geralmente apresentam-se aborrecidos e desatentos na sala de aula, desmotivados para o curso, refletindo em mau desempenho escolar e às vezes até abandono ou mudança de curso. Os professores perante classes hostis, com mau desempenho e freqüentes faltas e desistências, podem acabar reagindo de forma errada piorando a situação ou até desistirem da profissão (FELDER \& SILVERMAN, 1988). 
Para que a compatibilidade entre os estilos de aprendizagem e de ensino ocorra, proporcionando um ótimo ambiente de aprendizagem é necessário que o professor utilize um estilo de ensino compatível com a maioria (senão com todos) dos estilos de aprendizagem dos seus estudantes.

FELDER \& SILVERMAN (1988), propuseram uma classificação para os estilos de aprendizagem preferenciais dos estudantes e os compatíveis estilos de ensino dos professores, apresentada no quadro 2.5 a seguir.

\begin{tabular}{|c|c|}
\hline Estilo de aprendizagem preferencial & Estilo de ensino correspondente \\
\hline Percepção $\left\{\begin{array}{l}\text { Sensorial } \\
\text { Intuitiva }\end{array}\right.$ & Conteúdo $\left\{\begin{array}{l}\text { Concreto } \\
\text { Abstrato }\end{array}\right.$ \\
\hline Alimentação $\left\{\begin{array}{l}\text { Visual } \\
\text { Auditiva }\end{array}\right.$ & Apresentação $\left\{\begin{array}{l}\text { Visua } \\
\text { Verbal }\end{array}\right.$ \\
\hline Organização $\left\{\begin{array}{l}\text { Indutiva } \\
\text { Dedutiva }\end{array}\right.$ & Organização $\left\{\begin{array}{l}\text { Indutiva } \\
\text { Dedutiva }\end{array}\right.$ \\
\hline Processamento $\left\{\begin{array}{l}\text { Ativo } \\
\text { Reflexivo }\end{array}\right.$ & Participação $\left\{\begin{array}{l}\text { Indutiva } \\
\text { Dedutiva }\end{array}\right.$ \\
\hline Compreensão $\left\{\begin{array}{l}\text { Sequencial } \\
\text { Global }\end{array}\right.$ & Perspectiva $\left\{\begin{array}{l}\text { Sequencial } \\
\text { Global }\end{array}\right.$ \\
\hline
\end{tabular}

QUADRO 2.5 - CLASSIFICAÇÃO DOS ESTILOS DE APRENDIZAGEM E DE ENSINO QUANTO AOS CINCO TÓPICOS

Esta classificação está dividida em cinco dimensões para o estilo de aprendizagem,

- percepção: como o estudante prefere perceber a informação, sensorialmente através de imagens, sons, sensações físicas, ou intuitivamente através de possibilidades, intuições ou palpites;

- alimentação: como o estudante prefere receber a informação (como o estudante recebe mais efetivamente a informação), visualmente através de diagramas, figuras, gráficos, esquemas, ou auditivamente através de palavras ou sons;

- organização: como o estudante prefere que a informação recebida esteja organizada, de forma indutiva apresentando-se fatos e informações e inferindo-se os princípios básicos, ou dedutiva apresentando-se dados e sucessivamente deduzindo-se conseqüências e aplicações;

- processamento: como o estudante prefere processar a informação, ativamente "pondo a mão na massa" ou discutindo-se, ou reflexivamente, isto é, instropectivamente; 
- compreensão: como o estudante consegue entender a informação, seqüencialmente onde a informação é apresentada de forma seqüencial, ou globalmente através de visões gerais e grandes saltos da informação;

e em cinco dimensões para o correspondente estilo de ensino,

- conteúdo: tipo de informação enfatizado pelo professor, informação concreta (realista) ou abstrata (conceitual, teórica);

- apresentação: modo de apresentação enfatizado pelo professor, visual através de figuras, filmes, diagramas, etc, ou verbal através de leituras, preleções e discussões;

- organização: modo como o professor organiza a informação, indutivamente (dos fenômenos aos princípios) ou dedutivamente (dos princípios aos fenômenos);

- participação do estudante: tipo de participação do estudante propiciada pela apresentação, ativa onde os estudantes falam, executam tarefas, refletem, ou passiva onde os estudantes apenas ouvem e observam;

- perspectiva: tipo de perspectiva fornecida pela informação, seqüencial através da progressão passo a passo, ou global através do contexto e da relevância.

A partir das cinco dimensões, é possível efetuarmos $32\left(2^{5}\right)$ combinações distintas para classificar um estudante quanto as suas preferências, por exemplo, um estudante pode ser do tipo sensorial/auditivo/indutivo/reflexivo/global. Entretanto, segundo FELDER \& SILVERMAN (1988), a maioria dos estudantes presentes nos cursos de engenharia são do tipo visual/sensorial/indutivo/ativo/seqüencial. No entanto, segundo BELHOT (1998), é necessário que o professor proporcione a aprendizagem em todos os estudantes, isto é, nas outras possíveis combinações. Para isto, o professor deve adotar um estilo de ensino que atinja estudantes visuais e auditivos, sensoriais e intuitivos, indutivos e dedutivos, ativos e reflexivos, e seqüenciais e globais.

A princípio, pode parecer uma tarefa muito complexa, porém, como os métodos educacionais usuais presentes na engenharia são geralmente do tipo intuitivo/auditivo/dedutivo/reflexivo/seqüencial, uma pequena reestruturação destes métodos para tentar contemplar também os estudantes sensoriais, visuais, indutivos, ativos e globais seria mais acessível para o professor. 
FELDER \& SILVERMAN (1988), propuseram também algumas técnicas de ensino para atingir todos os estilos de aprendizagem, no entanto o professor não precisa aplica-las ao todo em uma única aula, o que pode ser até impossível devido a fatores como carga horária e conteúdo curricular. O professor deve aplicar e trocar algumas destas técnicas a cada aula, e assim selecionar as que apresentarem melhor efeito sobre a aprendizagem dos estudantes. Estas técnicas de ensino estão no quadro 2.6 a seguir.As técnicas do quadro 2.6 não são únicas e outros modelos citados por FELDER (1996b), com o mesmo objetivo - proporcionar um melhor ambiente de aprendizagem na engenharia, capaz de formar melhores profissionais para a sociedade - poderiam ser escolhidos.

O quanto o estudante aprende depende tanto de suas capacidades inatas ou anteriormente adquiridas como também do desempenho do professor durante o ensino, no entanto, se houver incompatibilidade entre os estilos de aprendizagem e de ensino, com certeza o quanto o estudante aprende será prejudicado. 
- Estimule a aprendizagem. Sempre que possível, relacione o conteúdo ministrado com o anteriormente visto e com o que estiver para vir na mesma disciplina, com conteúdo de outras disciplinas e também com as capacidades dos estudantes (indutivo/global);

- Mantenha um equilíbrio entre informação concreta (fatos, dados, experimentos reais ou hipotéticos e seus resultados) (sensorial) e conceitos abstratos (princípios, teorias e modelos matemáticos) (intuitivo);

- Mantenha equilíbrio entre material que enfatize métodos práticos de solução de problemas (sensorial/ativo) com material que enfatize a compreensão básica (intuitivo/reflexivo);

- Apresente ilustrações explícitas de comportamentos intuitivos (inferências lógicas, reconhecimento de padrões, generalizações) e comportamentos sensoriais (observação do entorno, experimentação empírica, atenção para detalhes), e encoraje todos os estudantes a exercitar os dois comportamentos (sensoriallintuitivo). Não espere que qualquer subgrupo consiga operacionalizar os processos do outro imediatamente;

- Siga o método científico na apresentação de material teórico. Forneça exemplos concretos dos fenômenos que a teoria descreve ou prediz (sensoriallindutivo); então desenvolva a teoria ou formule o modelo (intuitivolindutivo/seqüencial); mostre como a teoria ou o modelo pode ser validado, e deduza suas conseqüências (dedutivo/seqüencial); e apresente aplicações (sensorial/dedutivo/seqüencial);

- Use figuras, esquemas, gráficos e simples esboços liberalmente antes, durante e depois da apresentação verbal da matéria (sensorial/visual). Exiba filmes (sensorial/visual). Apresente demonstrações, com as mãos na massa se possível (ativo);

- Não preencha cada minuto da aula falando e escrevendo no quadro negro. Faça intervalos mesmo que breves - para que os estudantes possam pensar sobre o que acaba de ser apresentado (reflexivo);

- Proporcione oportunidades para os estudantes fazerem algo além de apenas tomar notas. Atividades de tempestade cerebral para pequenos grupos, que não durem mais do que cinco minutos, são extremamente efetivas para essa meta (ativo);

- Especifique alguns exercícios de treinamento para garantir a prática nos métodos básicos que estão sendo ensinados (sensorial/ativo/seqüencial), mas não exagere nessa atividade (intuitivo/reflexivo/global). Apresente também alguns exercícios e problemas abertos que exigem análise e síntese (intuitivo/reflexivo/global);

- Dê aos estudantes a opção de trabalhar extensivamente em grupos na solução de problemas dados para casa (ativo). Aprendizes ativos geralmente aprendem mais quando interagem com outros; se Ihes for negada essa oportunidade, estarão sendo privados de sua ferramenta de aprendizagem mais efetiva;

- Aplauda soluções criativas, mesmo as incorretas (intuitivo/global);

- Converse com os estudantes sobre estilos de aprendizagem, em particular ou na sala de aula. Os estudantes são estimulados ao descobrir que suas dificuldades acadêmicas podem ser devidas às suas inadequações pessoais. Explicando aos aprendizes sensoriais, aos ativos ou aos globais como eles podem aprender mais eficientemente pode ser um ingrediente importante para ajuda-los a reformular suas experiências de aprendizagem para que elas sejam positivas (todos os tipos).

Conteúdo extraído de FELDER \& SILVERMAN (1988).

QUADRO 2.6 - TÉCNICAS DE ENSINO PARA ATINGIR TODOS OS ESTILOS DE APRENDIZAGEM 


\subsubsection{Sugestões para elaboração de uma disciplina}

BRENT \& FELDER (1999) propuseram sugestões para que uma disciplina

possa se desenvolver bem durante o semestre, consideradas importantes para o

modelo proposto. Algumas destas sugestões estão descritas no quadro 2.7 a seguir.

- Escreva os objetivos do curso: apresente os objetivos do curso aos estudantes, detalhando o que eles devem aprender com o material ministrado em aula, porque e onde utilizar as capacidades aprendidas. Evite colocar o estudante numa situação de obrigação com conjugações como "saiba", "entenda", "goste", "aprecie". Para isto, "parafraseie", "calcule", "mostre", "derive", "demonstre", "projete", "compare", mostrando a importância em se aprender o material ministrado;

- Defina um cronograma e regras a serem seguidas: apresente o sistema de avaliação para a disciplina, provas, exercícios, trabalhos, como serão considerados trabalhos atrasados ou não entregues e datas importantes. Definir tais informações ao início do curso pode evitar futuros mal entendidos. Discuta cronograma e regras com os estudantes no primeiro dia de aula;

- Conheça os estudantes: aprenda o nome dos estudantes (um tanto complicado para grandes classes), conheça suas preferências, opiniões e de oportunidade para se conhecerem entre eles. Em grandes classes nomeie um representante;

- Peça sugestões ao final da disciplina: verifique o que os estudantes acharam de você e da disciplina, quais sugestões para melhorar ou corrigir a disciplina. Mostre que as sugestões anteriores têm sido atendidas na medida do possível;

- Estimule discussões sobre a disciplina e seu conteúdo: crie listas de discussões através de e-mail ou um servidor web. As discussões podem ser anônimas facilitando a participação de estudantes mais isolados. As listas de discussões propiciam melhor integração entre estudantes e professores;

- Mostre o mundo real: associe conceitos e outras informações presentes na disciplina com o cotidiano do estudante. Exemplifique e discuta aplicações práticas com os estudantes, apresente um problema real envolvendo os conceitos presentes na disciplina e peça para resolverem-no e discuta as resoluções apresentadas. Estes problemas podem ser apresentados no início da disciplina e retomados mais adiante para que os estudantes vejam que conseguem resolve-lo com as capacidades adquiridas na disciplina.

Conteúdo extraído de BRENT \& FELDER (1999).

QUADRO 2.7 - SUGESTÕES PARA UM BOM DESENVOLVIMENTO DA DISCIPLINA

Este quadro, assim como os quadros 2.2, 2.3 e 2.6 (Capítulo II), não

representam a melhor solução ou o melhor método a ser adotado em uma disciplina, mas se utilizados podem proporcionar bons resultados para professores e estudantes.

A maioria dos estudantes não consegue assistir uma aula passivamente prestando atenção continuamente durante toda esta aula. Após aproximadamente dez minutos, a atenção deles começa a dispersar para outros assuntos (pensamentos 
distantes, conversa entre colegas, etc). Para isto o professor deve periodicamente retomar a atenção dos estudantes dando-lhe algo para fazer. Por exemplo, um exercício para ser resolvido em grupo ou uma pergunta pertinente ao assunto em pauta. (FELDER \& BRENT, 1999). 


\section{Capítulo III}

\section{Disciplinas introdutórias}

\subsection{Principais características}

As disciplinas introdutórias têm procurado motivar e preparar o calouro para o curso de engenharia, dando-lhe condições de escolher uma carreira a ser seguida (ENTERLINE; KALONJI; ERIDLEY, 1997). Flexibilidade e rápida adaptação às mudanças exigidas pelo mercado de trabalho são características que os futuros profissionais devem adquirir durante todo o curso de engenharia, começando pelas disciplinas introdutórias (NAHVI, 1998).

As principais características que devem ser encontradas em disciplinas de introdução à engenharia são:

- Motivação e preparação para o curso de engenharia;

- Preparação para o mercado de trabalho e para a sociedade;

- Integração entre estudantes, professores e departamento;

Estas características proporcionam um nivelamento necessário dos calouros (CRADDOCK, 1997) devido a algumas diferenças de conhecimentos não abordados pelo vestibular, que podem existir por virem de diferentes escolas, por exemplo, conhecimentos na área de informática ou familiarização com um computador. Dessa forma, o caráter das disciplinas introdutórias está mudando de apenas informativo, para também formativo. 


\subsubsection{Motivação, apresentação e preparação para o curso de engenharia}

O estudante novato ingressa em um curso de engenharia esperando encontrar em suas primeiras disciplinas um conteúdo técnico cheio de conceitos de engenharia, no entanto, defronta-se com uma realidade muito diferente, um novo ambiente de disciplinas de matemática e ciências. Embora este novo ambiente seja fundamental para todo o curso de engenharia, segundo NAHVI (1998), o primeiro ano contendo apenas disciplinas de matemática e ciências geralmente deixa o calouro desmotivado para a engenharia. Esta falta de motivação no estudante pode acarretar em mudança ou até abandono do curso (HIPPO; KENT; O’BRIEN, 1997).

Uma disciplina introdutória precisa atender as expectativas do calouro motivando-o para o curso de engenharia.

Procurando atender as expectativas do calouro, são apresentadas ferramentas computacionais como editores de texto, planilhas eletrônicas, apresentadores de trabalhos e simuladores a serem utilizados durante todo o curso da engenharia (HELMER, 1997). A presença destas ferramentas, além de atender as expectativas do estudante novato, estará preparando-o para o curso de engenharia, onde deverá desenvolver projetos contendo simulações e análises gráficas, a serem apresentados através de relatórios e ou palestras para os demais colegas. Para isso, o calouro também deverá aprender conceitos de organização, planejamento e apresentação de trabalhos (NARASIMHAN; TEMARES; LEE, 1997), sejam estes individuais ou em grupo.

Ainda procurando atender as expectativas do calouro, as disciplinas introdutórias contêm uma visão geral do conteúdo do curso de engenharia, como disciplinas, conceitos e laboratórios (CRADDOCK, 1997). 
Todo esse conteúdo para motivação, apresentação e preparação para o curso de engenharia, quando presente em uma disciplina introdutória, proporciona ao estudante novato condições de começar a escolher uma ênfase, uma carreira ou uma especialidade a seguir dentro da engenharia, conseqüentemente é reduzida a taxa de abandono do curso por estudantes desmotivados. Outra conseqüência é a redução da formação de profissionais frustrados, por terem escolhido erroneamente o curso e perceberem este erro muito tarde.

O planejamento e a entrega da instrução desse conteúdo pode ser facilitado com a utilização de técnicas de multimídia e recursos audiovisuais, o que também permitirá trabalhar melhor a motivação do calouro (STRAKOS \& KEBO, 1998).

\subsubsection{Preparação para o mercado de trabalho e para a sociedade}

Uma outra preocupação presente no ensino em engenharia é a preparação do estudante para o mercado de trabalho e para a sociedade (WULF, 1998), pois o profissional do século XXI deve apresentar um perfil de estrategista, capaz de compreender, captar, analisar e interpretar as necessidades do mercado de trabalho e da sociedade, adaptando toda a tecnologia disponível de forma rápida, eficiente e diferenciada (GEHRINGER; LONDON, 2001a).

Para isto, conceitos éticos, sociais e culturais (O’CONNELL, 1997) e o papel do engenheiro perante um mundo globalizado, competitivo e variável (NAHVI, 1998) têm sido introduzidos a partir do início do curso de engenharia.

\subsubsection{Integração entre estudantes, professores e departamento do curso de engenharia}

A integração entre estudantes, professores e departamento também têm sido um ponto abordado pelas disciplinas introdutórias como em SOLEN \& HARB 
(1997). Esta abordagem é feita através de trabalhos em grupos supervisionados por um monitor (professor, estudante veterano, estudante recém formado ou outros colaboradores) utilizando a infraestrutura da própria escola (laboratórios, bibliotecas, computadores, etc) (FREIS, 1998). O objetivo desta integração é desinibir estudantes mais tímidos eliminando uma possível "barreira” originada no ambiente escolar anterior ao vestibular e desenvolver dinâmicas de grupo.

\subsection{Estrutura básica}

\subsubsection{A teoria associada à vida real}

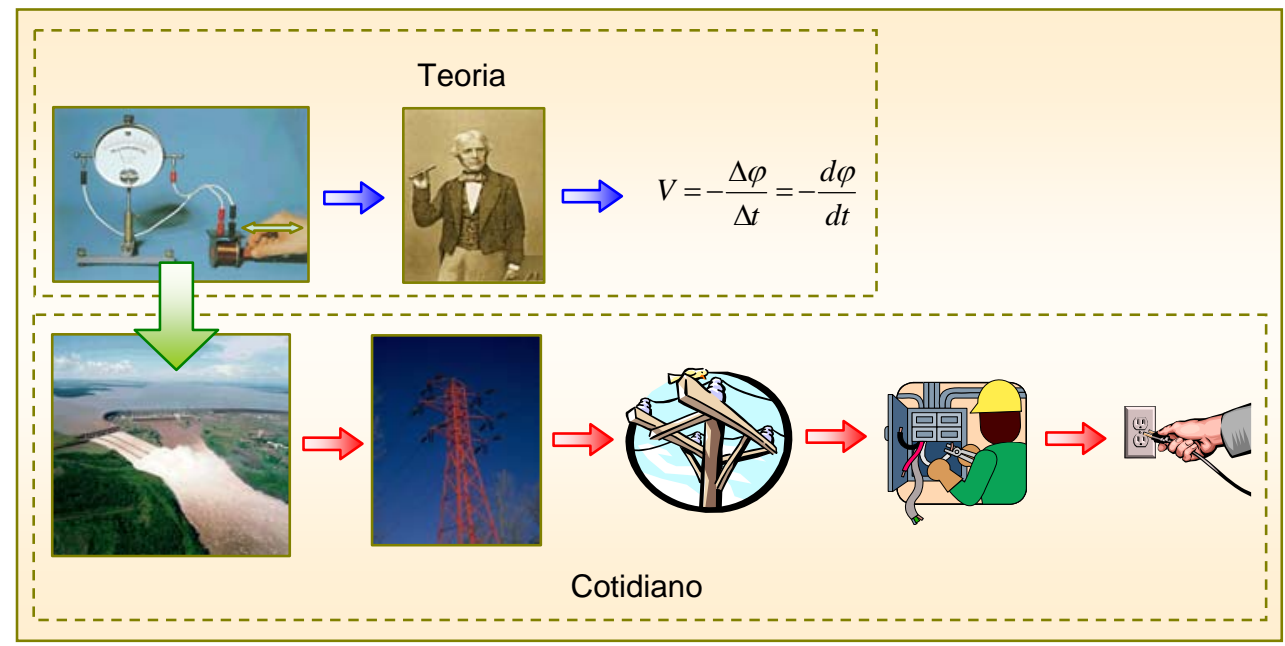

FIGURA 3.1 - EXEMPLO DE ASSOCIAÇÃO DA TEORIA COM O COTIDIANO

A estrutura básica presente nas disciplinas introdutórias é apresentar inicialmente uma visão geral sobre a própria disciplina, objetivos e conteúdo, e só depois apresentar uma visão mais detalhada a cada tópico (SOLEN \& HARB, 1998). Informações sobre currículo, especialidades da carreira, futuras disciplinas, conceitos éticos, sociais e econômicos, mercado de trabalho e ferramentas computacionais são apresentadas aos poucos a cada aula, dentro de uma seqüência programada. Os conceitos são genéricos seguidos de conhecimentos mais específicos, associando a 
teoria ao cotidiano e estimulando a confiança do estudante nos seus próprios conhecimentos (CHROBAK, 1998).

A figura 3.1 apresenta um exemplo, na qual a Lei de Faraday, presente em um simples gerador de tensão alternada, é associada à geração da energia elétrica, que sai de uma usina hidrelétrica e chega até a casa do estudante. Este mesmo exemplo pode ser associado ao ensino médio com a recordação do conceito de campo magnético, justificando sua aprendizagem nesta época, e também pode justificar a necessidade de disciplinas de matemática na engenharia, onde será aprendido o conceito de derivada.

O simples gerador pode ser montado a partir de um ímã e uma bobina feita com várias voltas de fio. A tensão alternada gerada e sua forma de onda senoidal podem ser constatadas respectivamente por meio de um galvanômetro e alguma ferramenta computacional como programas de animação gráfica ou de simulação de circuitos elétricos, onde os próprios estudantes têm oportunidade de operar tais ferramentas. O que proporciona um exercício prático individual ou em grupo.

Este exemplo também permite apresentar ao estudante uma das possíveis atuações do engenheiro eletricista, que é trabalhar na área de geração, transmissão e distribuição de energia elétrica, e para isto, outras disciplinas envolvendo esta área serão ministradas no decorrer do curso. Conseqüentemente, a situação brasileira de racionamento de energia elétrica e todas as suas implicações sócio-econômicas em 2001 podem e devem ser abordadas, por estarem relacionadas à mesma área.

Como o exemplo da figura 3.1, outros exemplos podem ser elaborados para justificar conhecimentos adquiridos no ensino médio, introduzir novos conceitos, mostrar a importância de outras disciplinas do curso, apresentar o campo de atuação 
do engenheiro e abordar assuntos sócio-econômicos afins, contribuindo construtivamente para a formação do futuro profissional de engenharia.

\subsubsection{Avaliação}

Uma disciplina introdutória, como qualquer outra disciplina, deve avaliar o quanto eficaz está sendo à formação do calouro. Para isso devem ser utilizados trabalhos em grupo procurando seguir os elementos básicos da aprendizagem cooperativa citados no quadro 2.4 do capítulo 2. Os trabalhos em grupo proporcionam maior entrosamento entre os estudantes permitindo a aprendizagem cooperativa e facilitando a avaliação do desenvolvimento dos estudantes, conseqüentemente a avaliação da disciplina.

A avaliação é fundamental para o professor analisar se o planejamento e a entrega da instrução estão alcançando seus objetivos. Para facilitar esta avaliação e permitir que os estudantes contribuam para o aperfeiçoamento da disciplina, um fórum de discussões pode ser implementado através de páginas WEB (NEWMAN, 1998). Estas páginas também podem ser utilizadas para divulgação de notas, cronogramas, apostilas e outras aplicações pertinentes à disciplina.

\subsubsection{O lado pedagógico}

A estrutura básica e as principais características necessárias numa disciplina introdutória foram obtidas a partir das experiências e dos trabalhos publicados por educadores e pesquisadores nesse campo da engenharia.

Estas estrutura e características obtidas, quando analisadas a partir do conteúdo pedagógico apresentado no capítulo 2, são compatíveis com as técnicas de ensino do quadro 2.6 e as sugestões do quadro 2.7 do mesmo capítulo. 
Por exemplo, quando é apresentado primeiro uma visão geral, para depois se apresentar uma visão mais detalhada passo a passo, os estudantes seqüenciais e globais estão sendo contemplados. A utilização do ímã e da bobina, associados à Lei de Faraday e a uma usina hidrelétrica, contempla os estudantes visuais, indutivos e dedutivos. Os estudantes auditivos estão sempre contemplados, pois uma das principais ferramentas do professor é a fala, desde que a mesma seja utilizada. Os exercícios práticos que requerem análise e síntese atendem aos estudantes ativos e sensoriais. Estes exemplos foram escolhidos aleatoriamente e não contemplam exclusivamente os estilos mencionados. Os demais estilos podem estar sendo contemplados também, mas com menor intensidade.

Dentre as sugestões do quadro 2.7 pode ser observado, por exemplo, a utilização de um fórum de discussões e a apresentação do mundo real, através de exemplos práticos ou de fatos ocorridos no cotidiano do estudante. 


\section{Capítulo IV}

\section{Um modelo de disciplina introdutória em engenharia elétrica}

\subsection{Objetivos}

O modelo proposto neste projeto, baseado nos capítulos II e III, procura motivar e preparar o calouro para o curso de engenharia, o mercado de trabalho e a sociedade, proporcionar a integração entre estudantes, professores e departamento, e permitir uma reciclagem pedagógica dos docentes envolvidos no curso.

\subsection{Estrutura}

\subsubsection{Definir a "coluna vertebral" da disciplina}

Um grande projeto de engenharia amplamente divulgado na mídia, deverá ser escolhido e fragmentado em pequenas partes, contendo conceitos básicos como a Lei de Ohm e a Lei de Faraday, noções básicas com exemplos práticos sobre eletrônica, controle, sistemas de potência, instrumentação, sistemas digitais, telecomunicações e ferramentas computacionais de grande aplicação no curso de engenharia elétrica (ALTAFIM; CANOVA; et al., 1998).

A fragmentação não gera partes físicas, mas envolve subáreas, especialidades ou ênfases da engenharia elétrica, que estão presentes dentro do grande projeto. Por exemplo, a Lei de Ohm está presente em qualquer subárea, especialidade ou ênfase e em qualquer circuito elétrico, mesmo no mais simples dos circuitos. Se o projeto 
possuir comunicação através de sinal de rádio, conceitos de telecomunicações poderão ser associados ${ }^{7}$, e assim por diante. Como ferramenta computacional, pode ser considerado, por exemplo, um simulador de circuitos ou um editor de textos. Estas ferramentas permitem ao estudante familiarizar-se com o conceito de simulação e também aprender a redigir relatórios, preparando-o para o resto do curso, onde deverá simular vários circuitos e elaborar muitos relatórios em grupo.

Deve ficar claro ao calouro, que a disciplina não está lhe propondo a concepção de um projeto semelhante ao extraído da mídia, está apenas mostrando a importância do aprendizado de vários conceitos e ferramentas da engenharia elétrica e o relacionamento desta com outras áreas do conhecimento. Assim, o exemplo escolhido será a “coluna vertebral” da disciplina introdutória, com a função de interligar e sustentar a necessidade de cada fragmento gerado.

\subsubsection{Uma disciplina modular}

A partir daqui, cada fragmento gerado será chamado de módulo e deverá possuir começo, meio e fim, iniciando com uma introdução para expor ao estudante seu conteúdo e o que poderá ser aprendido com o mesmo. Na seqüência deverão ser aplicados os conceitos técnicos, éticos, sociais e econômicos e as ferramentas computacionais afins. Por último, deverá haver uma conclusão encerrando o módulo.

Cada módulo deverá ser independente dos demais. A compreensão do mesmo não dependerá do conteúdo de módulos anteriores, mas sempre que possível deverá haver referências aos demais módulos e à própria “coluna vertebral” da disciplina,

\footnotetext{
${ }^{7}$ Está claro que a subárea de telecomunicações não se resume apenas a uma transmissão por sinal de rádio.
} 
mostrando importantes conexões entre subáreas, especialidades ou ênfases da engenharia elétrica e de outras áreas.

Como cada módulo representará uma subárea, ênfase ou especialidade da engenharia, tornar-se-á interessante que o mesmo seja elaborado e ministrado por um professor da mesma subárea, ênfase ou especialidade. Isto não significa que um certo professor seja incapaz de elaborar todos os módulos, porém é uma tendência natural do professor, às vezes inconscientemente, abordar temas e experiências pertinentes à sua área de atuação ou pesquisa.

Todo conceito ou explicação deverá ser apresentado ao estudante com vocabulário de fácil compreensão, considerando-se os conhecimentos adquiridos antes do exame vestibular, e sempre que possível relacionando o conceito em pauta com o cotidiano, com outros conceitos já vistos ou a serem vistos, mantendo-se um equilíbrio entre informação concreta e conceitos abstratos. O professor deverá procurar manter a atenção dos estudantes à aula, por meio de pequenos exercícios ou perguntas no decorrer da aula evitando-se longos intervalos de fala, no máximo dez minutos.

Os calouros deverão ser incentivados a desenvolverem trabalhos em grupo visando a aprendizagem cooperativa. Os professores também terão a oportunidade de fazerem o mesmo, pois cada módulo deverá ser apresentado ao corpo docente da disciplina, para que em trabalho cooperativo possa conhecer e contribuir com sugestões para o aperfeiçoamento da disciplina.

Após a elaboração de cada módulo, também deverá ser elaborado um módulo de introdução da disciplina para apresentar ao calouro o objetivo, a estrutura, o conteúdo e regras e forma de avaliação da disciplina introdutória. 


\subsubsection{Avaliação da disciplina}

Ao final da disciplina e de cada módulo deverá ser efetuada uma avaliação dos mesmos, por parte dos estudantes. Esta avaliação poderá ser feita por meio de questionários, discussões em sala de aula, listas de discussões, etc. Os estudantes deverão poder dar sugestões para melhorar a disciplina, e saberem as sugestões anteriores têm sido atendidas na medida do possível.

Deverá haver também uma avaliação do que os estudantes realmente aprenderam. Esta avaliação pode ser feita por meio de exercícios práticos, relatórios, apresentações de trabalhos para os demais colegas, utilizando-se todos os conhecimentos adquiridos durante a disciplina. Por exemplo, se um editor de texto foi apresentado aos estudantes, os trabalhos práticos deverão ser redigidos nesta ferramenta, se um simulador de circuitos elétricos foi apresentado aos estudantes, trabalhos práticos de simulação de um circuito elétrico simples deverão ser aplicados.

Depois de efetuada a avaliação da disciplina e dos estudantes os professores envolvidos deverão efetuar uma análise geral sobre toda a disciplina e seu conteúdo, considerando as sugestões e as críticas dos estudantes de forma a contribuírem para o aperfeiçoamento da disciplina introdutória no próximo período.

\subsubsection{Corpo docente}

Um curso de graduação envolve muitos professores, cada um com seu estilo de ensino, seus princípios, suas pesquisas e seus compromissos. Tentar colocar todos estes professores em trabalho cooperativo de uma só vez para elaborar uma única disciplina, poderá ser um tanto desastroso. 
Dessa forma, apenas os professores realmente interessados e com condições de participar deverão elaborar a disciplina. Se cada módulo representar uma subárea da engenharia elétrica, seria interessante que pelo menos um professor dessa subárea participasse na elaboração do mesmo.

A cada período outros professores poderão se interessar e participar do processo evolutivo da disciplina.

\subsection{Qualidade total}

A implementação deste modelo pode ser considerada como uma pequena implementação de qualidade total no ambiente escolar, especificamente em uma disciplina, pois apresenta definições de objetivos instrutivos a serem seguidos para a adequada elaboração de uma disciplina introdutória, sendo posteriormente avaliado se tais objetivos foram atingidos ou não. A partir desta avaliação melhorias poderão ser feitas no modelo ou na implementação do mesmo. Repetindo-se periodicamente esta verificação a disciplina estará em um processo de melhoria contínua.

Ao se falar em qualidade total dentro do ambiente acadêmico, podem surgir muitos obstáculos para a sua implantação, como divergências de opiniões a favor e contra a qualidade total. Uma possibilidade de se evitar esses obstáculos é aplicar a qualidade total sem menciona-la, simplesmente aplique-a de forma gradativa (FELDER \& BRENT, 1999). 


\section{Capítulo V}

\section{Implementação do modelo proposto na disciplina SEL-300}

\subsection{Antiga estrutura da SEL-300}

Segundo o MANUAL DE GRADUAÇÃO NA HABILITAÇÃO EM ENGENHARIA ELÉTRICA (1999), a SEL-300 - Informação Profissional em Engenharia Elétrica é uma “disciplina de caráter informativo tratando de assuntos relativos ao desenvolvimento histórico da engenharia elétrica e conseqüências sócioeconômicas. Descobertas e invenções que representam saltos tecnológicos. Projeções para o século XXI. Características da profissão - aspectos legais e éticos. Currículo e estruturas opcionais no Curso de Engenharia Elétrica da EESC/USP”.

Esta disciplina é oferecida pelo $S E L^{8}$ e está presente na nova estrutura curricular de engenharia elétrica implantada a partir de 1997. Trata-se de uma disciplina obrigatória para todos os estudantes do curso de engenharia elétrica baseado na nova estrutura curricular, independente de ênfase e de estudo especial ${ }^{9}$ escolhido pelo estudante.

\footnotetext{
${ }^{8}$ SEL - Departamento de Engenharia Elétrica da EESC/USP.

${ }^{9}$ A nova estrutura curricular, implantada a partir de 1997 na EESC/USP, para o curso de engenharia elétrica, apresenta duas ênfases Eletrotécnica e Eletrônica. Dentro da segunda ênfase é possível obterse certificados de estudos especiais em Comunicações, Controle e Instrumentação e Sistemas Digitais. Maiores informações podem ser obtidas na página WEB http://www.sel.eesc.sc.usp.br.
} 
Segundo OLIVEIRA JR. $(2000)^{10}$, coordenador da SEL-300, esta disciplina era ministrada através palestras de professores do próprio $S E L$ ou de profissionais atuantes em grandes empresas. No entanto, tais palestras eram isoladas sem nenhuma relação entre as mesmas, sem um padrão de apresentação, às vezes sem o devido cuidado quanto à compatibilidade entre estilos de aprendizagem e estilos de ensino e às vezes com alto nível técnico para um estudante novato. Todos esses fatores poderiam influenciar o calouro de forma negativa na escolha da carreira a seguir. No primeiro ano de implantação da SEL-300, 1997, os professores convidados mostraram-se mais motivados e a maioria conseguiu passar este entusiasmo para os estudantes. No entanto, no segundo ano da disciplina, 1998, a maioria dos professores repetiu suas palestras com o material do ano anterior, sem nenhuma atualização de conteúdo e sem a mesma motivação anterior, o que também refletia de forma negativa sobre os estudantes. A partir do meio do semestre, verificava-se que a maioria dos estudantes estava desmotivada com uma atitude extremamente passiva e desinteressada pelo conteúdo da disciplina. Vários estudantes que iniciaram a SEL300, demonstrando-se motivados e interessados pela disciplina, encerraram-na com total apreço, apenas esperando a lista de presença para se retirarem, verificando-se assim a necessidade de reestruturar a SEL-300.

\subsection{Nova estrutura}

Perante a necessidade de uma nova estrutura, a SEL-300 foi modificada com a implementação do modelo proposto neste trabalho. Esta reestruturação iniciou-se em 1999, sendo mantida em 2000 e 2001.

\footnotetext{
10 OLIVEIRA JR., A. A. (2000). A antiga estrutura da $S E L-300$ e as necessidades de uma
} reestruturação. Personal e-mail (10 Apr). 
Apesar da nova estrutura, a mesma ementa foi mantida quase completamente, mudando-se apenas de uma disciplina só informativa, para uma disciplina também formativa, preocupada em preparar o calouro para o curso, o mercado de trabalho e a sociedade.

\subsubsection{Escolha do grande exemplo da mídia}

A reestruturação da $S E L-300$ começou com a escolha de um grande projeto de engenharia muito divulgado pela mídia em 1999, que pudesse ser associado às ênfases e os estudos especiais do currículo de engenharia elétrica da EESC/USP.

O projeto escolhido foi a Pathfinder Mission $^{11}$ da NASA ${ }^{12}$, que possui muitas áreas envolvidas como engenharias, física, química e matemática. Dentro das engenharias estaria a área de elétrica contendo muitos conceitos, teorias e subáreas como a Lei de Ohm, Lei de Faraday, controle com malha fechada, portas lógicas, microprocessadores, instrumentação e telecomunicações, conforme sugerido no modelo de disciplina introdutória.

\subsubsection{Estrutura Modular}

Foram definidos sete módulos para a disciplina introdutória, Módulo I Introdução, Módulo II - Circuitos Eletrônicos, Módulo III - Controle e Eletrônica de Potência, Módulo IV - Sistemas de Potência, Módulo V - Instrumentação e Medidas, Módulo VI - Sistemas Digitais e Módulo VII - Telecomunicações. Por meio destes módulos seria possível abordar não só as ênfases e os estudos especiais do curso de engenharia elétrica da EESC/USP, mas também outras ênfases como a habilitação

\footnotetext{
11 Maiores informações sobre o projeto Pathfinder Mission podem ser obtidas na página www.nasa.gov.

${ }^{12}$ Maiores informações sobre a Nasa podem ser obtidas na página www.nasa.gov.
} 
em controle e automação, criada recentemente pelo MEC. O caminho seguido para chegar a esta estrutura modular é apresentado na Figura 5.1 a seguir.

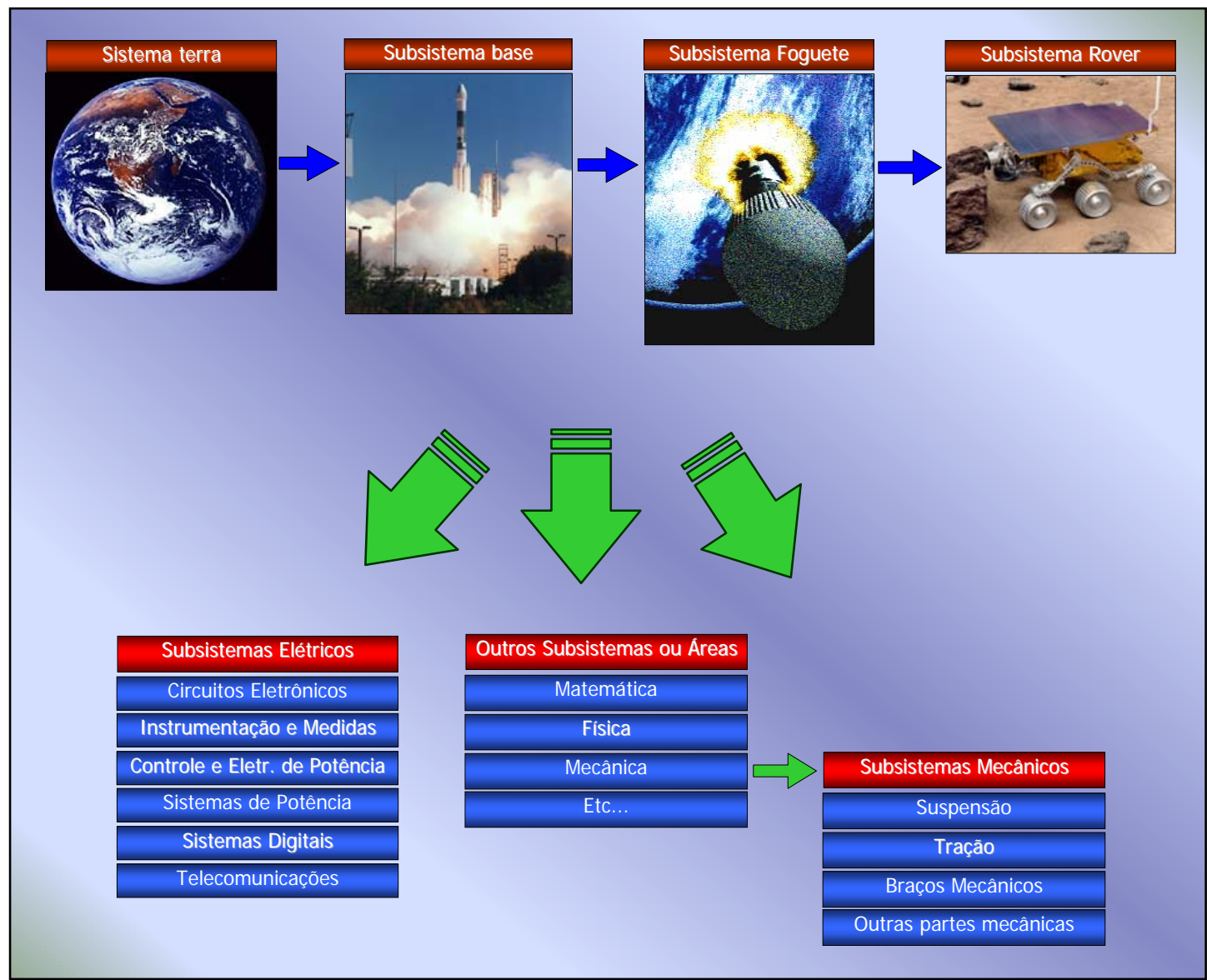

FIGURA 5.1 - CAMINHO TRAÇADO PARA A ESTRUTURA MODULAR

Neste quadro é possível verificar três subsistemas presentes no projeto Pathfinder Mission, a base de lançamento, o foguete de transporte e o robô Rover transportado até o planeta Marte. Dentro destes subsistemas, que na verdade também são sistemas, existem informações, conceitos e teorias de circuitos eletrônicos, instrumentação e medidas, controle e eletrônica de potência, sistemas de potência, sistemas digitais e telecomunicações. Os exemplos citados em aula não se resumiriam a apenas estes três subsistemas, exemplos como escadas rolantes, aviões, usinas hidrelétricas, computadores, multímetros e muitos outros também foram 
mencionados. Os três subsistemas da Figura 5.1 serviriam apenas como um ponto de partida para chamar a atenção dos estudantes.

O conteúdo de cada módulo definido, tópicos, conceitos, teorias, exemplos, diagramas, filmes e "slides” estão detalhados no capítulo 6.

\subsubsection{Corpo docente}

A implementação do modelo envolveu a participação de seis docentes ${ }^{13}$ do SEL selecionados a partir do interesse e da disponibilidade de participarem da reestruturação da SEL-300 em 1999. Alguns destes docentes haviam ministrado aulas na SEL-300 no período da antiga estrutura. Cada docente, especialista em uma subárea da engenharia elétrica, participou da elaboração de um dos módulos definidos inicialmente, do módulo de introdução à disciplina e do processo de avaliação dos estudantes e da própria disciplina.

O corpo docente foi composto também por uma pedagoga do CETEPE ${ }^{14}$, responsável pelo suporte pedagógico durante toda a disciplina em 1999.

Para acompanhar e cooperar com a implementação e evolução da nova estrutura, um estudante de pós-graduação (autor deste trabalho) esteve presente em 1999, 2000 e 2001 na elaboração dos módulos, no processo de avaliação e nas aulas teóricas e práticas.

\subsubsection{Planejamento e entrega da instrução}

Cada módulo foi projetado em conjunto com um professor, definindo-se tópicos, conceitos, figuras, filmes, exemplos, exercícios práticos e cuidados com o vocabulário a serem utilizados.

\footnotetext{
${ }^{13}$ Os seis docentes foram escolhidos aleatoriamente, considerando-se apenas a especialidade de cada um dentro da engenharia elétrica. Outros professores poderiam ser escolhidos desde que com a especialidade pertinente a cada módulo.

${ }^{14}$ CETEPE - Centro de Tecnologia Educacional para Engenharia da EESC.
} 
Todos os módulos foram elaborados na forma de "slides", utilizando-se recursos de animação e som, incluindo também (exceto no módulo de introdução) uma ferramenta computacional a ser apresentada aos estudantes. Depois de elaborado, cada módulo foi apresentado ao corpo docente para análise e possíveis ajustes. Uma análise durante sua aplicação em aula também foi efetuada, verificando-se alguns cuidados a serem considerados para o próximo módulo, como por exemplo, o uso às vezes despercebido de termos técnicos por parte do professor, sem a devida explicação do mesmo aos estudantes. A análise durante a aplicação de cada módulo só foi possível devido ao acompanhamento do estudante de pósgraduação como ouvinte e assistente do professor. A Figura 5.2, a seguir, apresenta a seqüência de elaboração e correção utilizada para cada módulo.

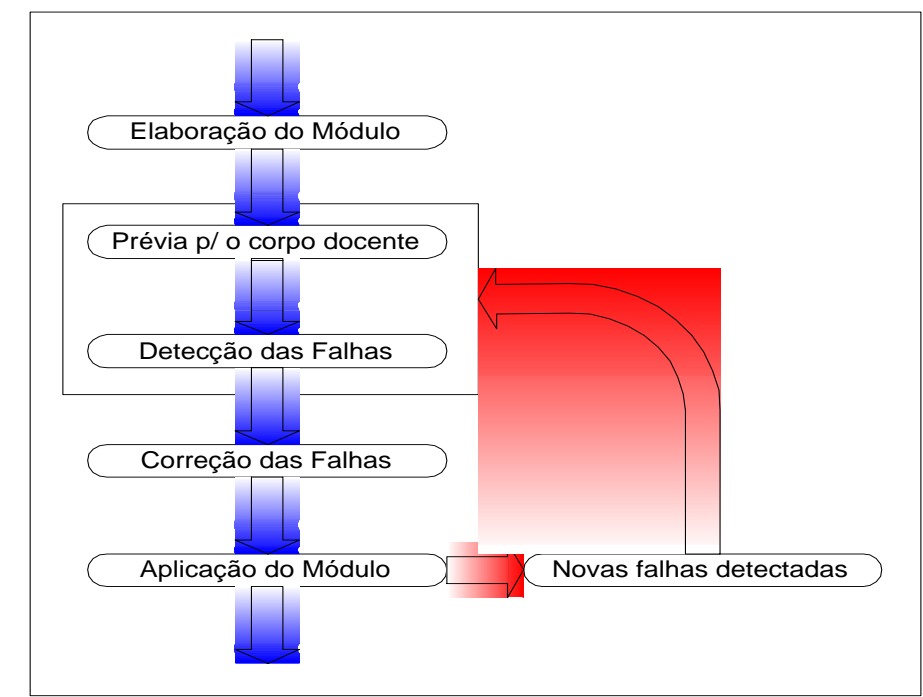

FIGURA 5.2 - SEQÜÊNCIA DE ELABORAÇÃO E CORREÇÃO DE CADA MÓDULO

Para iniciar a integração entre o departamento e os calouros, todas as aulas teóricas foram ministradas no anfiteatro do próprio departamento, ilustrado pela Figura 5.3 a seguir. As aulas práticas foram ministradas no laboratório de microcomputadores também do próprio departamento. 


\subsubsection{Avaliação}

A nova estrutura da SEL-300 foi avaliada com a participação dos corpos docente e discente. O corpo docente avaliou a participação dos calouros (perguntas,

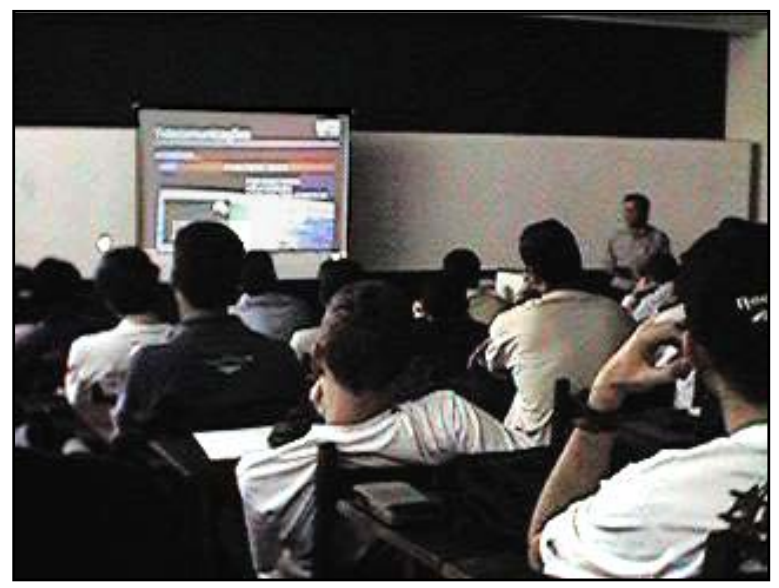

freqüências, comportamento ${ }^{15}$ ) durante toda a disciplina e os relatórios elaborados quanto à qualidade e o conteúdo referente a cada módulo. O corpo discente avaliou a disciplina por meio de um questionário analisando pontos como concepção, corpo docente, conteúdo, material utilizado, nível dos exercícios, rotatividade dos professores, sugestões e críticas. Este questionário, elaborado pelo corpo docente, continha questões de respostas direcionadas a conceitos pontuados de 1 à 5 (péssimo, insatisfatório, regular, bom e ótimo por exemplo) e questões com respostas por escrito para o calouro opinar livremente. Este questionário não pediu identificação do estudante (nome ou número de matrícula), pois poderia deixa-lo constrangido, influenciando as suas respostas.

\footnotetext{
${ }^{15}$ Comportamento externo observado por meio de gestos, atitudes, interesse ou apreço pelo assunto.
} 


\subsubsection{Buscando a qualidade total}

A definição de um objetivo a ser alcançado com a nova estrutura em 1999 e a melhoria contínua a cada módulo e a cada período durante 2000 e 2001 para alcançar este objetivo caracterizam a busca da qualidade total na disciplina SEL-300. 


\section{Capítulo VI}

\section{Os módulos}

\subsection{Módulo I - Introdução}

O primeiro módulo, chamado Módulo I - Introdução, foi elaborado na seqüência de tópicos indicada na Figura 6.1.1, a seguir. Este módulo começa com a apresentação da $S E L-300$, descrevendo aos calouros os objetivos, o corpo docente e a importância da disciplina que estão iniciando.

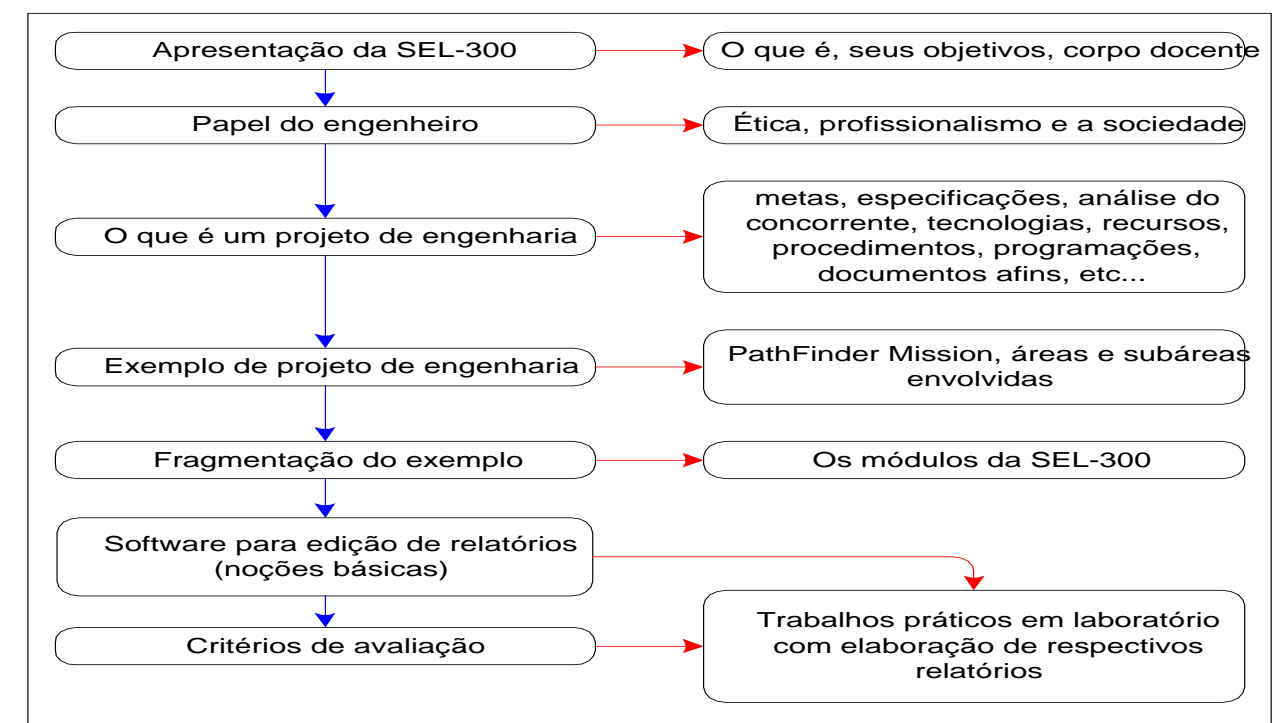

FIGURA 6.1.1 - SEQUÊNCIA DO CONTEÚDO DO MÓDULO I

O estudante passa a ser tratado como um futuro profissional, e para isso o papel do engenheiro, sua ética, seu profissionalismo e seu envolvimento na sociedade são abordados e cobrados a partir deste módulo. 
A noção de projeto de engenharia é apresentada aos calouros, abordando-se detalhes importantes como metas, especificações, análise do concorrente, tecnologias envolvidas, recursos e o relacionamento com outras áreas e subáreas.

Para exemplificar um grande projeto de engenharia, a Pathfinder Mission da NASA é apresentada aos estudantes por meio de um curto vídeo de animação gráfica com aproximadamente um minuto e meio de duração. Este vídeo ilustra a trajetória do robô Rover desde a saída do foguete na base da NASA até a sua chegada ao planeta Marte. Em seguida são destacados os nomes de cada módulo presentes na SEL-300. Alguns quadros deste vídeo estão numerados na Figura 6.1.2.

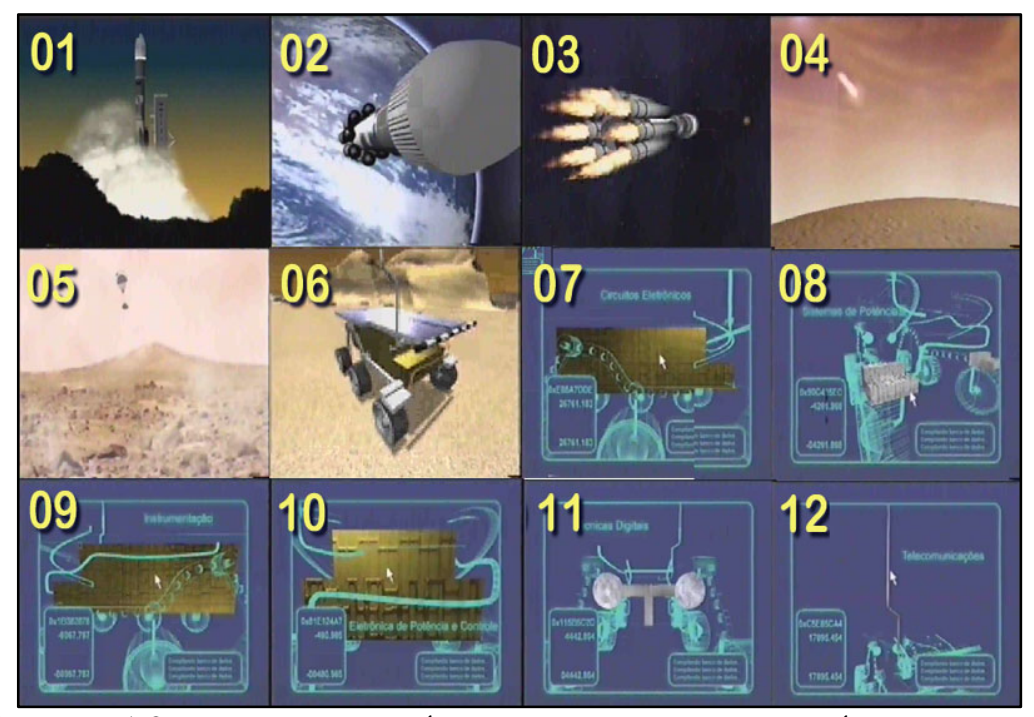

FIGURA 6.1.2-QUADROS EXTRAÍDOS SEQUENCIALMENTE DO VÍDEO DO ROVER

A partir do vídeo do Rover, são apresentados aos calouros os demais módulos da SEL-300, informando sem aprofundamento seus conteúdos, professores responsáveis e ferramentas computacionais afins.

Para encerrar, os critérios de avaliação e um formato padrão de relatório são apresentados, informando que ao final de cada módulo e a partir do segundo, um grupo de até quatro estudantes deverá elaborar um relatório referente ao conteúdo teórico e às práticas em laboratório. O relatório deverá estar digitado no software de 
edição de texto Microsoft ${ }^{\circledR}$ Word $^{16}$ (ver Figura 6.1.3) disponibilizado em microcomputadores do departamento ou da escola.

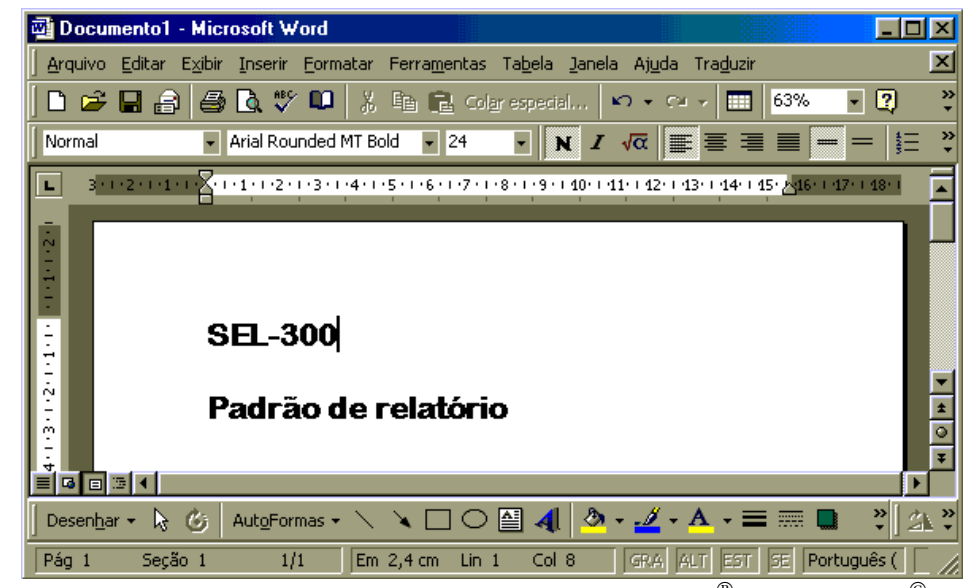

FIGURA 6.1.3 - TELA PRINCIPAL DO MICROSOFT ${ }^{\circledR}$ WORD $2000^{\complement}$

\subsection{Módulo II - Circuitos eletrônicos}

O segundo módulo, chamado Módulo II - Circuitos eletrônicos, foi elaborado na seqüência de tópicos indicada na Figura 6.2.1, a seguir. Este módulo começa com a apresentação geral do seu conteúdo teórico e prático.

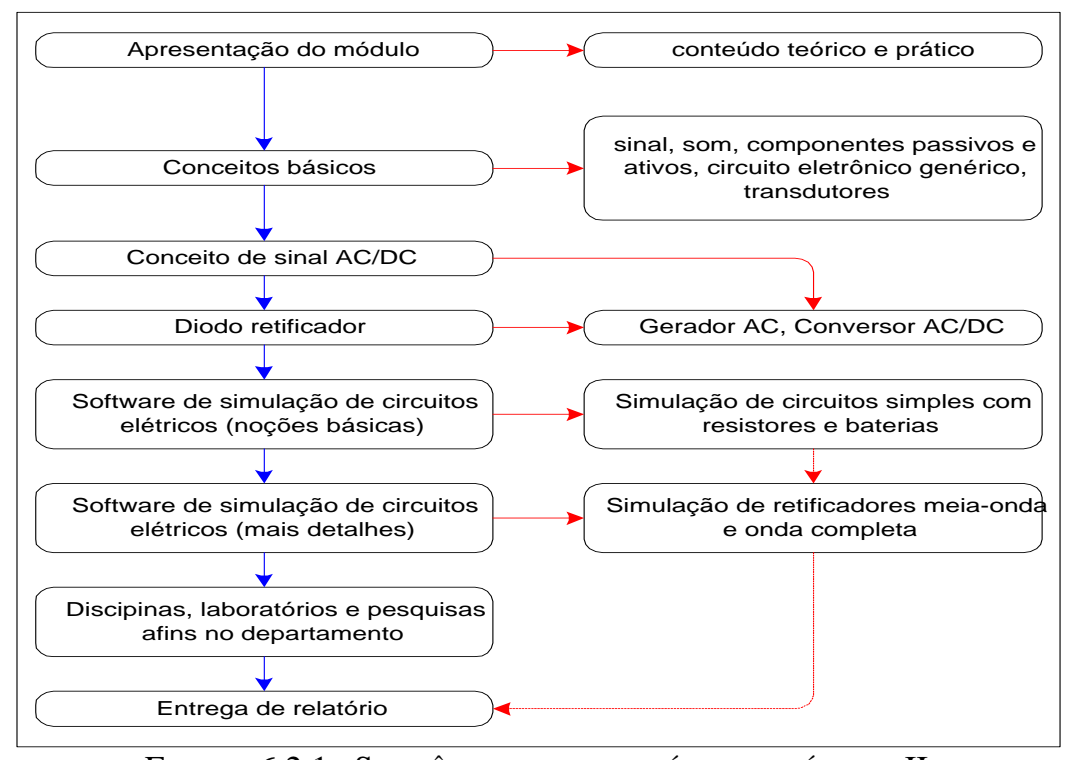

FIGURA 6.2.1 - SEQUÊNCIA DO CONTEÚDO DO MÓDULO II

${ }^{16}$ Microsoft $^{\circledR}$ Word 2000 - Copyright ${ }^{\odot}$ 1983-2000 Microsoft Corporation - Software de editoração eletrônica da Microsoft Corporation. Maiores informações no endereço http://www.microsoft.com. 
Os conceitos de sinal, som, componentes passivos (resistores, capacitores e indutores), componentes ativos (diodos, transistores, triacs, etc), partes importantes de um circuito eletrônico genérico (alimentação, entrada, saída, controle, ver Figura 6.2.2) e transdutores. Comparações com o cotidiano do estudante são feitas, como o aparelho de som que é um circuito eletrônico com alimentação, entrada, saída e controle.

Os conceitos de sinal AC e sinal DC constante e não constante são explicados por meio de gráficos com as formas de ondas senoidal, triangular e retangular. Após definição destes sinais, o componente ativo diodo é comparado a uma chave (ver Figura 6.2.2) quanto ao seu comportamento, que "fecha" (conduz) quando em polarização direta e “abre” (não conduz) quando em polarização reversa.
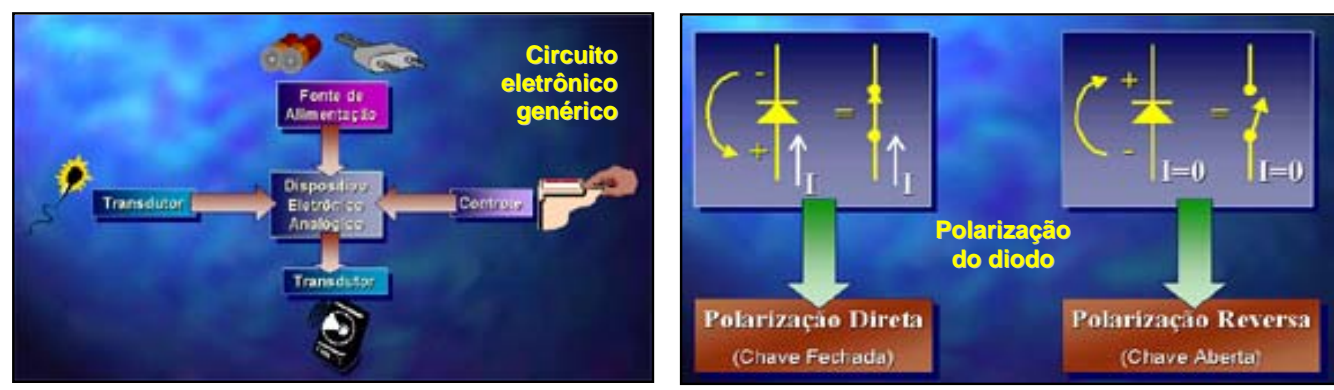

FIGURA 6.2.2 - ILUSTRAÇÕES APRESENTADAS AOS CALOUROS POR MEIO DE “SLIDES” ANIMADOS

O próximo conceito é o gerador de sinal AC composto por um ímã e uma bobina de fio enrolado, que ao girar dentro do campo magnético deste ímã, irá produzir uma tensão alternada (ver Figura 6.2.3) em seus terminais. Passando este sinal AC pelo diodo, o mesmo será transformado em DC, exemplificando assim um conversor AC/DC básico.

Por meio de um ou mais diodos associados adequadamente ao gerador de sinal AC, são apresentados aos calouros os retificadores de meia-onda e onda completa. A função do capacitor como filtro para a eliminação de ripple (ver Figura 6.2.3) é comparada a um balde quanto ao seu comportamento, que “enche” (carrega) 
com a subida da onda retificada e "esvazia” (descarrega) com a descida da onda retificada.
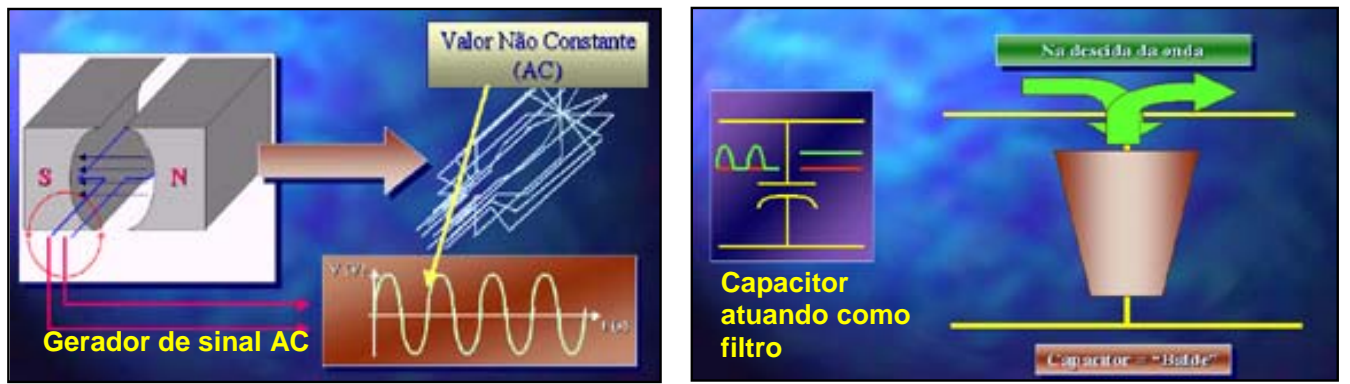

FIGURA 6.2.3 - ILUSTRAÇÕES APRESENTADAS AOS CALOUROS POR MEIO DE “SLIDES” ANIMADOS

Para demonstrar cada conceito mencionado, o software de simulação de circuitos elétricos Eletronic WorkBench ${ }^{17}$ (ver Figura 6.2.4) é apresentado aos calouros, que podem manipula-lo simulando inicialmente simples circuitos com resistores e baterias e posteriormente circuitos básicos de retificadores de meia-onda e onda completa.

O relatório obrigatório ao final deste módulo deverá abordar conceitos e exercícios de simulação com os respectivos resultados. Pesquisas poderão ser feitas na Internet ou nas bibliotecas dentro da escola para a elaboração do relatório.

O segundo módulo é encerrado com informações sobre disciplinas, laboratórios e pesquisas afins.

${ }^{17}$ Electronics WorkBench 5.0c - Copyright ${ }^{\circledR}$ 1989, 1992-1996 Interactive Image Technologies Ltd. Software para simulação de circuitos elétricos e eletrônicos. Maiores informações no endereço www.intusoft.com. 


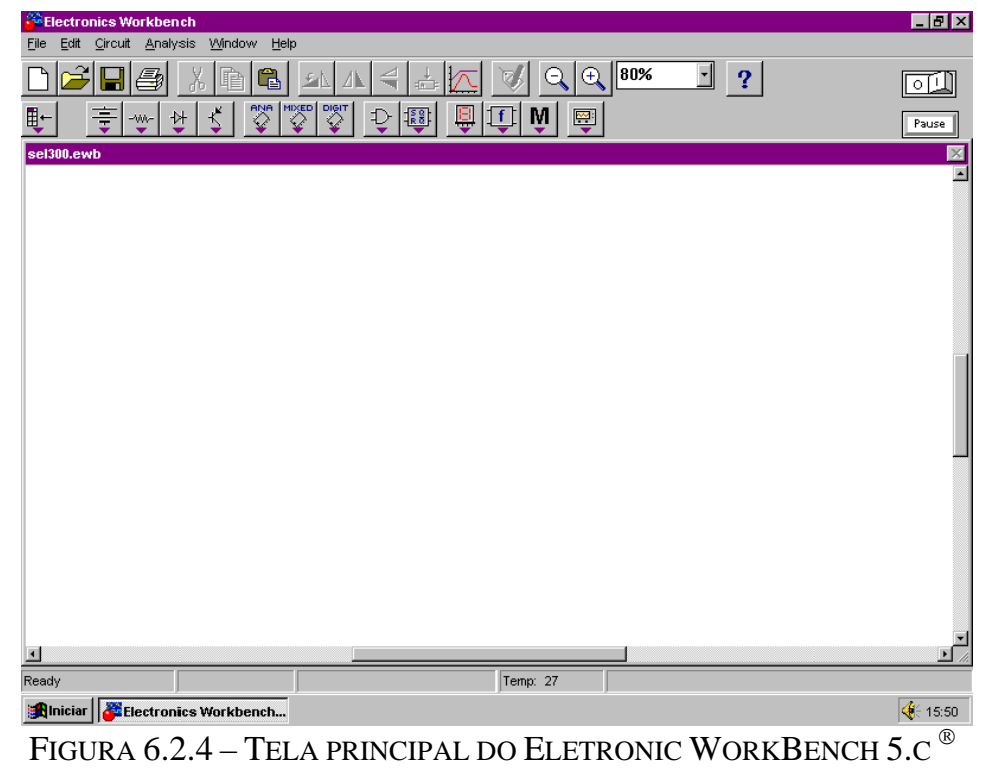

\subsection{Módulo III - Instrumentação e Medidas}

O terceiro módulo, chamado Módulo III - Instrumentação e Medidas, foi elaborado na seqüência de tópicos indicada na Figura 6.3.1, a seguir. Este módulo começa com a apresentação geral do seu conteúdo teórico e prático.

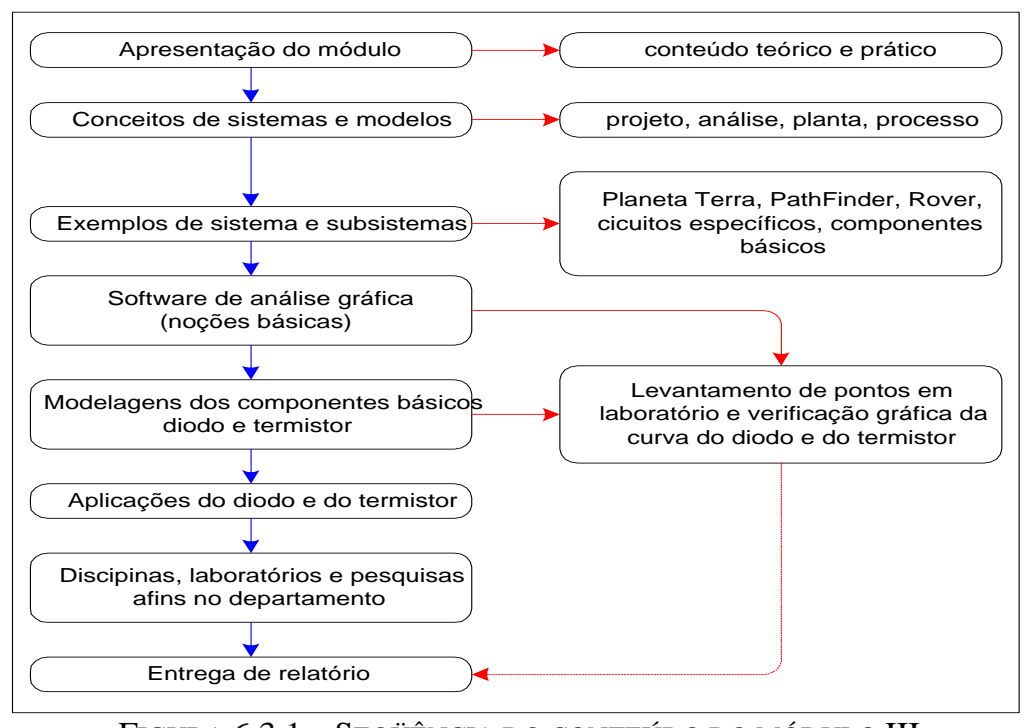

FIGURA 6.3.1 - SEQÜÊNCIA DO CONTEÚDO DO MÓDULO III

Os conceitos de sistemas e subsistemas apresentados no primeiro módulo são relembrados e associados aos conceitos de modelos, projeto, análise, planta e processo (ver Figura 6.3.2). Por meio da fragmentação, de um grande projeto chega- 
se aos componentes básicos, que também são pequenos sistemas e possuem seus modelos.
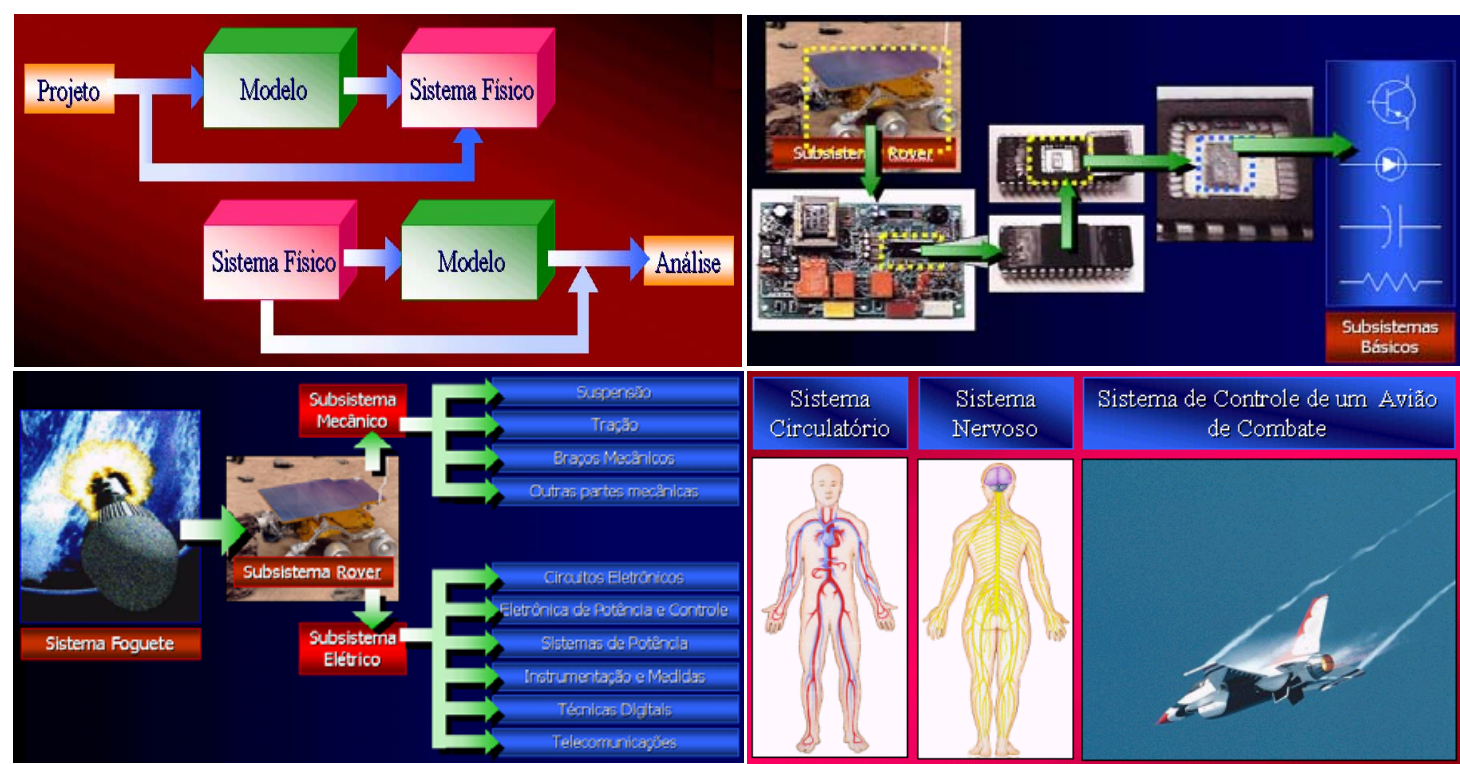

FIGURA 6.3.2 - ILUSTRAÇÕES APRESENTADAS AOS CALOUROS POR MEIO DE “SLIDES” ANIMADOS

Dentre vários componentes o diodo é abordado novamente, porém quanto a sua modelagem, por meio de medida de tensão e corrente sobre um modelo genérico obtendo-se a curva $I_{D} \times V_{D}$ (ver Figura 6.3.3). São explicadas as diferenças entre comportamento ideal e real do diodo. Além do diodo também é feita a modelagem de um termistor obtendo-se a curva $R_{R} \times T_{R}$.
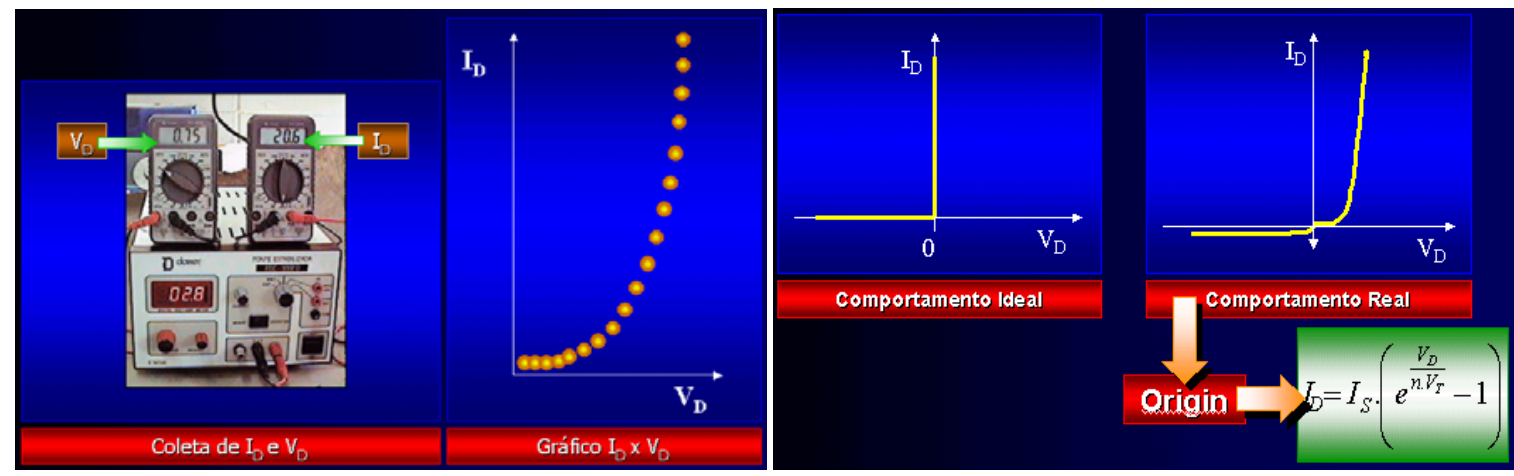

FIGURA 6.3.3 - ILUSTRAÇÕES APRESENTADAS AOS CALOUROS POR MEIO DE “SLIDES”ANIMADOS 
O software de análise gráfica Microcal Origin $^{18}$ (ver Figura 6.3.4) é apresentado aos calouros, que deverão traçar as curvas do diodo e do termistor, verificando os recursos de aproximação de curvas e obtenção das respectivas funções, disponíveis nesta ferramenta.

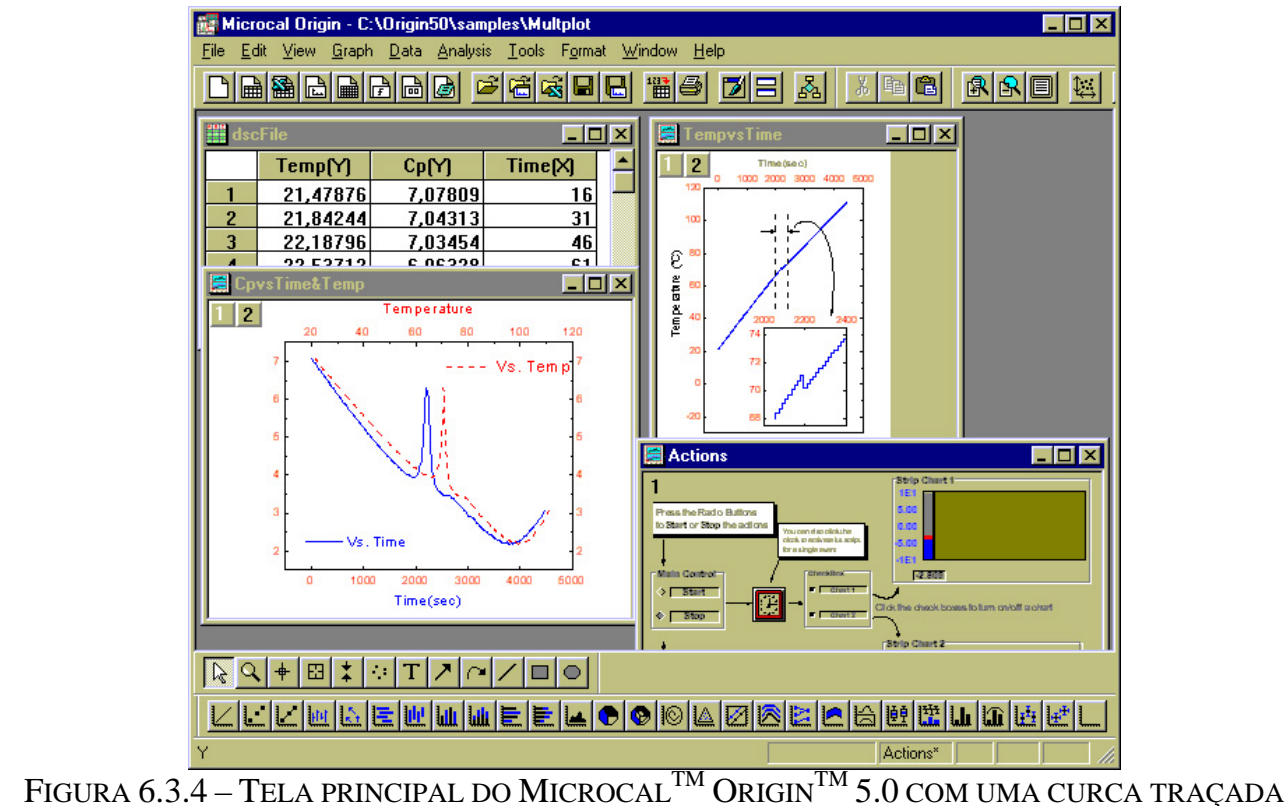

Aplicações do diodo e do termistor são citadas, como leds, retificadores, lasers e sensores individuais ou integrados (ver Figura 6.3.5).
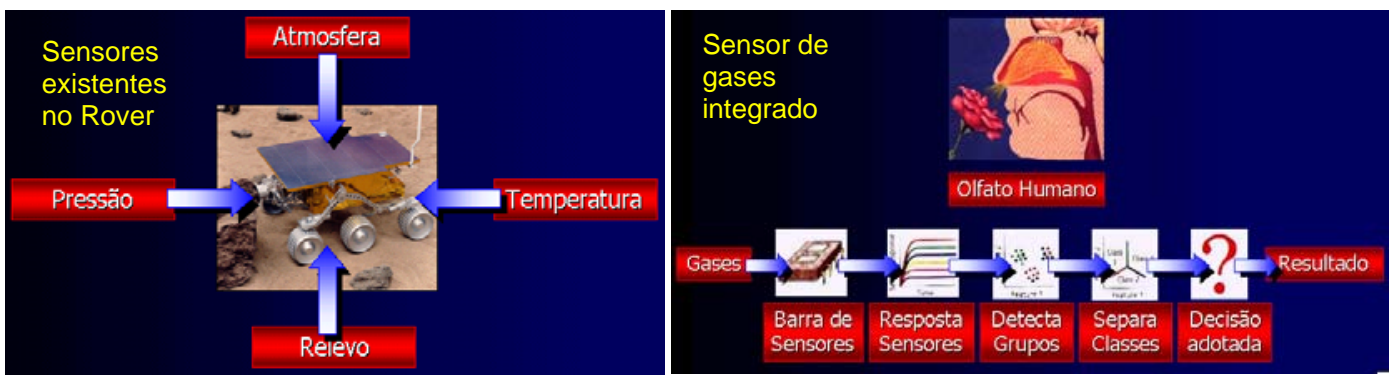

FIGURA 6.3.5 - ILUSTRAÇÕES APRESENTADAS AOS CALOUROS POR MEIO DE “SLIDES”ANIMADOS

O relatório obrigatório ao final deste módulo deverá abordar conceitos e exercícios das curvas traçadas. Pesquisas poderão ser feitas na Internet ou nas bibliotecas disponíveis dentro da escola para a elaboração do relatório.

\footnotetext{
${ }^{18}$ Microcal $^{T M}$ Origin $^{T M} 5.0$ - Copyright C 1991-1997 Microcal Software Inc. - Software para traçar curvas e superfícies com vários recursos gráficos e de análise matemática.
} 
O terceiro módulo é encerrado com informações sobre disciplinas, laboratórios e pesquisas afins.

\subsection{Módulo IV - Controle e Eletrônica de Potência}

O quarto módulo, chamado Módulo IV - Controle e Eletrônica de potência, foi elaborado na seqüência de tópicos indicada na Figura 6.4.1, a seguir. Este módulo começa com a apresentação geral do seu conteúdo teórico e prático.

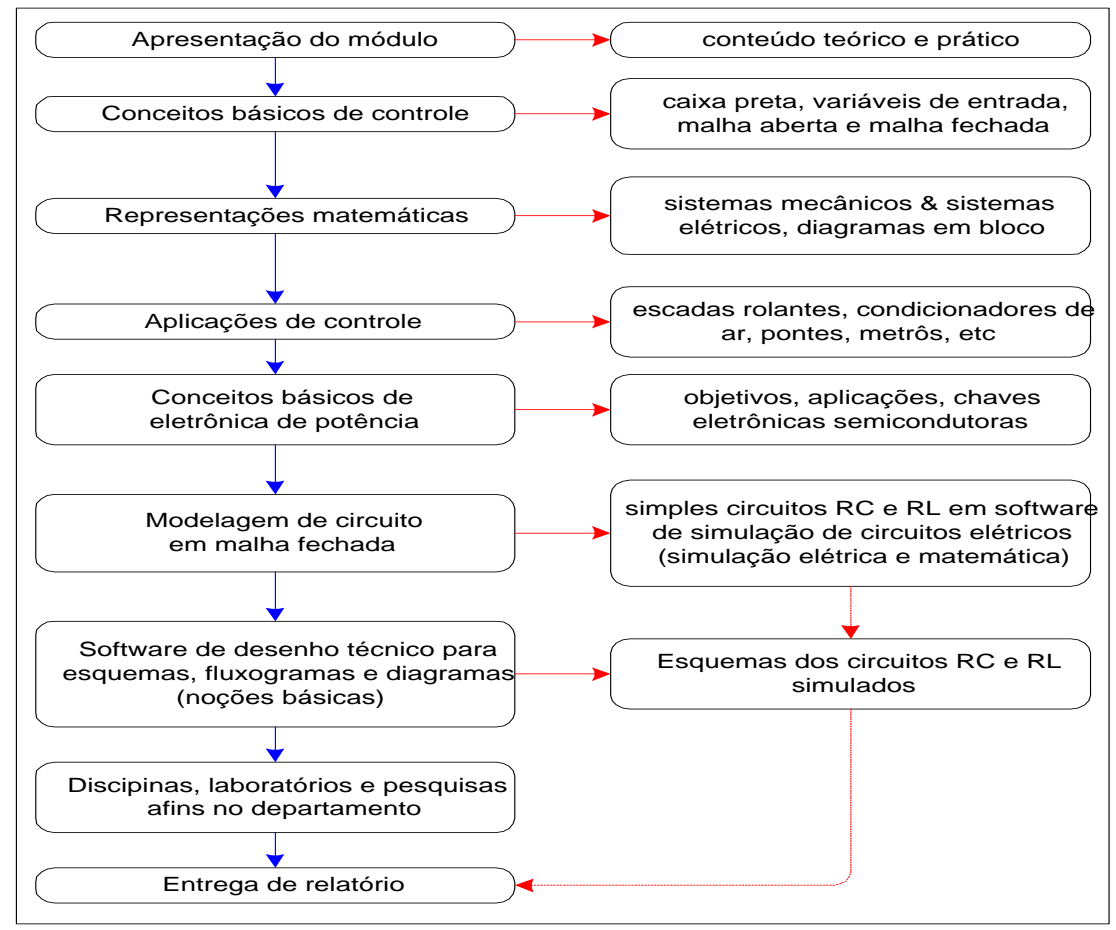

FIGURA 6.4.1 - SEQÜÊNCIA DO CONTEÚDO DO MÓDULO IV

Os conceitos básicos de controle como caixa preta, variáveis de entrada, malha aberta e malha fechada são apresentados aos calouros por meio de exemplos do cotidiano como o controle de um aquecedor elétrico (ver Figura 6.4.2).

Representações matemáticas, modelos, de componentes elétricos básicos são apresentados e comparados a componentes mecânicos básicos, mostrando aos estudantes que alguns problemas mecânicos podem ser resolvidos com as mesmas equações de problemas elétricos (ver Figura 6.4.3). 

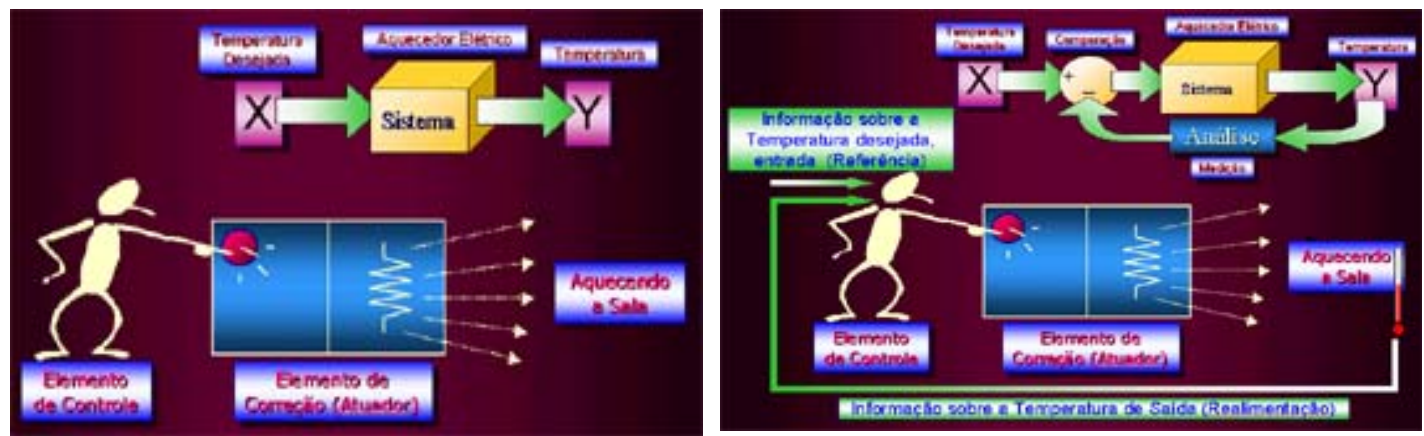

FIGURA 6.4.2 - ILUSTRAÇÕES APRESENTADAS AOS CALOUROS POR MEIO DE “SLIDES”ANIMADOS

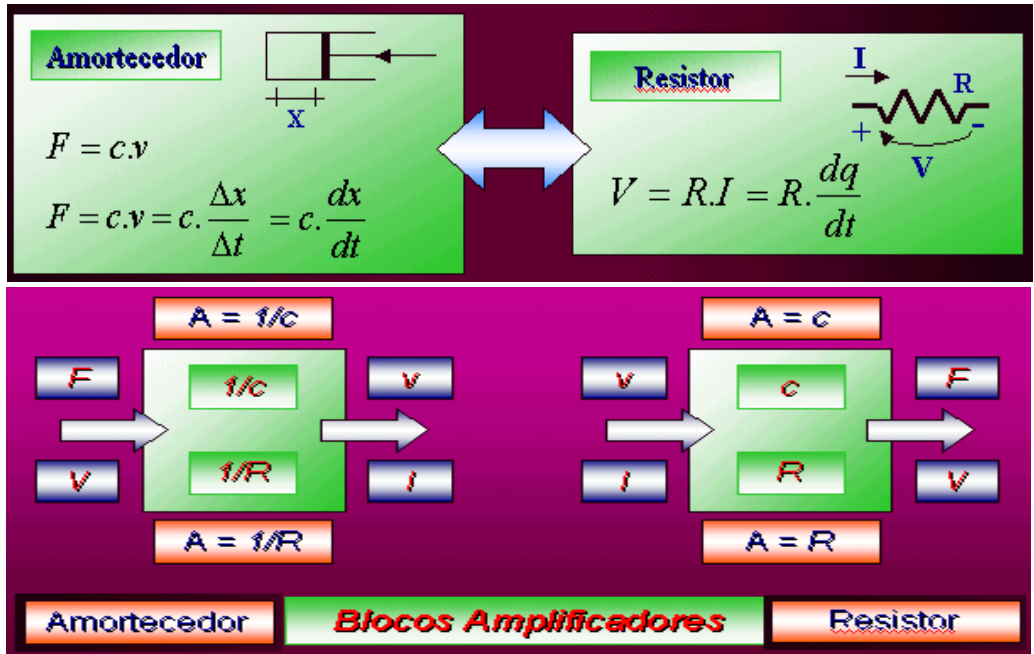

FIGURA 6.4.3 - ILUSTRAÇÕES APRESENTADAS AOS CALOUROS POR MEIO DE “SLIDES”ANIMADOS

A eletrônica de potência é apresentada dando destaque aos seus objetivos e aplicações, que em conjunto com controle, estão presentes freqüentemente em nosso cotidiano, usinas hidrelétricas, fornos, metrôs, pontes, escadas rolantes, etc.

O objetivo de alcançar o melhor rendimento possível (diminuir a perda de energia) é explicado por meio do elemento básico da eletrônica de potência, a chave eletrônica semicondutora, seu comportamento e os vários tipos existentes (ver Figura 6.4.4). 

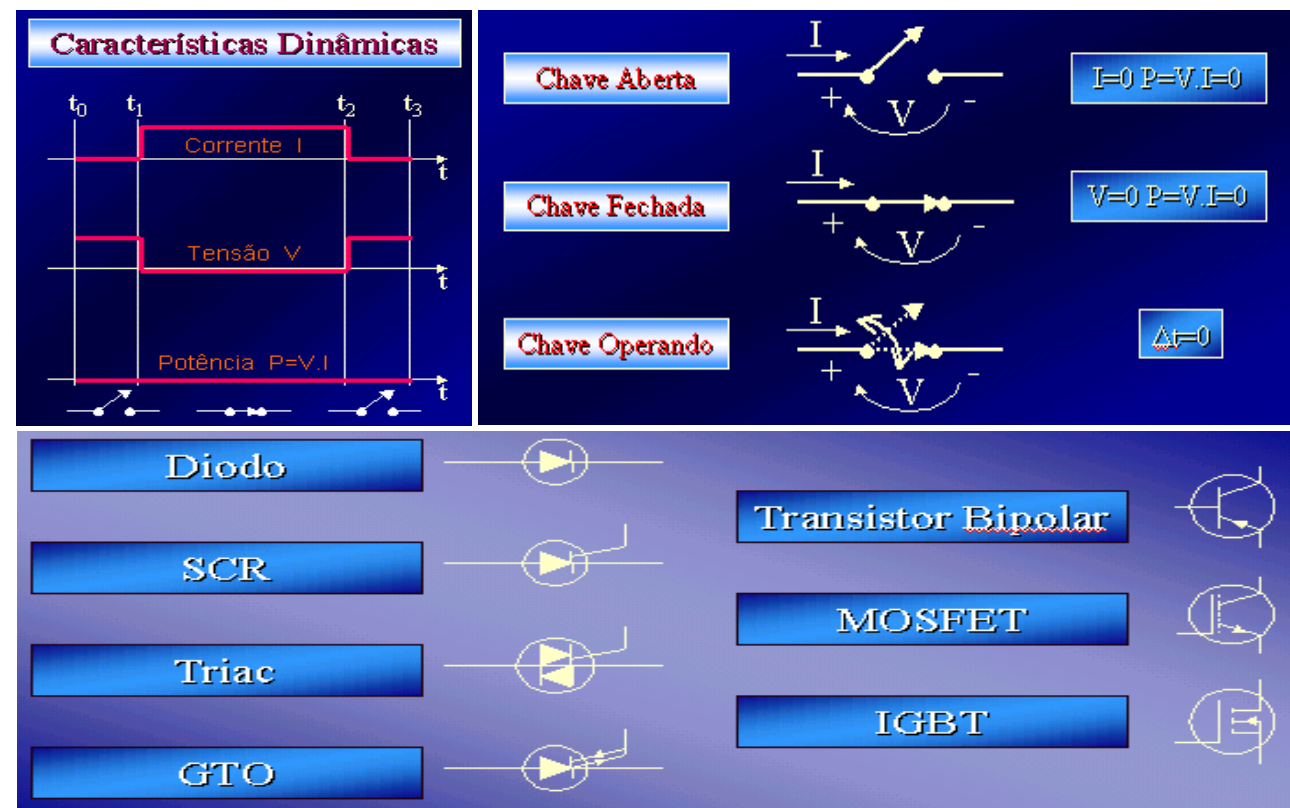

FIGURA 6.4.4 - ILUSTRAÇÕES APRESENTADAS AOS CALOUROS POR MEIO DE “SLIDES”ANIMADOS

Neste módulo, os calouros têm outra oportunidade de utilizarem o Eletronic

WorkBench. Um simples circuito $R L$ é apresentado com seus modelos matemáticos e elétricos pelo professor e por semelhança os estudantes deverão desenvolver os mesmos passos para um circuito $R C$ (ver Figura 6.4.5). Os modelos matemáticos e elétricos são simulados e comparados no Electronic WorkBench.

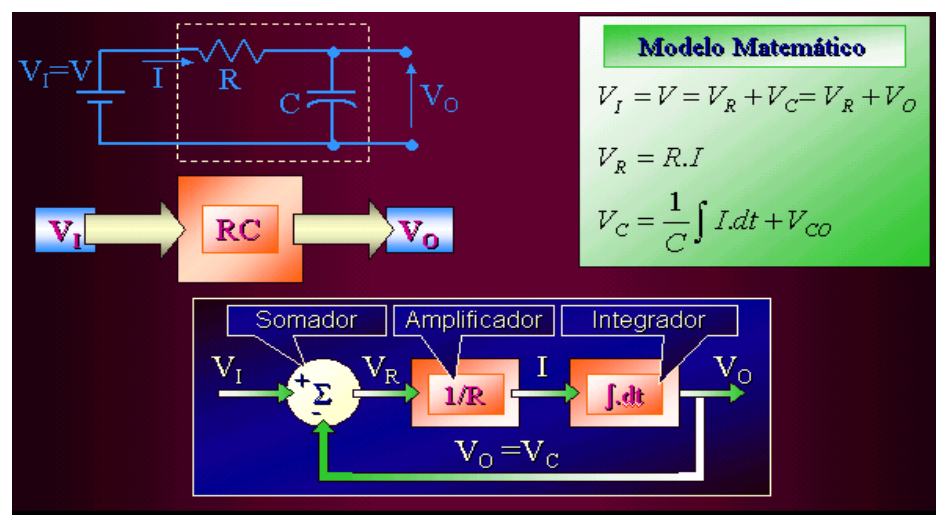

FIGURA 6.4.5 - ILUSTRAÇÕES APRESENTADAS AOS CALOUROS POR MEIO DE “SLIDES”ANIMADOS

Um novo software é apresentado neste módulo, o Visio $^{\circledR}$ Technical $^{19}$ (ver Figura 6.4.6), onde deverão ser desenhados os esquemas dos circuitos $R L$ e $R C$.

\footnotetext{
${ }^{19}$ Visio ${ }^{\circledR}$ Technical 5.0c Plus for Microsoft (International Version) Windows - Copyright (ㄱ 19911998 Visio Corporation ${ }^{19}$ - Software para desenhos de diagramas, esquemas e figuras técnicas em geral.
} 


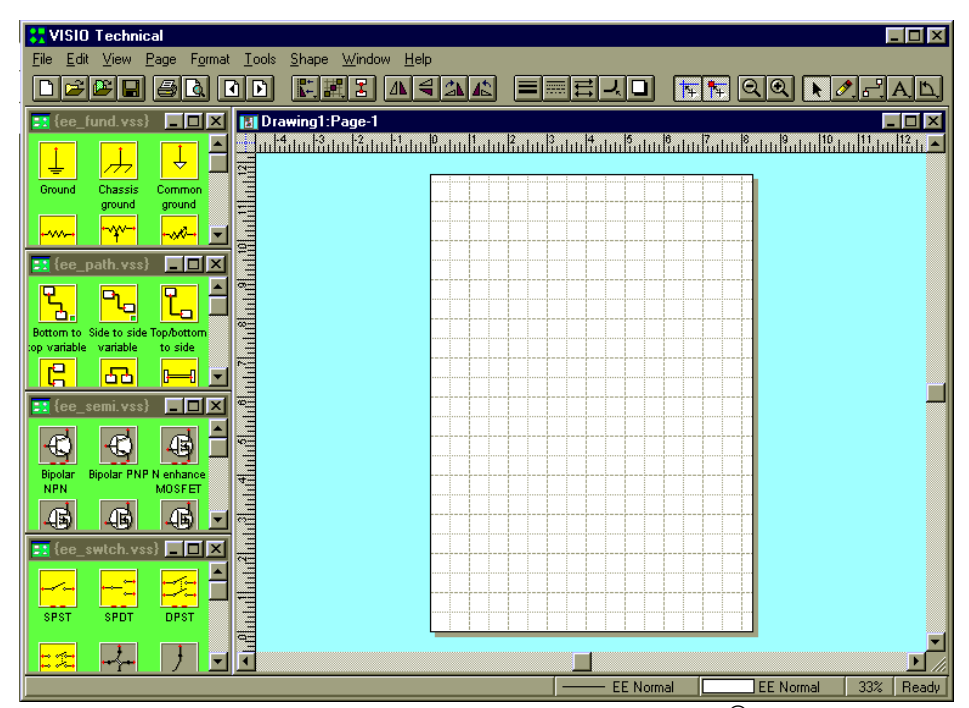

FigURA 6.4.6 - TELA PRINCIPAL DO SOFTWARE VISIO ${ }^{\circledR}$ TECHNICAL 2000

O relatório obrigatório ao final deste módulo deverá abordar conceitos e exercícios de modelagem e desenho técnico. Pesquisas poderão ser feitas na Internet ou nas bibliotecas disponíveis dentro da escola para a elaboração do relatório.

O quarto módulo é encerrado com informações sobre disciplinas, laboratórios e pesquisas afins.

\subsection{Módulo V - Sistemas de Potência}

O quinto módulo, chamado Módulo V-Sistemas de Potência, foi elaborado na seqüência de tópicos indicada na Figura 6.5.1, a seguir. Este módulo começa com a apresentação geral do seu conteúdo teórico e prático.

Os conceitos básicos são apresentados a partir da Lei de Faraday em conjunto com conceitos de eletromagnetismo aprendidos no ensino médio (ver Figura 6.5.2). A partir destes conceitos, a geração de energia é descrita, considerando-se as formas hidráulicas, eólicas e nucleares.

Na seqüência os processos de geração, transmissão e distribuição de energia são expostos utilizando como exemplo o caminho da energia elétrica gerada na usina hidrelétrica de Itaipu até a casa do consumidor final (ver Figura 6.5.2). 


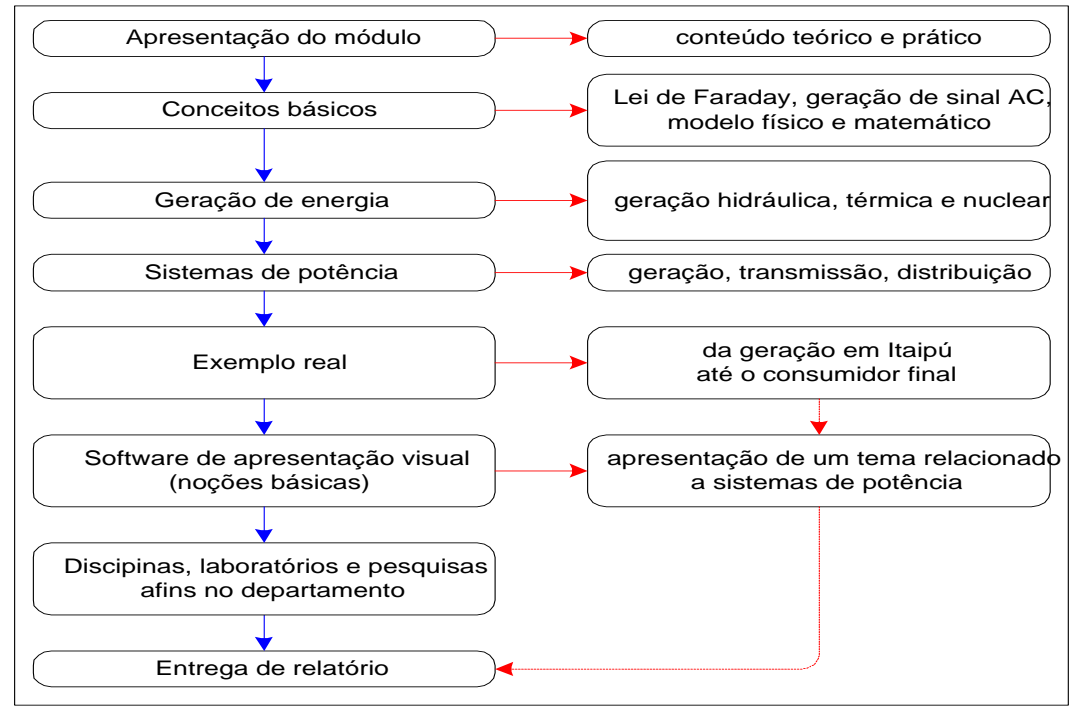

FIGURA 6.5.1 - SEQÜÊNCIA DO CONTEÚDO DO MÓDULO V
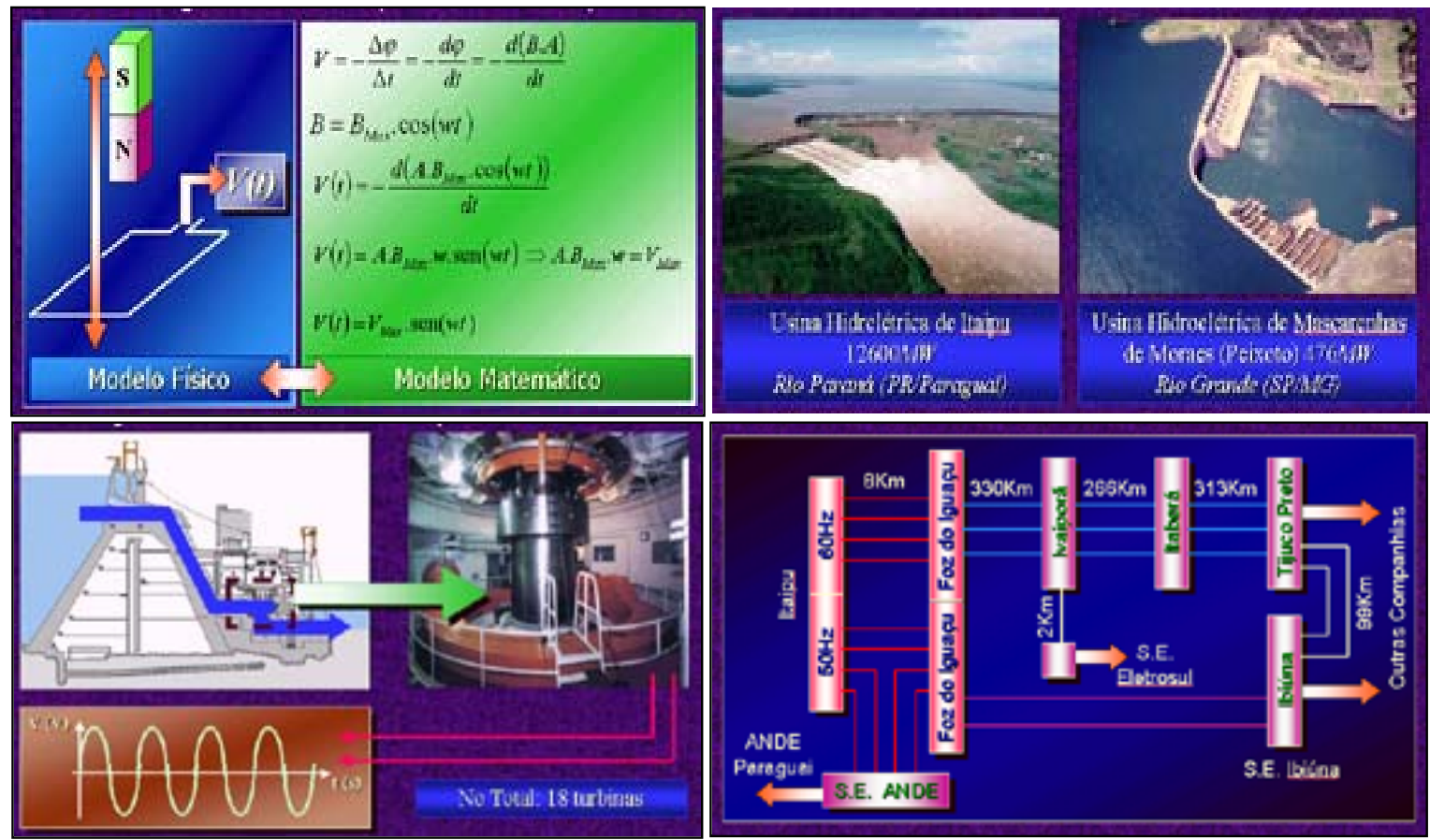

FIGURA 6.5.2 - ILUSTRAÇÕES APRESENTADAS AOS CALOUROS POR MEIO DE “SLIDES”ANIMADOS

Temas atuais como racionamento de energia, apagões e “blackouts” também

são abordados e discutidos. Os temas discutidos devem ser elaborados em forma de “slides” por pequenos grupos de calouros. Para as apresentações cada grupo deverá utilizar o software Microsoft ${ }^{\circledR}$ PowerPoint $^{\mathcal{O}} 2000^{20}$, que também é apresentado neste módulo (ver Figura 6.5.3).

${ }^{20}$ Microsoft $^{\circledR}$ PowerPoint 2000 - Copyright (C 1987-2000 Microsoft Corporation - Software para apresentações de "slides", transparências e “data-shows". 


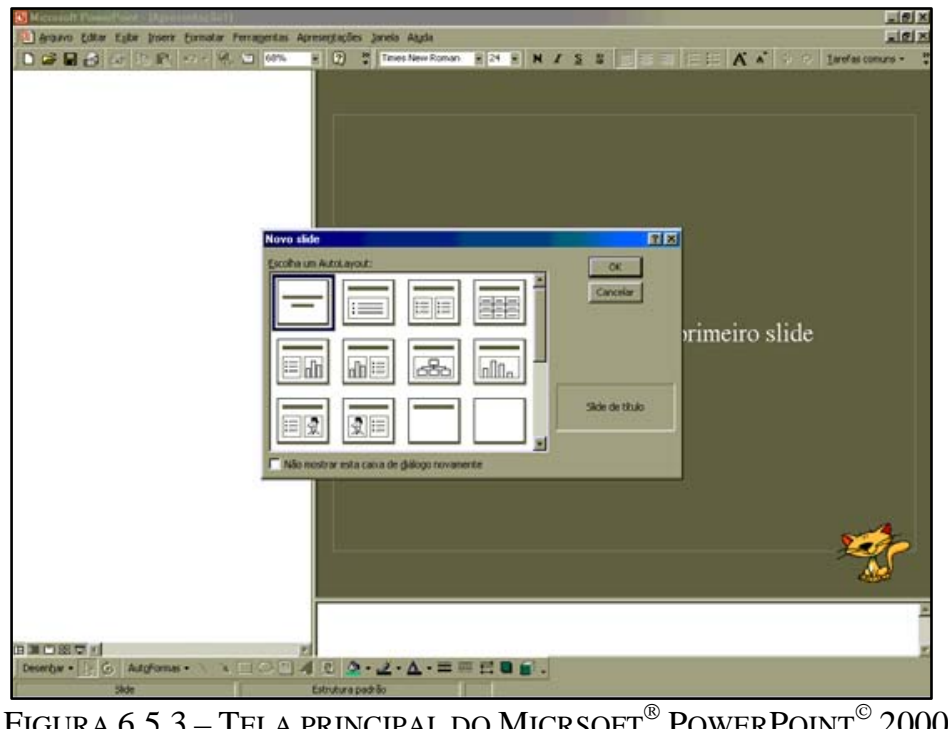

O relatório obrigatório ao final deste módulo deverá abordar conceitos e temas discutidos e apresentados pelos calouros. Pesquisas poderão ser feitas na Internet ou nas bibliotecas disponíveis dentro da escola para a elaboração do relatório.

O quinto módulo é encerrado com informações sobre disciplinas, laboratórios e pesquisas afins.

\subsection{Módulo VI - Sistemas Digitais}

O sexto módulo, chamado Módulo VI - Sistemas Digitais, foi elaborado na seqüência de tópicos indicada na Figura 6.6.1, a seguir. Este módulo começa com a apresentação geral do seu conteúdo teórico e prático. 


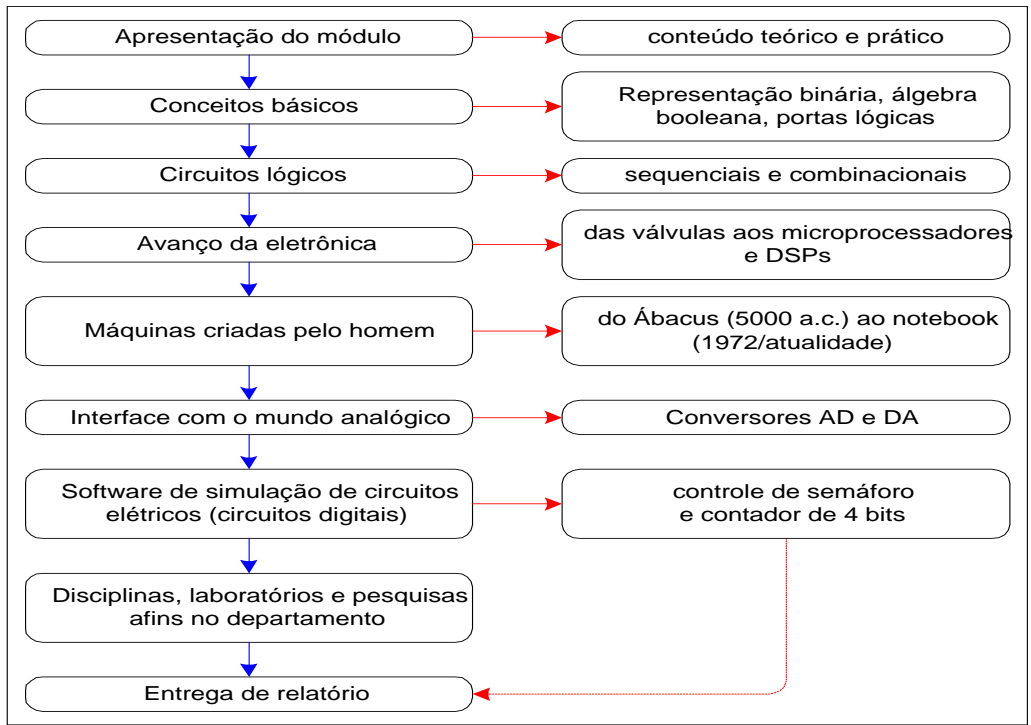

FIGURA 6.6.1 - SEQUÊNCIA DO CONTEÚDO DO MÓDULO VI

Os conceitos de representação binária, álgebra booleana (E, OU e complemento), portas lógicas (AND, OR, NOT, XOR, NAND e NOR) e circuitos lógicas seqüenciais e combinacionais como “flip-flops” e “memória” são apresentados (ver Figura 6.6.2).
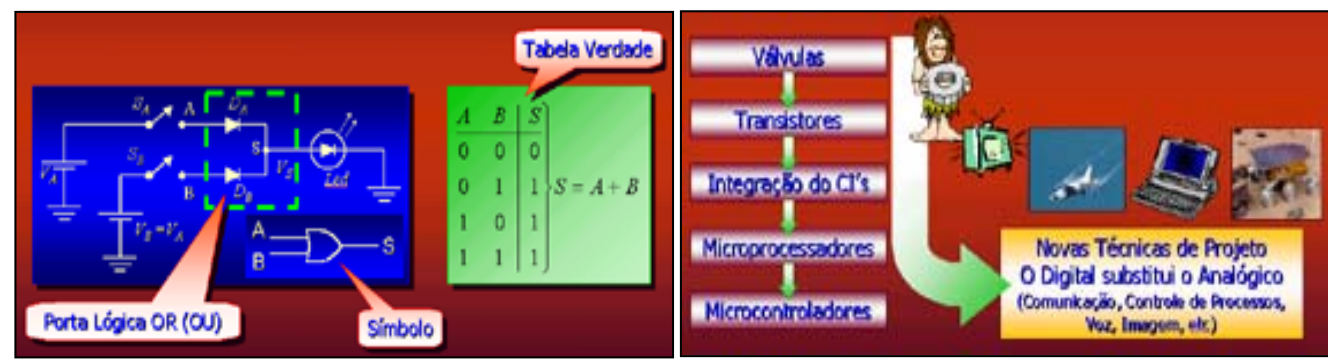

FIGURA 6.6.2 - ILUSTRAÇÕES APRESENTADAS AOS CALOUROS POR MEIO DE “SLIDES”ANIMADOS

As conseqüências do avanço da eletrônica, desde a válvula até os poderosos circuitos integrados com alto grau de integração como DSPs (processadores digitais de sinais) e microcontroladores, as grandes máquinas de calcular criadas pelo homem e a contínua substituição do analógico pelo digital são abordadas neste módulo (ver Figura 6.6.3). 
No tópico das grandes máquinas de calcular é apresentada também a história do microcomputador pessoal, o PC, desde o Altair até os modelos atuais mais avançados, passando pelo surgimento e crescimento da empresa Microsoft.

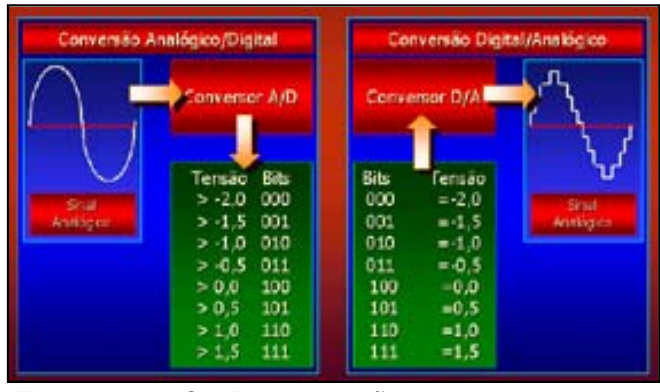

FIGURA 6.6.3 - ILUSTRAÇÕES APRESENTADAS AOS CALOUROS POR MEIO DE “SLIDES”ANIMADOS

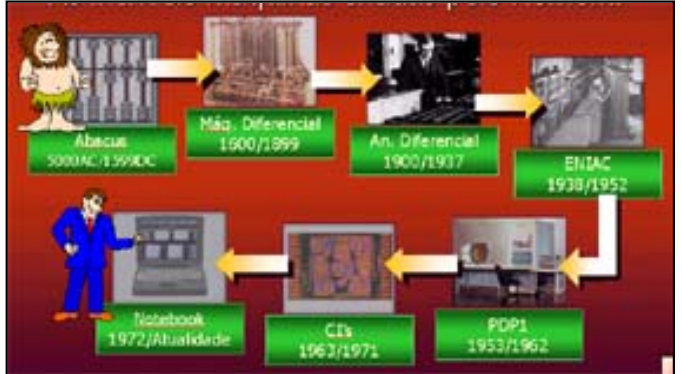

circuitos elétricos Electronic

WordBench é utilizado, porém para circuitos digitais, um controlador de semáforos e um contador de 4 bits.

O relatório obrigatório ao final deste módulo deverá abordar conceitos e circuitos digitais simulados pelos calouros. Pesquisas poderão ser feitas na Internet ou nas bibliotecas disponíveis dentro da escola para a elaboração do relatório.

O sexto módulo é encerrado com informações sobre disciplinas, laboratórios e pesquisas afins.

\subsection{Módulo VII - Telecomunicações}

O sétimo e último módulo, chamado Módulo VII - Telecomunicações, foi elaborado na seqüência de tópicos indicada na Figura 6.7.1, a seguir. Este módulo começa com a apresentação geral do seu conteúdo teórico e prático.

A evolução das telecomunicações é contada da pré-história à atualidade, iniciando com a comunicação por gestos e sons do homem das cavernas, passando pelo surgimento da escrita através dos continentes, a invenção do telégrafo, a transmissão de informação por ondas de rádio e microondas, fibra-optica e chegando 
às últimas tecnologias como GPS, WWL e consórcios de satélite dentre outras (ver Figura 6.7.2).

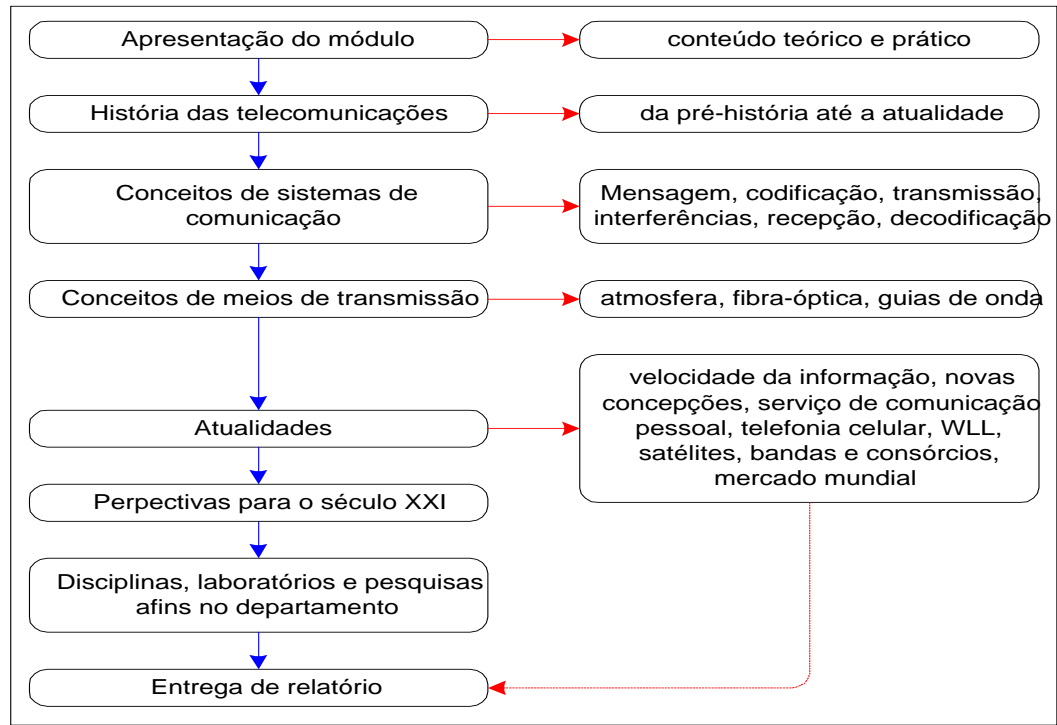

FIGURA 6.7.1 - SEQUÊNCIA DO CONTEÚDO DO MÓDULO VII
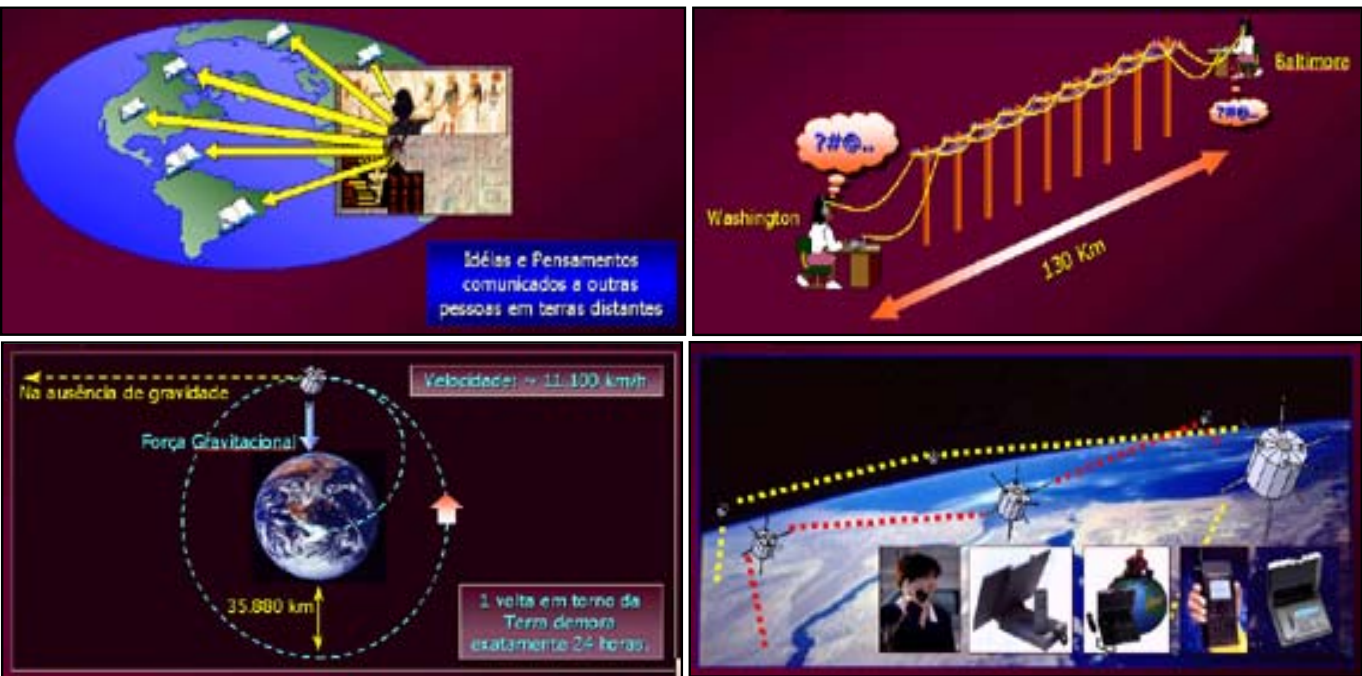

FIGURA 6.7.2 - ILUSTRAÇÕES APRESENTADAS AOS CALOUROS POR MEIO DE “SLIDES”ANIMADOS

Conceitos básicos de sistema de comunicação como, informação, codificação, transmissão em diversos meios, interferências, recepção e decodificação (ver Figura 6.7.3) são apresentados e identificados em vários exemplos, a troca de informação dos índios por meio da fumaça e a transmissão via ondas de rádio. 


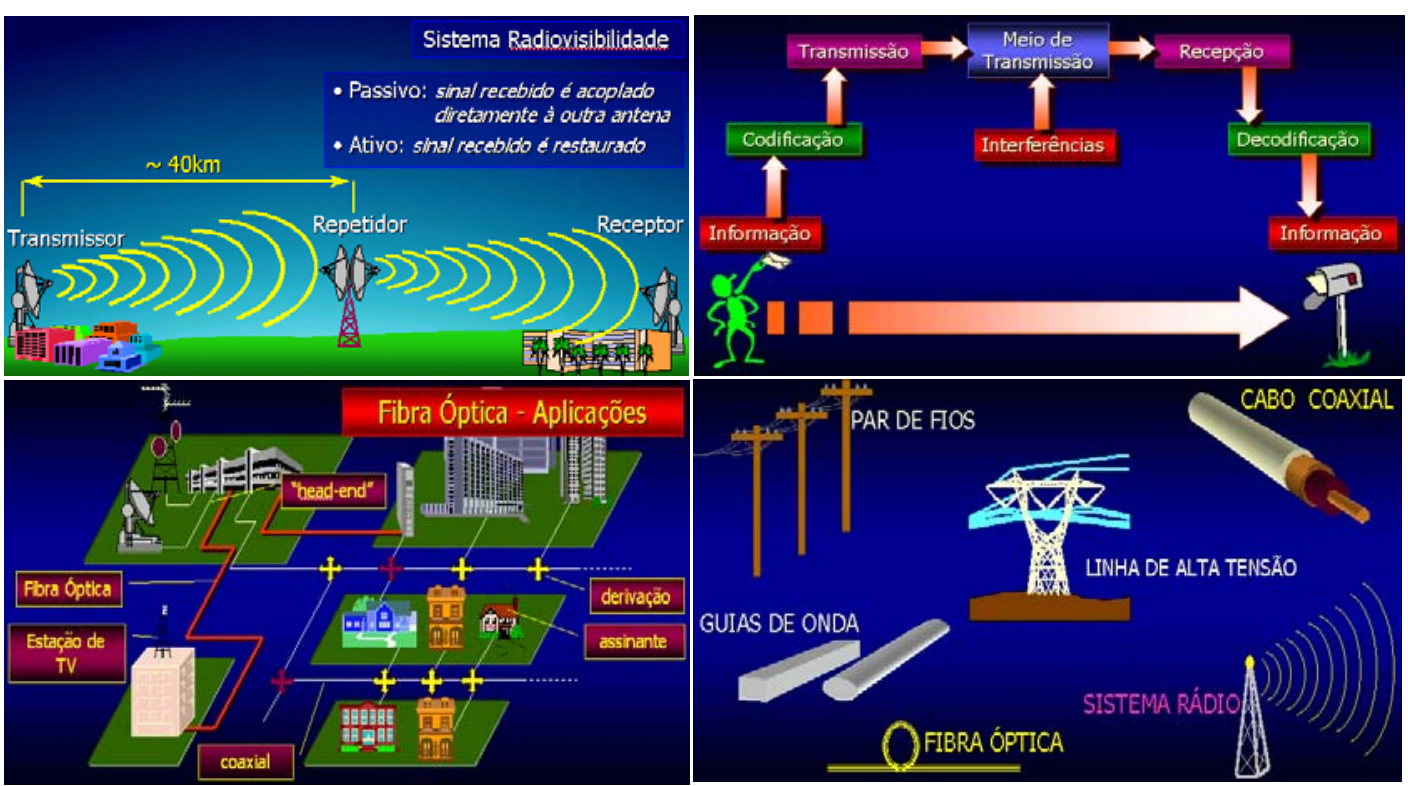

FIGURA 6.7.3 - ILUSTRAÇÕES APRESENTADAS AOS CALOUROS POR MEIO DE “SLIDES”ANIMADOS

O relatório obrigatório ao final deste módulo deverá abordar conceitos e atualidades das telecomunicações. Pesquisas poderão ser feitas na Internet ou nas bibliotecas disponíveis dentro da escola para a elaboração do relatório.

O sétimo módulo é encerrado com informações sobre disciplinas, laboratórios e pesquisas afins. 


\section{Capítulo VII}

\section{Avaliação da nova SEL-300}

\subsection{Avaliação pelo corpo docente}

\subsubsection{Participação dos calouros}

A avaliação da participação foi realizada por meio de observação do comportamento dos estudantes, que evidenciasse interesse e atenção ao conteúdo teórico e prático da disciplina. Esta observação foi efetuada (por observadores externos) pelo professor responsável de cada módulo em conjunto com o estudante de pós-graduação (autor deste trabalho), lembrando-se que às vezes nem todo o comportamento externo do educando representa de forma confiável o que ocorre internamente (na mente) no mesmo.

Por meio de reuniões periódicas, cada professor expôs a sua análise quanto à participação dos calouros dentro de seu módulo e a classificou dentro de uma escala de 0 (péssima, sem participação) a 10 (excelente, participação total). Para esta análise, o professor deveria considerar o comportamento externo dos calouros como atitudes, perguntas, conversas paralelas, freqüência ${ }^{21}$, interesse ou apreço pelo conteúdo teórico e prático do módulo.

\footnotetext{
${ }^{21}$ Em todas as aulas da SEL-300 de 1999, 2000 e 2001, o índice de presença dos estudantes foi igual ou superior a $75 \%$. Assim o comportamento observado pôde se considerado como o comportamento de todos os estudantes.
} 
Mesmo com reuniões periódicas e diretrizes de análise pré-determinadas, cada professor teve como referência apenas a participação dentro de seu módulo, assim para tentar compensar uma possível variação desta análise, o estudante de pósgraduação pertencente ao corpo docente analisou a participação dos calouros em todos os módulos, pois sempre esteve presente como ouvinte ou assessor do professor. Esta análise obedeceu às mesmas escala e diretrizes seguidas pelos professores.

Os resultados das análises de 1999 a 2001 estão na tabela Figura 7.1.1. Para cada ano existe uma média entre a pontuação do professor e a do estudante de pósgraduação. Esta média está ilustrada no gráfico da Figura 7.1.2.

\begin{tabular}{|c|c|c|c|c|c|c|c|c|c|}
\hline \multirow{2}{*}{ Módulo } & \multicolumn{3}{|c|}{1999} & \multicolumn{3}{|c|}{2000} & \multicolumn{3}{|c|}{2001} \\
\hline & Prof. & Pós-Grad. & Média & Prof. & Pós-Grad. & Média & Prof. & Pós-Grad. & Média \\
\hline$I$ & 9 & 9 & 9,0 & 9 & 9 & 9,0 & 8 & 8 & 8,0 \\
\hline II & 8 & 9 & 8,5 & 8 & 9 & 8,5 & 8 & 8 & 8,0 \\
\hline III & 8 & 8 & 8,0 & 8 & 7 & 7,5 & 7 & 7 & 7,0 \\
\hline IV & 9 & 9 & 9,0 & 9 & 8 & 8,5 & 8 & 8 & 8,0 \\
\hline$v$ & 9 & 9 & 9,0 & 9 & 9 & 9,0 & 8 & 8 & 8,0 \\
\hline VI & 9 & 9 & 9,0 & 9 & 9 & 9,0 & 8 & 8 & 8,0 \\
\hline VII & 9 & 9 & 9,0 & 8 & 8 & 8,0 & 8 & 7 & 7,5 \\
\hline
\end{tabular}

FIGURA 7.1.1 -PONTUAÇÃO PARA PARTICIPAÇÃO DOS CALOUROS EM CADA MÓDULO

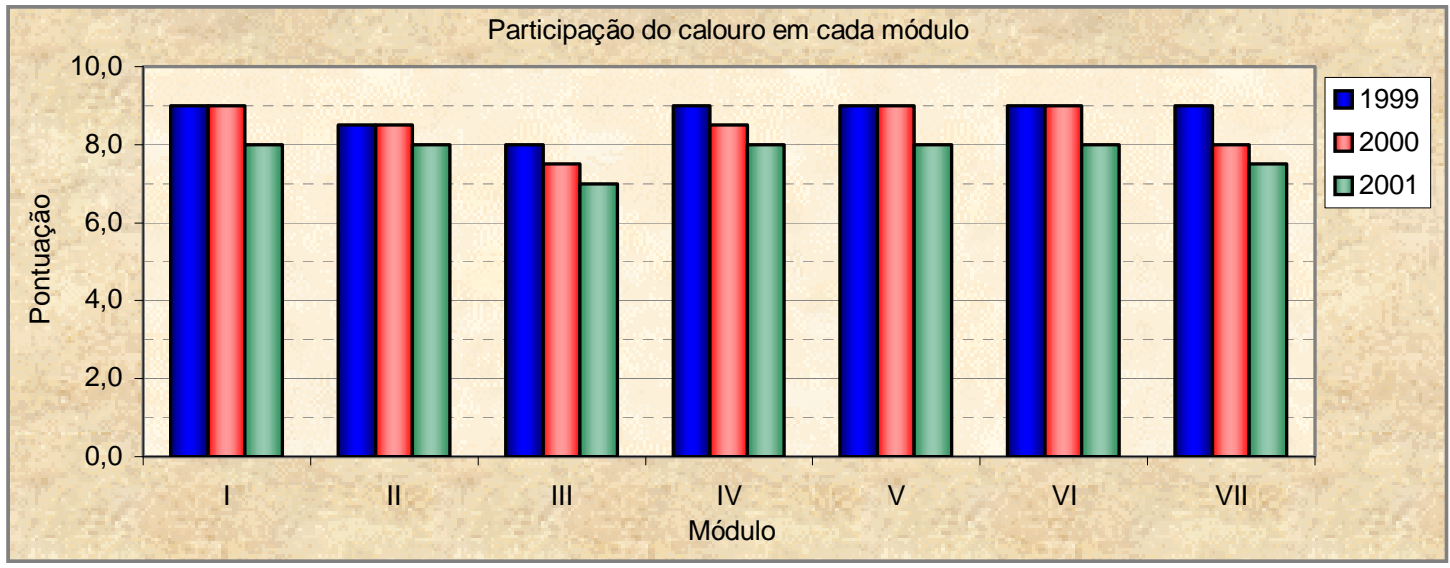

FIGURA 7.1.2 - PONTUAÇÃO MÉDIA PARA A PARTICIPAÇÃO DOS CALOUROS EM CADA MÓDULO

No gráfico da Figura 7.1.2 é possível observar uma pequena queda da participação dos calouros no decorrer de 1999 a 2001, sendo mais acentuada no terceiro módulo. A média geral dos três anos e de todos os módulos é 8,35, o que 
aponta uma boa participação nos três anos, principalmente quando comparada com a antiga estrutura da SEL-300.

A pequena queda observada pode ser conseqüência de pequenas diferenças existentes no nível de cada turma ingressante a cada ano na graduação. Este fato merece um estudo mais profundo com análise da participação dos calouros nas próximas turmas e se possível da variação do nível dos estudantes desde 1999.

\subsubsection{Qualidade e conteúdo dos relatórios}

Os relatórios de cada módulo elaborados pelos calouros foram avaliados quanto à qualidade (formato padrão e prazo de entrega) e o conteúdo teórico (notas de aula) e prático (exercícios em laboratório) do respectivo módulo. O interesse do calouro em buscar material na Internet ou nas bibliotecas para melhor elaborar seu relatório também foi considerado na avaliação.

Cada relatório recebeu uma nota de avaliação de 0 (insatisfatório) a 10 (execelente). As notas foram agrupadas em dez intervalos descritos na tabela “Ocorrência de notas (\%)” da Figura 7.1.3.

\begin{tabular}{|c|rrr|}
\hline \multicolumn{4}{|c|}{ Ocorrência de notas (\%) } \\
\hline Intervalo & 1999 & 2000 & \multicolumn{1}{c|}{2001} \\
\hline$[0$ a 1) & 0,00 & 0,00 & 0,00 \\
{$[1$ a 2) } & 0,00 & 0,00 & 0,00 \\
{$[2$ a 3) } & 0,00 & 0,00 & 0,00 \\
{$[3$ a 4) } & 0,00 & 0,00 & 0,00 \\
{$[4$ a 5) } & 0,00 & 0,00 & 0,00 \\
{$[5$ a 6) } & 0,00 & 0,00 & 1,89 \\
{$[6$ a 7) } & 0,00 & 3,92 & 15,09 \\
{$[7$ a 8) } & 0,00 & 5,88 & 5,66 \\
{$[8$ a 9) } & 15,38 & 41,18 & 24,53 \\
{$[9$ a 10] } & 84,62 & 49,02 & 52,83 \\
Total & 100,00 & 100,00 & 100,00 \\
\hline
\end{tabular}

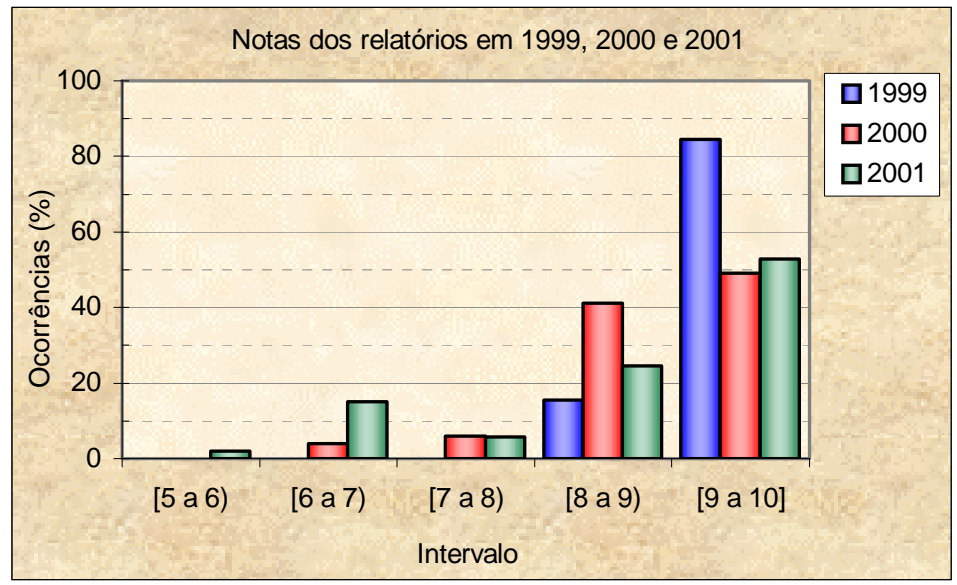

FIGURA 7.1.3 - DISTRIBUIÇÃO DAS NOTAS DE AVALIAÇÃO DOS RELATÓRIOS EM 1999, 2000 E 2001

Na tabela e no gráfico da Figura 7.1.3 é possível observar também uma queda de 1999 para 2000 e 2001, caracterizada pela maior distribuição das notas do 
intervalo [9 a 10) para os intervalos anteriores, principalmente o intervalo [8 a 9). A média geral das notas é 8,97, o que aponta que os relatórios apresentaram foram bem elaborados.

A pequena queda, melhor descrita como uma redistribuição das notas entre mais intervalos, pode ser conseqüência das avaliações um pouco mais rigorosas a partir de 2000 e ou conseqüência das mesmas causas mencionadas no item 7.1.1 Participação dos calouros, merecendo também um estudo mais profundo.

\subsection{Avaliação pelo corpo discente}

O questionário elaborado pelo corpo docente e aplicado ao final da $S E L-300$ em 1999, 2000 e 2001 foi dividido em duas partes, a primeira contendo 16 questões com respostas dadas em pontuação de 1 a 5 e a segunda parte, contendo 7 questões de resposta livre, sendo no total 23 questões descritas a seguir, com a contagem da pontuação para as questões da primeira parte e um resumo das respostas para as questões da segunda parte.

\subsubsection{Primeira parte - Questões por pontuação}

\section{Questão 1}

No início do semestre, você foi informado sobre a programação geral da disciplina? (1 Não ... 5 - Sim, muito bem informado)

Esta questão foi elaborada para verificar se o Módulo I - Introdução atingiu seu objetivo, apresentar o conteúdo e a programação geral da SEL-300. As respostas estão na Figura 7.2.1. 


\begin{tabular}{|c|ccc|}
\hline \multicolumn{5}{|c|}{ Questão 1 } \\
\hline Resposta & 1999 & 2000 & 2001 \\
0 & 6 & 5 & 0 \\
1 & 1 & 0 & 3 \\
2 & 1 & 6 & 0 \\
3 & 7 & 9 & 12 \\
4 & 18 & 17 & 14 \\
5 & 20 & 10 & 20 \\
\hline
\end{tabular}

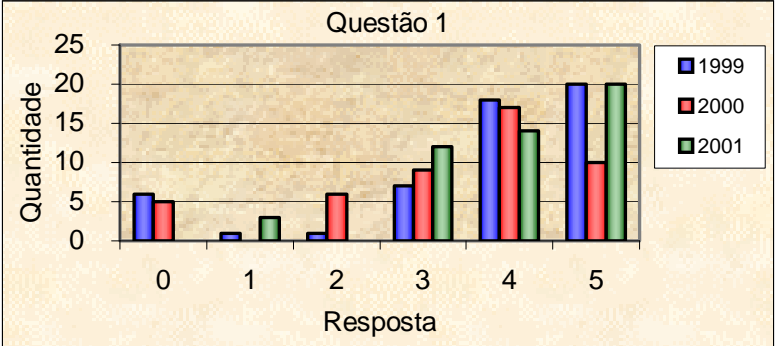

FIGURA 7.2.1 - LEVANTAMENTO DAS RESPOSTAS PARA A QUESTÃo 1

\section{Questão 2}

A disciplina contribuiu para despertar seu interesse pelo curso? (1 - Não ... 5 - Sim, bastante)

Esta questão foi elaborada para verificar se a SEL-300 despertou o interesse do calouro pelo curso, independente do seu interesse ao início do mesmo ${ }^{22}$. As respostas estão na Figura 7.2.2.

\begin{tabular}{|c|c|c|c|}
\hline \multicolumn{5}{|c|}{ Questão 2 } \\
\hline Resposta & 1999 & 2000 & 2001 \\
0 & 0 & 1 & 0 \\
1 & 1 & 0 & 2 \\
2 & 1 & 6 & 3 \\
3 & 9 & 17 & 8 \\
4 & 13 & 13 & 22 \\
5 & 29 & 10 & 14 \\
\hline
\end{tabular}

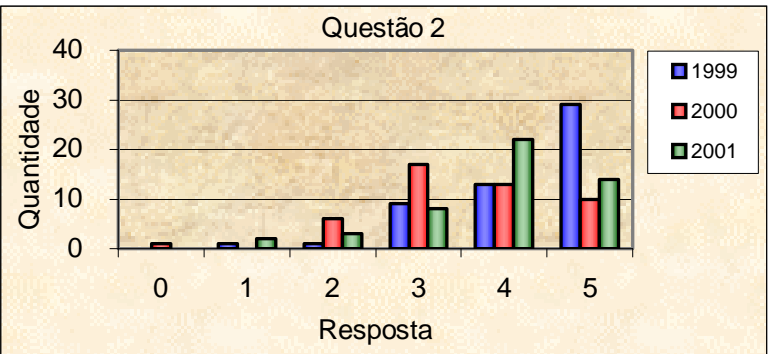

FIGURA 7.2.2 - LEVANTAMENTO DAS RESPOSTAS PARA A QUESTÃO 2

\section{Questão 3}

Como você avalia a organização adotada para a disciplina? (1 - Péssima ... 5 - Excelente)

Esta questão foi elaborada para verificar se a organização geral da disciplina, conteúdo, apresentação e recursos envolvidos foram adequados aos calouros. As respostas estão na Figura 7.2.3.

\footnotetext{
${ }^{22}$ Existem estudantes que iniciam uma determinada carreira sem possuírem inicialmente interesse pela mesma. Este interesse pode aparecer, aumentar, diminuir ou até nunca existir durante a carreira.
} 


\begin{tabular}{|c|c|c|c|}
\hline \multicolumn{5}{|c|}{ Questão 3 } \\
\hline Resposta & 1999 & 2000 & 2001 \\
0 & 0 & 0 & 0 \\
1 & 1 & 2 & 0 \\
2 & 0 & 5 & 3 \\
3 & 14 & 18 & 13 \\
4 & 24 & 16 & 25 \\
5 & 14 & 6 & 8 \\
\hline
\end{tabular}

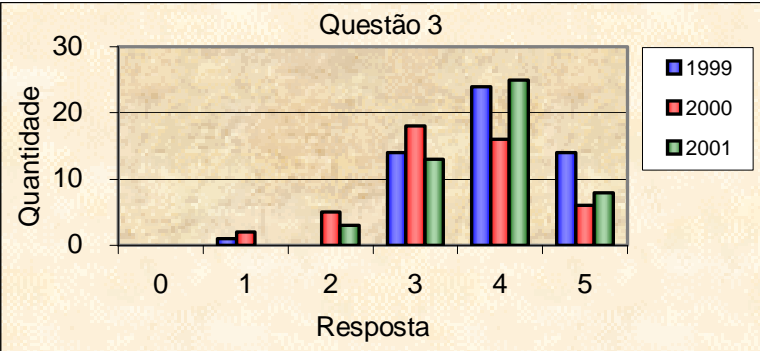

FIGURA 7.2.3 - LEVANTAMENTO DAS RESPOSTAS PARA A QUESTÃo 3

\section{Questão 4}

Em relação à programação da disciplina, a carga horária foi (1 - Insatisfatória ... 5 Amplamente satisfatória)

Esta questão foi elaborada para verificar se a carga horária ${ }^{23}$ considerada na SEL-300 foi suficiente para a aplicação de todo o conteúdo. As respostas estão na Figura 7.2.4.

\begin{tabular}{|c|ccc|}
\hline \multicolumn{5}{|c|}{ Questão 4 } \\
\hline Resposta & 1999 & 2000 & 2001 \\
0 & 0 & 0 & 0 \\
1 & 0 & 0 & 1 \\
2 & 4 & 5 & 1 \\
3 & 7 & 6 & 6 \\
4 & 20 & 24 & 18 \\
5 & 22 & 12 & 23 \\
\hline
\end{tabular}

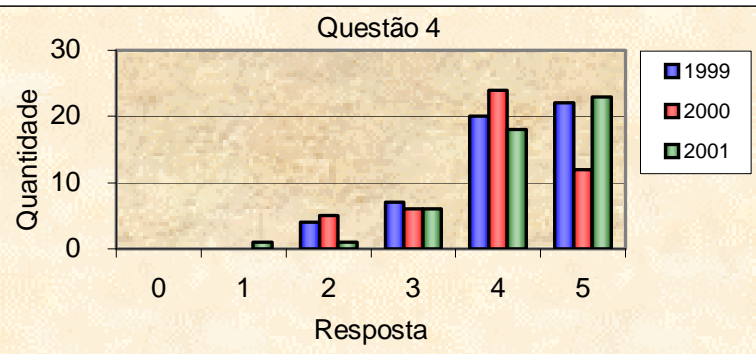

FIGURA 7.2.4 - LEVANTAMENTO DAS RESPOSTAS PARA A QUESTÃO 4

\section{Questão 5}

A apresentação dos conteúdos foi interessante e motivadora? (1 - Não ... 5 - Sim, completamente)

Esta questão foi elaborada para verificar se a forma de apresentação adotada, recursos audiovisuais e ferramentas computacionais, surtiu efeito sobre o interesse e a motivação dos calouros. As respostas estão na Figura 7.2.5.

\footnotetext{
${ }^{23}$ A carga horária é considerada em créditos (aulas) de 50 minutos cada.
} 


\begin{tabular}{|c|ccc|}
\hline \multicolumn{5}{|c|}{ Questão 5 } \\
\hline Resposta & 1999 & 2000 & 2001 \\
0 & 0 & 1 & 0 \\
1 & 2 & 1 & 0 \\
2 & 3 & 5 & 1 \\
3 & 10 & 10 & 8 \\
4 & 25 & 17 & 20 \\
5 & 13 & 13 & 20 \\
\hline
\end{tabular}

FIGURA 7.2.5 - LEVANTAMENTO DAS RESPOSTAS PARA A QUESTÃO 5

\section{Questão 6}

O material utilizado nas aulas mostrou-se relevante ao conteúdo ministrado? (1 - Não ... 5 Sim, completamente)

Esta questão foi elaborada para verificar se a relevância do material utilizado nas aulas (“slides” e exercícios práticos) foi relevante ao conteúdo da disciplina. As respostas estão na Figura 7.2.6.

\begin{tabular}{|c|ccc|}
\hline \multicolumn{5}{|c|}{ Questão 6 } \\
\hline Resposta & 1999 & 2000 & 2001 \\
0 & 0 & 1 & 0 \\
1 & 2 & 0 & 0 \\
2 & 2 & 2 & 5 \\
3 & 11 & 12 & 11 \\
4 & 24 & 20 & 20 \\
5 & 14 & 12 & 13 \\
\hline
\end{tabular}

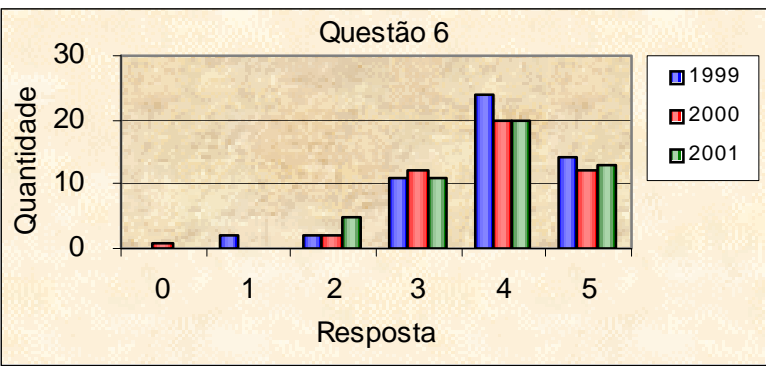

FIGURA 7.2.6 - LEVANTAMENTO DAS RESPOSTAS PARA A QUESTÃO 6

\section{Questão 7}

Os exemplos e exercícios dados facilitaram a compreensão dos conteúdos? (1 - Não … 5 Sim, bastante)

Esta questão foi elaborada para verificar se os exemplos nas aulas teóricas e os exercícios práticos dados aos calouros ajudaram a compreensão dos conteúdos. As respostas estão na Figura 7.2.7. 


\begin{tabular}{|c|ccc|}
\hline \multicolumn{5}{|c|}{ Questão 7 } \\
\hline Resposta & 1999 & 2000 & 2001 \\
0 & 0 & 1 & 0 \\
1 & 5 & 2 & 3 \\
2 & 7 & 5 & 8 \\
3 & 16 & 14 & 17 \\
4 & 13 & 18 & 14 \\
5 & 12 & 7 & 7 \\
\hline
\end{tabular}

FIGURA 7.2.7 - LEVANTAMENTO DAS RESPOSTAS PARA A QUESTÃO 7

\section{Questão 8}

Os recursos utilizados nas aulas contribuíram para o aproveitamento na disciplina? (1 - Não ... 5 - Sim, significativamente)

Esta questão foi elaborada para verificar se os recursos (recursos audiovisuais, ferramentas computacionais, exercícios práticos) ajudaram no aproveitamento da $S E L-300$. As respostas estão na Figura 7.2.8.

\begin{tabular}{|c|ccc|}
\hline \multicolumn{5}{|c|}{ Questão 8 } \\
\hline Resposta & 1999 & 2000 & 2001 \\
0 & 1 & 2 & 1 \\
1 & 0 & 1 & 0 \\
2 & 1 & 4 & 1 \\
3 & 7 & 4 & 14 \\
4 & 25 & 22 & 14 \\
5 & 19 & 14 & 19 \\
\hline
\end{tabular}

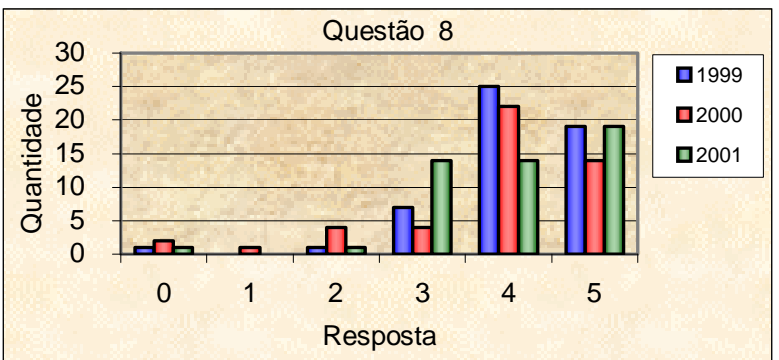

FIGURA 7.2.8 - LEVANTAMENTO DAS RESPOSTAS PARA A QUEST̃̃O 8

\section{Questão 9}

Os recursos utilizados demonstraram organização e preparo cuidadoso? (1 - Não ... 5 Sim, completamente)

Esta questão foi elaborada para verificar se os calouros consideraram a concepção da disciplina organizada cuidadosamente. As respostas estão na Figura 7.2.9. 


\begin{tabular}{|c|ccc|}
\hline \multicolumn{5}{|c|}{ Questão 9 } \\
\hline Resposta & 1999 & 2000 & 2001 \\
0 & 0 & 0 & 0 \\
1 & 0 & 0 & 2 \\
2 & 0 & 0 & 4 \\
3 & 4 & 9 & 12 \\
4 & 20 & 15 & 14 \\
5 & 29 & 23 & 17 \\
\hline
\end{tabular}

FIGURA 7.2.9 - LEVANTAMENTO DAS RESPOSTAS PARA A QUESTÃO 9

\section{Questão 10}

Na sua opinião, o sistema de avaliação adotado na disciplina foi: (1 - Insatisfatório ... 5 Completamente satisfatório)

Esta questão foi elaborada para verificar se os calouros consideraram a avaliação utilizada na SEL-300 compatível com o conteúdo apresentado. As respostas estão na Figura 7.2.10.

\begin{tabular}{|c|ccc|}
\hline \multicolumn{5}{|c|}{ Questão 10 } \\
\hline Resposta & 1999 & 2000 & 2001 \\
0 & 1 & 2 & 0 \\
1 & 7 & 3 & 0 \\
2 & 5 & 8 & 1 \\
3 & 10 & 15 & 9 \\
4 & 21 & 9 & 26 \\
5 & 9 & 10 & 13 \\
\hline
\end{tabular}

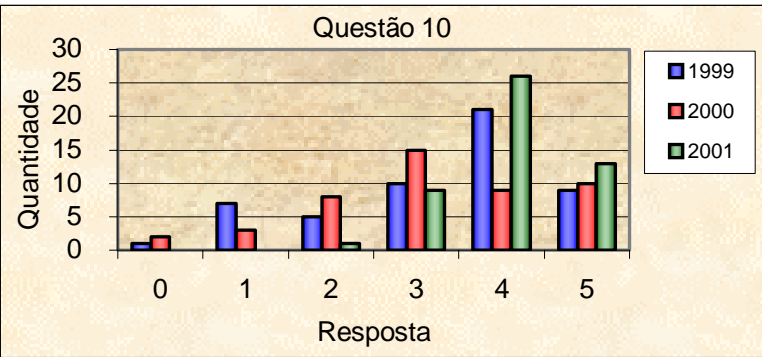

FIGURA 7.2.10 - LEVANTAMENTO DAS RESPOSTAS PARA A QUESTÃO 10

\section{Questão 11}

A estrutura adotada para a disciplina (módulos), permitiu estabelecer relações entre os diversos assuntos abrangidos pela disciplina? (1 - Não ... 5 - Sim, completamente)

Esta questão foi elaborada para verificar se a nova estrutura da disciplina facilitou a compreensão das relações entre os diversos assuntos contidos na disciplina. As respostas estão na Figura 7.2.11. 


\begin{tabular}{|c|ccc|}
\hline \multicolumn{5}{|c|}{ Questão 11 } \\
\hline Resposta & 1999 & 2000 & 2001 \\
0 & 0 & 1 & 0 \\
1 & 1 & 0 & 0 \\
2 & 1 & 2 & 4 \\
3 & 6 & 14 & 12 \\
4 & 24 & 17 & 21 \\
5 & 21 & 13 & 12 \\
\hline
\end{tabular}

FIGURA 7.2.11 - LEVANTAMENTO DAS RESPOSTAS PARA A QUESTÃO 11

\section{Questão 12}

Na sua opinião, a rotatividade de professores adotada na disciplina foi: (1 - Péssima ... 5 Excelente)

Esta questão foi elaborada para verificar se os calouros consideraram adequada a SEL-300 ministrada por vários docentes, cada um especialista no conteúdo de cada módulo. As respostas estão na Figura 7.2.12.

\begin{tabular}{|c|c|c|c|}
\hline \multicolumn{5}{|c|}{ Questão 12 } \\
\hline Resposta & 1999 & 2000 & 2001 \\
0 & 0 & 0 & 0 \\
1 & 2 & 1 & 0 \\
2 & 0 & 0 & 2 \\
3 & 7 & 6 & 8 \\
4 & 21 & 21 & 16 \\
5 & 23 & 19 & 23 \\
\hline
\end{tabular}

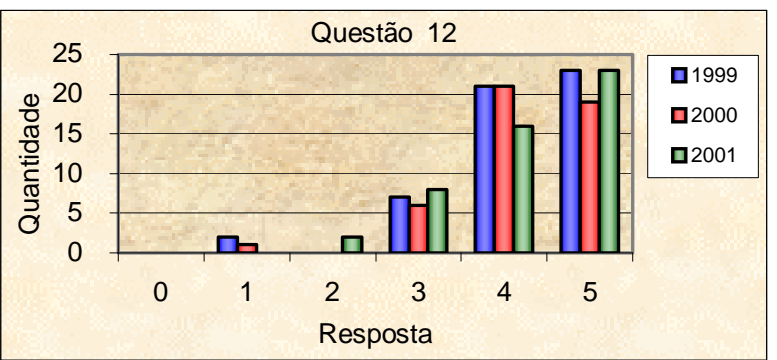

FIGURA 7.2.12 - LEVANTAMENTO DAS RESPOSTAS PARA A QUESTÃO 12

\section{Questão 13}

A disciplina forneceu o esclarecimento necessário sobre sua futura carreira? (1 - Não ... 5 Sim, completamente)

Esta questão foi elaborada para verificar se a $S E L-300$ ajudou a conhecer melhor o curso de engenharia elétrica da EESC, possibilitando verificar se esta carreira foi uma boa escolha. As respostas estão na Figura 7.2.13. 


\begin{tabular}{|c|ccc|}
\hline \multicolumn{5}{|c|}{ Questão 13 } \\
\hline Resposta & 1999 & 2000 & 2001 \\
0 & 0 & 1 & 0 \\
1 & 1 & 5 & 2 \\
2 & 4 & 9 & 5 \\
3 & 16 & 11 & 16 \\
4 & 23 & 16 & 22 \\
5 & 9 & 5 & 4 \\
\hline
\end{tabular}

FIGURA 7.2.13 - LEVANTAMENTO DAS RESPOSTAS PARA A QUESTÃO 13

\section{Questão 14}

O programa da disciplina satisfez as suas expectativas? (1 - Não ... 5 - Sim, completamente)

Esta questão foi elaborada para verificar se as expectativas dos calouros ao ingressarem no curso de engenharia, foram satisfeitas. As respostas estão na Figura 7.2.14.

\begin{tabular}{|c|c|c|c|}
\hline \multicolumn{5}{|c|}{ Questão 14 } \\
\hline Resposta & 1999 & 2000 & 2001 \\
0 & 0 & 1 & 0 \\
1 & 3 & 4 & 1 \\
2 & 1 & 6 & 6 \\
3 & 20 & 10 & 14 \\
4 & 21 & 23 & 25 \\
5 & 8 & 3 & 3 \\
\hline
\end{tabular}

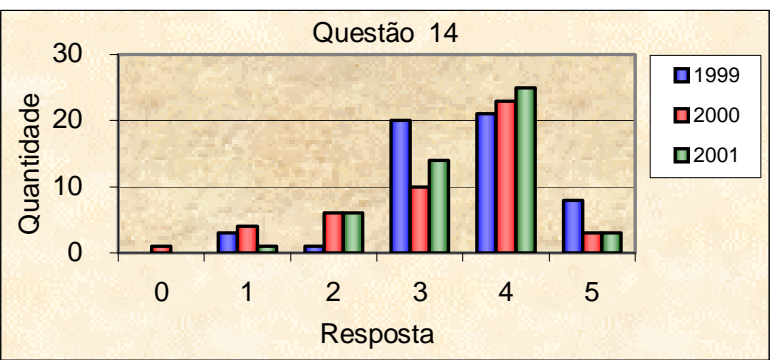

FIGURA 7.2.14 - LEVANTAMENTO DAS RESPOSTAS PARA A QUESTÃO 14

\section{Questão 15}

A disciplina forneceu uma nova idéia sobre o que é Engenharia Elétrica? (1 - Não ... 5 Sim, completamente)

Esta questão foi elaborada para verificar se a idéia dos calouros sobre a engenharia elétrica no início da disciplina, foi alterada (corrigida, melhorada, etc). As respostas estão na Figura 7.2.15. 


\begin{tabular}{|c|ccc|}
\hline \multicolumn{5}{|c|}{ Questão 15 } \\
\hline Resposta & 1999 & 2000 & 2001 \\
0 & 0 & 1 & 0 \\
1 & 3 & 7 & 5 \\
2 & 4 & 2 & 3 \\
3 & 14 & 13 & 12 \\
4 & 16 & 20 & 19 \\
5 & 16 & 4 & 10 \\
\hline
\end{tabular}

FIGURA 7.2.15 - LEVANTAMENTO DAS RESPOSTAS PARA A QUESTÃO 15

\section{Questão 16}

Ficou convencido de que a opção por Engenharia Elétrica foi a mais acertada? (1 - Não ... 5 - Sim, completamente)

Esta questão foi elaborara para verificar se os calouros após estarem mais informados sobre a engenharia elétrica, consideraram que esta carreira foi uma boa opção a seguirem. As respostas estão na Figura 7.2.16.

\begin{tabular}{|c|c|c|c|}
\hline \multicolumn{5}{|c|}{ Questão 16 } \\
\hline Resposta & 1999 & 2000 & 2001 \\
0 & 1 & 1 & 0 \\
1 & 2 & 2 & 2 \\
2 & 2 & 1 & 1 \\
3 & 9 & 8 & 8 \\
4 & 12 & 9 & 13 \\
5 & 27 & 26 & 25 \\
\hline
\end{tabular}

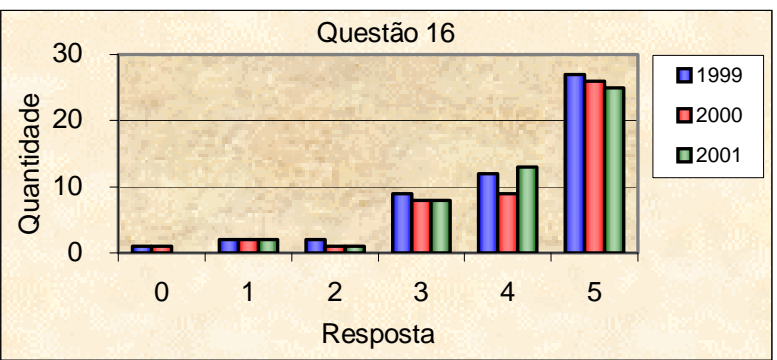

FIGURA 7.2.16 - LEVANTAMENTO DAS RESPOSTAS PARA A QUESTÃO 16

\subsubsection{Segunda parte - Questões por escrito}

\section{Questão 17}

O que você destacaria como pontos favoráveis e/ou desfavoráveis no desenvolvimento da disciplina?

Esta questão foi elabora para que os calouros pudessem expor suas sugestões a fim de contribuírem para um aperfeiçoamento da disciplina. Os pontos favoráveis mais apontados estão indicados no quadro Figura 7.2.17-A. 


\section{Pontos favoráveis}

Variedade de recursos utilizados na apresentação, qualidade de preparo e organização dos módulos Abordagem de diversas áreas Rotatividade dos professores

Quebra de rotina das disciplinas de matemática e física;

Apresentação de ferramentas computacionais (softwares) utilizados na engenharia.

FIGURA 7.2.17.A - PONTOS FAVORÁVEIS APRESENTADOS NA QUESTÃO 1

Os pontos desfavoráveis mais apontados estão indicados no quadro da Figura

\subsubsection{B:}

\begin{tabular}{|l|c|c|c|}
\hline \multicolumn{1}{|c|}{ Pontos desfavorávies } & 1999 & 2000 & 2001 \\
\hline Poucas aulas práticas e pouco material de apoio & $\sqrt{ }$ & $\sqrt{ }$ & \\
\hline $\begin{array}{l}\text { Pouco esclarecimento sobre alguns tópicos por parte de alguns professores sobre } \\
\text { alguns conceitos mais complexos, seguidos de exercícios às vezes difíceis }\end{array}$ & $\sqrt{ }$ & $\sqrt{ }$ & $\sqrt{ }$ \\
\hline Muita ênfase na eletrônica & $\sqrt{ }$ & & \\
\hline Não uniformidade e falta de seqüência dos módulos & $\sqrt{ }$ & & \\
\hline Pouco tempo para a disciplina & $\sqrt{ }$ & $\sqrt{ }$ & $\sqrt{ }$ \\
\hline
\end{tabular}

FIGURA 7.2.17.B - PONTOS DESFAVORÁVEIS APRESENTADOS NA QUESTÃO 1

\section{Questão 18}

Dos módulos apresentados Circuitos Eletrônicos, Eletrônicos de Potência e Controle, Sistemas de Potência, Instrumentação e Medidas, Sistemas Digitais e Telecomunicações, qual o que despertou mais a sua atenção? Por que?

Esta questão foi elaborada para verificar qual ou quais módulos chamaram mais a atenção dos estudantes e qual o motivo disto. Os módulos mais apontados pelos estudantes, na ordem decrescente de preferência e com os respectivos motivos, foram:

o Telecomunicações: por ser muito bem apresentado, por identificar-se com o módulo, por apresentar grandes perspectivas;

o Sistemas Digitais: por ser muito bem apresentado, por estar presente em muitas aplicações do cotidiano;

o Controle e Eletrônica de Potência: por ser bem apresentado, por tratar de automação e robótica, por ser multidisciplinar;

o Sistemas de Potência: pela forma empolgante que foi apresentado o módulo;

o Circuitos Eletrônicos: por estar presente em quase todas as coisas;

o Instrumentação e Medidas, por identificar-se com o módulo. 
Por meio do gráfico da Figura 7.2.18.A, é mais fácil verificar as respostas dos estudantes em 1999 e 2000. A contagem foi baseada no número de vezes que cada módulo foi apontado pelos estudantes. Este resultado indica que os módulos mais apontados pelos estudantes foram o de Telecomunicações e o de Sistemas Digitais, seguidos pelo de Controle e Eletrônica de Potência. Os demais módulos não foram muito apontados pelos estudantes.

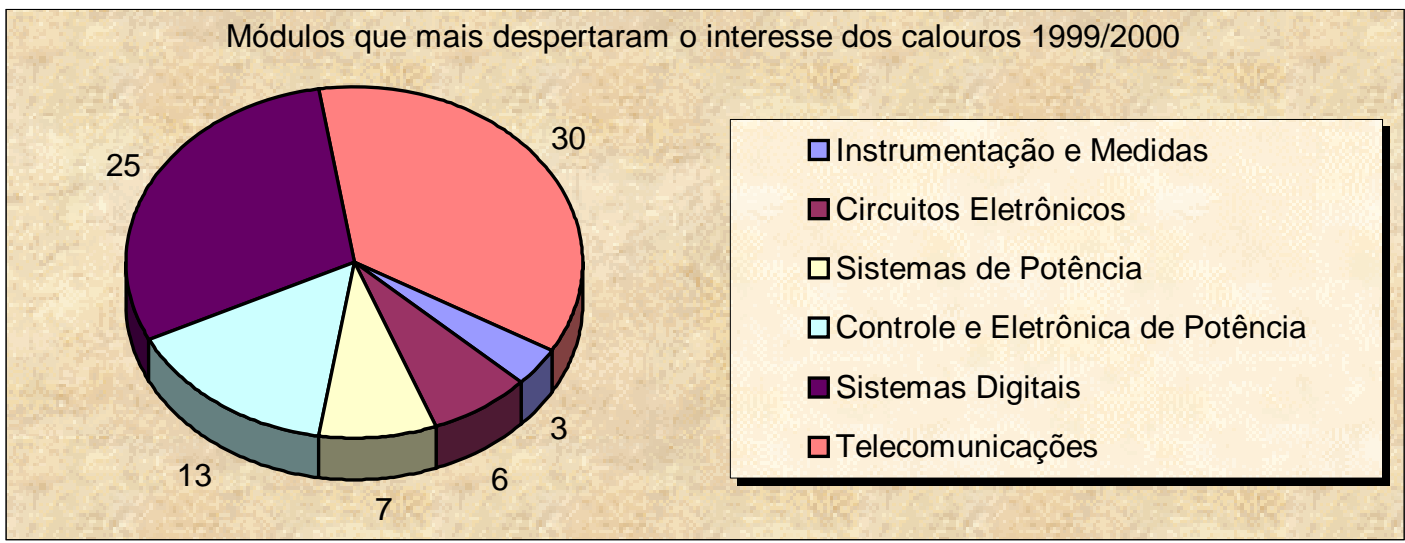

FIGURA 7.2.18.A - MÓDULOS QUE MAIS DESPERTARAM O INTERESSE DOS CALOUROS EM 1999 E 2000

Em 2001 o módulo de Sistemas de Potência apresentou uma maior citação em relação aos anos anteriores, estando em equilíbrio com os módulos Telecomunicações, Sistemas Digitais e Controle e Eletrônica de Potência como indica a Figura 7.2.18.B.

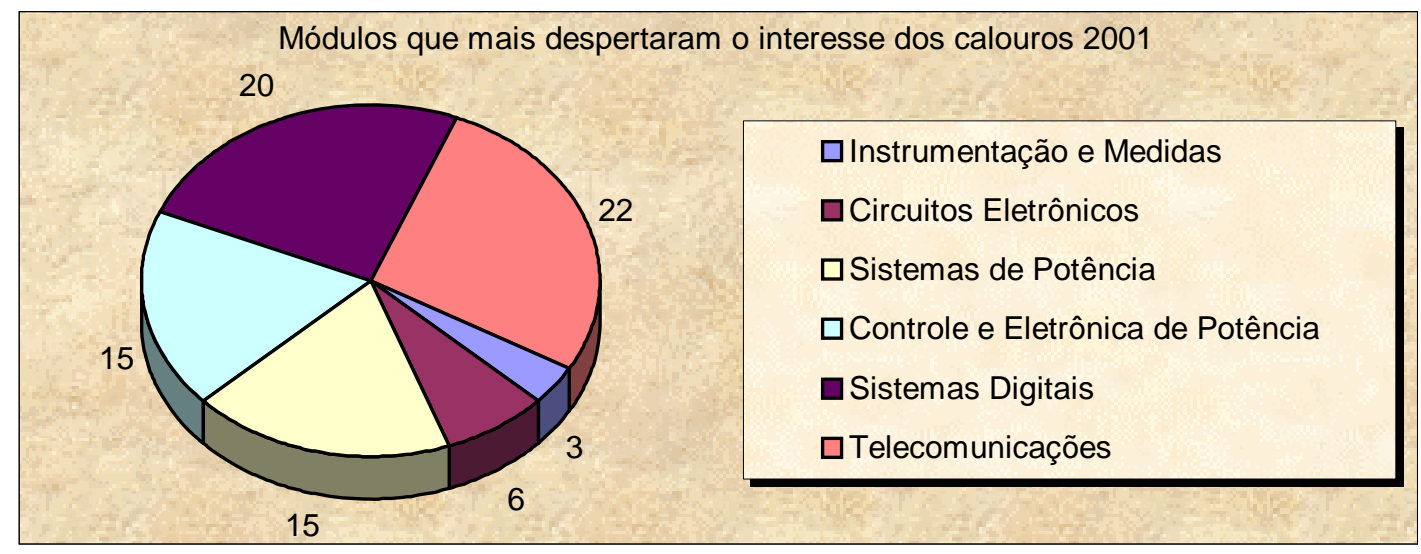

FIGURA 7.2.18.B - MÓDULOS QUE MAIS DESPERTARAM O INTERESSE DOS CALOUROS EM 2001 


\section{Questão 19}

Com qual das áreas da Engenharia Elétrica você mais se identifica?

Esta questão foi elaborada para verificar com qual das áreas da engenharia elétrica o estudante se identifica mais. Nesta questão a contagem também foi baseada no número de vezes que cada área foi apontada pelos estudantes. As áreas mais apontadas pelos estudantes, em ordem decrescente de preferência, foram:

o Telecomunicações;

o Sistemas Digitais;

o Controle e Eletrônica de Potência;

o Circuitos Eletrônicos;

o Instrumentação e Medidas;

o Sistemas de Potência;

o Bioengenharia.

Por meio do gráfico na Figura 7.2.19.A em 1999 e 2000, é mais fácil verificar as respostas dos estudantes. Este resultado indica que as áreas mais apontadas foram Telecomunicações e Sistemas Digitais, seguidas de Controle e Eletrônica de Potência. Um fato interessante observado foi a presença da Bioengenharia, apesar de não estar explicitamente presente em algum dos módulos.

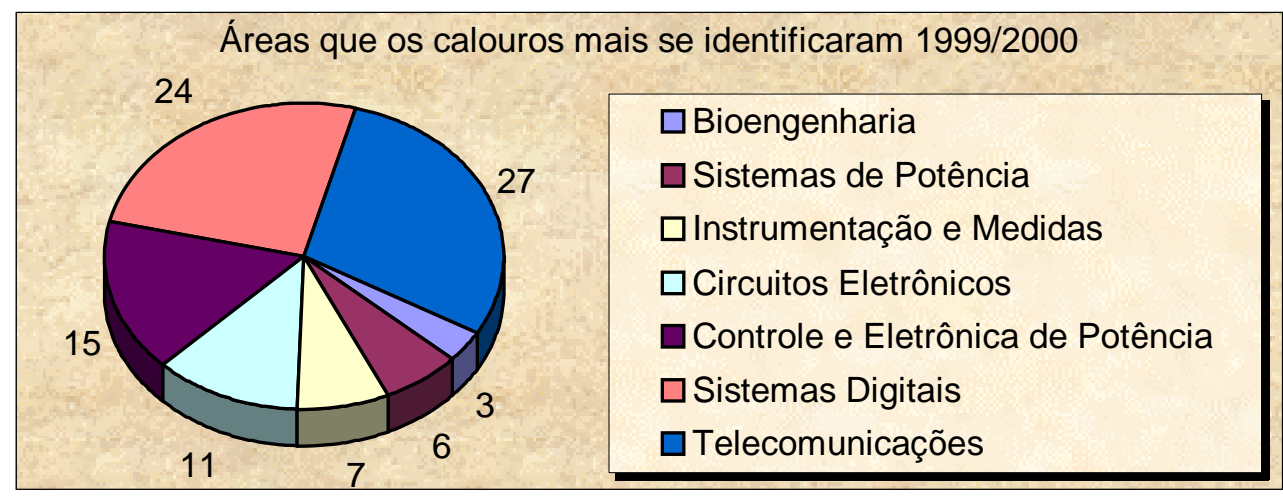

FIGURA 7.2.19.A - ÁREAS MAIS APONTADAS PELOS CALOUROS EM 1999/2000

Em 2001 a área Sistema de Potência apresentou maior citação em relação aos anos anteriores como está indicado no gráfico da Figura 7.2.19.B. 


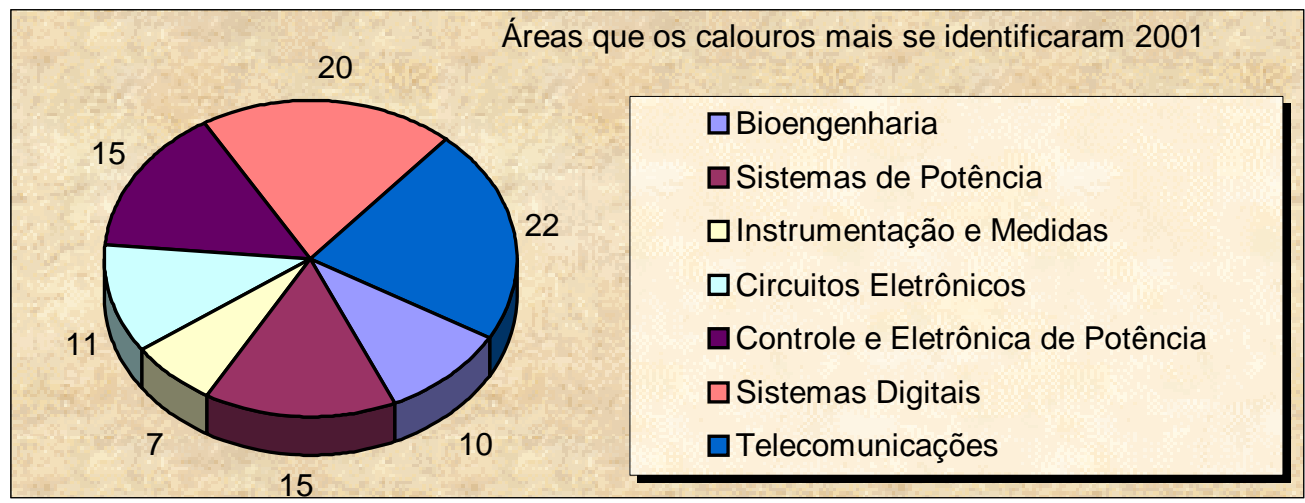

FIGURA 7.2.19.B - ÁREAS MAIS APONTADAS PELOS CALOUROS EM 2001

\section{Questão 20}

Que melhoras sugere para a disciplina?

Esta questão foi elaborada para que os estudantes dessem ou confirmassem as sugestões feitas na questão 17.

As sugestões mais apresentadas pelos estudantes estão indicadas no quadro da Figura 7.2.20.

\begin{tabular}{|l|c|c|c|}
\hline \multicolumn{1}{|c|}{ Sugestões apresentadas } & 1999 & 2000 & 2001 \\
\hline $\begin{array}{l}\text { Maior contato com o departamento, por meio de visitas e mais práticas } \\
\text { laboratoriais }\end{array}$ & $\sqrt{ }$ & $\sqrt{ }$ & \\
\hline $\begin{array}{l}\text { Maior carga horária e até criação de uma disciplina para o segundo semestre } \\
\text { melhorando-se o aproveitamento do conteúdo }\end{array}$ & $\sqrt{ }$ & $\sqrt{ }$ & $\sqrt{ }$ \\
\hline $\begin{array}{l}\text { Material de apoio mais denso para auxiliar os trabalhos propostos que também } \\
\text { foram um pouco difíceis }\end{array}$ & $\sqrt{ }$ & $\sqrt{ }$ & \\
\hline Alguns módulos foram muito técnicos & $\sqrt{ }$ & $\sqrt{ }$ & \\
\hline Vários responderam que está bom & $\sqrt{ }$ & $\sqrt{ }$ & $\sqrt{ }$ \\
\hline Mais informações da bioengenharia & $\sqrt{ }$ & $\sqrt{ }$ & $\sqrt{ }$ \\
\hline
\end{tabular}

FIGURA 7.2.20 - SUGESTÕES APRESENTADAS PELOS CALOUROS

\section{Questão 21}

Você precisa de mais esclarecimentos?

Esta questão foi elaborada com o mesmo objetivo das questões 17 e 20, induzir os estudantes a darem mais sugestões.

Os esclarecimentos mais apontados pelos estudantes estão indicados no quadro da Figura 7.2.21. 


\begin{tabular}{|l|c|c|c|}
\hline \multicolumn{1}{|c|}{ Esclarecimentos necessários } & 1999 & 2000 & 2001 \\
\hline Quais as áreas de pesquisa do departamento & $\sqrt{ }$ & $\sqrt{ }$ & \\
\hline Mais detalhes sobre circuitos eletrônicos & $\sqrt{ }$ & $\sqrt{ }$ & \\
\hline Mais detalhes sobre Instrumentação e medidas & $\sqrt{ }$ & $\sqrt{ }$ & $\sqrt{ }$ \\
\hline Mais abordagem sobre bioengenharia & $\sqrt{ }$ & $\sqrt{ }$ & $\sqrt{ }$ \\
\hline Mais informações sobre mercado de trabalho e área de atuação do engenheiro & $\sqrt{ }$ & $\sqrt{ }$ & \\
\hline Mais informações sobre iniciação científica & & $\sqrt{ }$ & $\sqrt{ }$ \\
\hline
\end{tabular}

FIGURA 7.2.21 - ESCLARECIMENTOS NECESSÁRIOS

\section{Questão 22}

Dê um conceito geral para a disciplina e justifique esse conceito.

Esta questão foi elaborada para que o estudante desse uma avaliação geral sobre a SEL-300, justificando sua resposta. O conceito geral mais apresentado pelos estudantes foi:

o Boa ou ótima, pois proporcionam um contato imediato com a engenharia elétrica e também descreveu melhor o que é a engenharia elétrica, porém algumas falhas deveriam ser corrigidas.

\section{Questão 23}

Fique à vontade para fazer os comentários e sugestões que julgar relevante a respeito do curso, disciplina ou deste questionário. Se necessário utilize o verso desta folha.

Esta questão foi elaborada para novamente induzir o estudante a dar mais sugestões sobre a SEL-300. Os comentários e sugestões mais apontados pelos estudantes estão indicados no quadro da Figura 7.2.23.

\begin{tabular}{|l|c|c|c|}
\hline \multicolumn{1}{|c|}{ Comentários e sugestões finais } & 1999 & 2000 & 2001 \\
\hline Mais explicações nas aulas práticas & $\sqrt{ }$ & $\sqrt{ }$ & $\sqrt{ }$ \\
\hline Este questionário é de grande importância & & $\sqrt{ }$ & $\sqrt{ }$ \\
\hline Maior carga horária e mais aulas práticas & $\sqrt{ }$ & $\sqrt{ }$ & $\sqrt{ }$ \\
\hline As aulas foram muito corridas & $\sqrt{ }$ & $\sqrt{ }$ & \\
\hline Esta disciplina está conseguindo atingir seus objetivos & & $\sqrt{ }$ & $\sqrt{ }$ \\
\hline
\end{tabular}

FIGURA 7.2.23 - COMENTÁRIOS E SUGESTÕES FINAIS

\subsection{Análise das avaliações}

As avaliações efetuadas pelos corpos docente e discente em 1999, 2000 e 2001 permitiram analisar a nova estrutura da $S E L-300$, corrigindo e aperfeiçoando pontos relevantes ao bom andamento da disciplina, como a participação dos calouros, 
o sistema de avaliação adotado, a rotatividade de professores, sugestões e críticas dos calouros, dentre outros.

A participação dos calouros, apesar de uma pequena queda como indicado nos dados das Figuras 7.1.1 e 7.1.2, foi boa. Esta queda pode ser conseqüência da pequena variação do nível dos calouros que ingressam a cada ano na graduação.

As notas dos relatórios elaboradas pelos calouros também apresentaram uma queda conforme os dados indicados na Figura 7.1.3, porém foram boas, principalmente se for considerado o maior rigor na correção dos mesmos em 2000 e 2001. A melhor elaboração destes relatórios também foi observada.

Os resultados das questões 2, 14, 15 e 16 (ver Figuras 7.2.2, 7.2.14, 7.2.15 e 7.2.16 respectivamente), sugerem que a SEL-300 despertou o interesse do calouro para o curso de engenharia elétrica satisfazendo suas expectativas e fornecendo esclarecimentos necessários. Os calouros ingressaram com uma boa noção sobre a engenharia elétrica e puderam verificar com a SEL-300 que escolheram corretamente a carreira a seguirem.

A questão 17 (ver Figuras 7.2.17A e 7.2.17B) indicou vários pontos favoráveis mantidos em 1999, 2000 e 2001, como quebra da rotina das disciplinas de matemática e física e apresentação de ferramentas computacionais. Esta questão indicou também pontos desfavoráveis em 1999, como muita ênfase na eletrônica e não uniformidade dos módulos. Estes pontos foram corrigidos em 2000 e 2001. O ponto pouco tempo para a disciplina (carga horária insuficiente para o conteúdo ministrado) foi apontado nos três anos, porém possibilidades de ampliação desta disciplina estão sendo estudadas. 
A questão 18 (ver Figuras 7.2.18A e 7.2.18B) indicou as principais subáreas de interesse dos calouros em 1999 e 2000, Telecomunicações, Sistemas Digitais e Controle e Eletrônica de Potência. Em 2001 a subárea Sistemas de Potência apareceu dividindo pontuação com as subáreas mais indicadas nos anos anteriores. Este fato pode ter sido conseqüência da situação crítica de energia elétrica no Brasil em 2000 e 2001, que destacou a subárea de Sistemas de Potência.

A subárea Bioengenharia foi muito requisitada nos três anos, mesmo com uma maior abordagem por pelo módulo de Instrumentação e Medidas. A inclusão da bioengenhaira como módulo está sendo estudada.

Estes e outros pontos também observados nos questionários estão sendo discutidos com os professores participantes da SEL-300 para 2002. 


\section{Capítulo VIII}

\section{Conclusões}

\subsection{Objetivos alcançados}

Os resultados obtidos com as avaliações feitas pelos corpos docente e discente indicaram em 1999, 2000 e 2001 que o modelo proposto de disciplina introdutória nesta dissertação está adequado para o curso de engenharia elétrica. Os objetivos propostos pelo modelo - motivar e preparar o calouro para o curso de engenharia, o mercado de trabalho e a sociedade, proporcionar a integração entre estudantes, professores e departamento, e permitir uma reciclagem pedagógica dos docentes envolvidos no curso - estão sendo alcançados desde o início da implementação em 1999 e aperfeiçoados nos anos seguintes.

Os calouros apresentaram uma participação significante na SEL-300 durante os três anos consecutivos, fato não observado na antiga estrutura da disciplina.

Segundo KURI (2000) ${ }^{24}$ o perfil dos estilos de aprendizagem dos calouros do curso de engenharia da EESC é o apresentado na tabela da Figura 7.3.

\footnotetext{
${ }^{24}$ KURI, N. P. (2000). Pedagoga do CETEPE. Relata o seu levantamento dos estilos de aprendizagem dos calouros do curso de engenharia elétrica da EESC/USP. Personal e-mail (07 Apr).
} 


\begin{tabular}{|c|c|c|}
\hline Estilo de ap & rendizagem & $\%$ \\
\hline \multirow{2}{*}{ Percepção - } & - Sensoriais & 71 \\
\hline & - Intuitivos & 29 \\
\hline \multirow{2}{*}{ Alimentação - } & - Visuais & 78 \\
\hline & - Verbais & 22 \\
\hline \multirow{2}{*}{ Processamento - } & - Ativos & 69 \\
\hline & - Reflexivos & 31 \\
\hline \multirow{2}{*}{ Compreensão - } & - Seqüenciais & 58 \\
\hline & - Globais & 42 \\
\hline
\end{tabular}

FIGURA 7.3 - PERFIL DOS ESTILOS DE APRENDIZAGEM DOS CALOUROS EM 2001

Esta figura indica que o perfil da maioria dos calouros é sensorial/visual/ativo/seqüencial, conferindo com o perfil descrito por FELDER \& SILVERMAN (1988). Comparando os estilos de ensino praticados na SEL-300 com os estilos de aprendizagem da maioria dos calouros, é possível verificar a compatibilidade entre os mesmos, pois:

- a presença de imagens e sons contemplou os calouros com percepção sensorial e alimentação visual;

- a presença de conceitos básicos associando-os a exemplos do cotidiano e a apresentação exemplos do cotidiano para apresentar outros conceitos atingiu contemplou os calouros com organização indutiva e dedutiva;

- a presença de simples exercícios práticos e discussões sobre temas atuais e a proposta de exercícios que necessitavam de reflexões sobre alguns conceitos vistos em teoria contemplaram os calouros com processamento ativo e reflexivo;

- a presença de um módulo introdutório e introduções iniciais a cada módulo, sendo cada tópico abordado seqüencialmente conforme as indicado nas introduções contemplaram os calouros com compreensão seqüencial e global. 
Apesar do perfil apontado FELDER \& SILVERMAN (1988) e verificado por KURI (2001), o perfil da minoria dos calouros, intuitivo/verbal/refrexivo/global também foi contemplado na nova estrutura da SEL-300.

Para os docentes participantes houve uma reciclagem pedagógica, por meio da integração entre os mesmos em um trabalho cooperativo e da utilização de recursos audiovisuais. Esta integração se deu por meio das reuniões periódicas com o objetivo de avaliarem cada módulo e darem sugestões para que o mesmo fosse aperfeiçoado antes de ser ministrado na SEL-300. A utilização de recursos audiovisuais, como o software de apresentação de “slides”, já era familiar a alguns dos docentes, que a utilizavam com freqüência há algum tempo em suas aulas. No entanto, os outros docentes, apesar de conhecerem tais recursos, ainda não os utilizavam com freqüência em suas aulas, mas demonstraram-se motivados e interessados a utilizar estes recursos com maior freqüência.

Um resultado indireto e inesperado alcançado foi a utilização de trechos de alguns módulos em outras disciplinas do curso de engenharia, por parte de docentes que participaram ou não participaram da SEL-300. Por exemplo, alguns trechos do Módulo VII - Telecomunicações foram utilizados em uma disciplina contendo conceitos de antenas, meios de transmissão e radiovisibilidade.

Perante os resultados obtidos com a nova estrutura da SEL-300 em 1999, 2000 e 2001, conclui-se que o modelo aqui proposto é adequado para uma disciplina introdutória em engenharia elétrica, sendo compatível com o perfil dos calouros e atendendo as necessidades do mercado de trabalho e da sociedade. Como este modelo enquadra-se em um processo de melhoria contínua buscando a qualidade 
total, sempre haverá pontos a serem corrigidos, pois o ensino deverá sempre acompanhar as mudanças constantes do mundo globalizado.

\subsection{Importância de um elo de ligação}

Um fato importante constatado foi a necessidade de uma pessoa (estudante de pós-graduação e autor desta dissertação) exercer a função de elo de ligação entre todos os docentes, pois os mesmos possuíam outras atividades como pesquisa e outras disciplinas para ministrarem.

Por exemplo, durante a implementação da nova estrutura da SEL-300, o conteúdo e a seqüência de cada módulo, inicialmente propostos por um professor foram adequados e reorganizados pelo estudante de pós-graduação segundo os moldes do modelo de disciplina introdutória.

A execução de cada módulo durante a SEL-300 foi acompanhada pelo estudante de pós-graduação, que verificou falhas apresentando-as aos demais docentes para que não as repetissem nos demais módulos.

Assim a função deste elo de ligação na implementação de um modelo semelhante ao proposto é analisar, buscar, cobrar, verificar, desenvolver, fazer e pesquisar para que o modelo aconteça.

\subsection{Sugestões e trabalhos futuros}

Para os próximos períodos da SEL-300, mais professores deverão ser convidados a participarem da nova estrutura, para que mais conhecimentos possam ser compartilhados, contribuindo para a melhoria contínua desta e de outras disciplinas. 
O modelo pode ser adaptado para outros cursos de engenharia, pois todo o seu fundamento não está restrito à engenharia elétrica, e os conceitos abordados podem e devem ser utilizados em outras disciplinas, como por exemplo, os estilos de aprendizagem e ensino e a aprendizagem cooperativa.

Para o aperfeiçoamento da disciplina e seguindo o avanço natural do ensino em engenharia e outras áreas, tanto o modelo como a própria $S E L-300$ podem ser transformados em um curso para a Internet, possibilitando o ensino à distância. 


\section{Bibliografia}

[1]. AltAFIM, R. A. C.; CANOVA, J. S.; VERONESE, P.; SARTORI, J.; OLIVEIRA, A. A. J. (1998). A didactic methodology based in the fragmentation of great problems of electric engineering. In: INTERNATIONAL CONFERENCE ON ENGINEERING EDUCATION, Rio de Janeiro, 1998. (CD-ROM).

[2]. BELHOT, R. V. (1998). Searching for new ways of teaching. In: INTERNATIONAL CONFERENCE ON ENGINEERING EDUCATION, Rio de Janeiro, 1998. (CD-ROM).

[3]. BELHOT, R. V.; GUERRA, J. H. L.; KURI, N. P. (1998). Problem-based learning in engineering education. INTERNATIONAL CONFERENCE ON ENGINEERING EDUCATION, Rio de Janeiro, 1998. (CD-ROM).

[4]. BRENT, R.; FELDER, R. M. (1999). It's a start. http://www2.ncsu.edu/ unity/lockers/users/f/felder/public/Papers/Getting_started.html (20 Dez 1999).

[5]. CHROBAK, R. (1998). The globalization and the engineering teaching for the XXI century. In: INTERNATIONAL CONFERENCE ON ENGINEERING EDUCATION, Rio de Janeiro, 1998. (CD-ROM).

[6]. COLL, C.; PALACIOS, J.; MARCHESI, A. (1996). Desenvolvimento psicológico e educação - Psicologia da educação. v.2. Trad. por Angélica Mello Alves. Porto Alegre, Artes Médicas.

[7]. CRADDOCK, J. N. (1997). Some experiences with then introduction and teaching of an introduction to civil engineering class. In: INTERNATIONAL CONFERENCE ON ENGINEERING EDUCATION, Rio de Janeiro, 1997. Anais.

[8]. DICIONÁRIO AURÉLIO ELETRÔNICO (1996). Márcio Ellery Girão Barbosa. versão 2.0. São Paulo, Nova Fronteira.

[9]. DICIONÁRIO DIDÁTICO DE PORTUGUÊS (1998). Maria Tereza Camargo Biderman. ed. 2. São Paulo, Editora Ática.

[10]. ENTERLINE, J. G.; KALONJI, G.; ERIDLEY, J. L. (1997). Introduction to engineering design at the university of Washington. In: INTERNATIONAL CONFERENCE ON ENGINEERING EDUCATION, Rio de Janeiro, 1997. Anais. 
[11]. FELDER, R. M. (1995). A longitudinal study of engineering student performance and retention. IV. Instrucional methods and student responses to them.

http://www2.ncsu.edu/unity/lockers/users/f/felder/public/Papers/long4.html (5 Nov 1999).

[12]. FELDER, R. M. (1996a) Learning styles. http://www2.ncsu.edu/unity/lockers/ users/f/felder/public/Learning_Styles.html (5 Nov 1999).

[13]. FELDER, R. M. (1996b). Matters of style. (American Society of Engineering Education Prism, v.6, n.4 , p.18-23 (dec).

[14]. FELDER, R. M.; BRENT, R. (1994). Cooperative learning in technical courses: procedures, pitfalls and payoffs. http://www2.ncsu.edu/unity/ lockers/users/f/felder/public/Papers/Coopreport.html (5 Nov 1999).

[15]. FELDER, R. M.; BRENT, R. (1999). How to improve teaching quality. http://www2.ncsu.edu/unity/lockers/users/f/felder/public/Papers/TQM.htm (20 Dec 1999).

[16]. FELDER, R. M.; SILVERMAN, L. K. (1988). Learning and teaching styles in engineering education. Engineering Education, v. 78, n. 7, p. 674-681, April.

[17]. FONTOURA, A. A. (1964). Psicologia educacional - Psicologia da aprendizagem - Psicologia diferencial. v.6. Aurora.

[18]. FREITAS, Z. L. (1998). Project subject on the first year of engineering course: a leader experiment on mechanic engineering. In: INTERNATIONAL CONFERENCE ON ENGINEERING EDUCATION, Rio de Janeiro, 1998. (CD-ROM).

[19]. GAGNÉ, R. M. (1975). Princípios essenciais da aprendizagem para o ensino. Trad. por Rute Vivian Ângelo. Porto Alegre, Globo S.A.

[20]. GEHRINGER, M.; LONDON, J. (2001a). Odisséia Digital. SuperInteressante. Suplemento especial.

[21]. GEHRINGER, M.; LONDON, J. (2001b). Odisséia Digital 2. SuperInteressante. Suplemento especial.

[22]. GOLEMAN, D. (1995). Inteligência emocional. 65.ed. Trad. Marcos Santarrita. Rio de Janeiro, Objetiva Ltda.

[23]. HELMER, W. A. (1997). Some new design techniques for introductory engineering courses. In: INTERNATIONAL CONFERENCE ON ENGINEERING EDUCATION, Rio de Janeiro, 1997. Anais.

[24]. HIPPO, E; KENT, A. C.; O’BRIEN, W. S. (1997). Effect of introductory design course on retention rates. In: INTERNATIONAL CONFERENCE ON ENGINEERING EDUCATION, Rio de Janeiro, 1997. Anais. 
[25]. JOHNSON, D.W.; JOHNSON, R.T.; SMITH, K.A. (1998). Maximizing Instruction Through Cooperative Learning. http://www.asee.org/pubs/html/ cooperative learning.htm (5 Nov 1999).

[26]. KULACKI, F.A.; KRUEGER, E.R. (1998). Trends in Engineering Education An International Perspective. In: INTERNATIONAL CONFERENCE ON ENGINEERING EDUCATION, Rio de Janeiro, 1998. (CD-ROM).

[27]. MANUAL DE GRADUAÇÃO DA HABILITAÇÃO EM ENGENHARIA ELÉTRICA (1999). Universidade de São Paulo - Escola de Engenharia Elétrica.

[28]. NAHVI, M. (1996). Transfer of state-of-art DSP technology to undergraduate electrical and computer engineering education: attractions, promises, and pitfalls. http://www.ee.calpoly.edu/ mnahvi/nahvi.htm (5 Mov 1999).

[29]. NAHVI, M. (1998). Developing Freshman-Year Experience in Electrical Engineering: Primary Functions and Possible Features. http:// www.ee.calpoly.edu/ mnahvi/fie98a.html (5 Nov 1999).

[30]. NAHVI, M. (1999). Integration o DSP Theory, Experiments, and Design: Report of a 7-Year Experience with an Undergraduate Course. http://www.ee.calpoly.edu/ mnahvi/ASEE99.htm (5 Nov 1999).

[31]. NARASIMHAN, B.; TEMARES, M. L.; LEE, S. S. (1997) Introduction to engineering - a first year course. In: INTERNATIONAL CONFERENCE ON ENGINEERING EDUCATION, Rio de Janeiro, 1997. Anais.

[32]. NEWMAN, D. J. (1998). Interactive Web-based and Hands-on Engineering Education: A Freshman Aerospace and Design Course at MIT. In: INTERNATIONAL COFERENCE ON ENGINEERING EDUCATION, Rio de Janeiro, 1998. (CD-ROM).

[33]. NOVAK, J. D. (1981). Uma teoria de educação. Trad. por Marco António Moreira. São Paulo, Pioneira.

[34]. O’CONNELL, J. P.; P M. A. (1997). Collaborative teching of first-year engineering analysis design and communication skills. In: INTERNATIONAL CONFERENCE ON ENGINEERING EDUCATION, Rio de Janeiro, 1997. Anais.

[35]. PFROMM NETO, S. P. (1987). Psicologia da aprendizagem e do ensino. São Paulo, EPU/EDUSP.

[36]. RIBAS, P. A. V.; SILVA FILHO, J. F.; COMIOTTO, M. S. (1998). A new paradigm in engineering education in PUC-RS. In: INTERNATIONAL CONFERENCE ON ENGINEERING EDUCATION, Rio de Janeiro, 1998. (CD-ROM). 
[37]. SOLEN, K. A.; HARB, J. N. (1997). A first-year course as a foundation for engineering education. In: INTERNATIONAL CONFERENCE ON ENGINEERING EDUCATION, Rio de Janeiro, 1998. (CD-ROM).

[38]. STRAKOS, V.; KEBO, V. (1998). Technical Education of Engineers in the Context of Multimedia Computer Technologies. INTERNATIONAL CONFERENCE ON ENGINEERING EDUCATION, Rio de Janeiro, 1998. (CD-ROM).

[39]. VERONESE, P. R. (2000). A nova estrutura da SEL-300. Personal e-mail ( Apr).

[40]. WANKAT, P. C.; Oreovicz, F. S. (1993). Teaching engineering. United States, McGraw-Hill.

[41]. WULF, W. A. (1998). The Urgency of Engineering Education Reform. http://www4.nationalacademies.org/nae/nae.nsf/NAE+Publications/Bridge/The +Urgency+of+Engineering+Education+Reform?OpenDocument (5 Nov 1999). 